\title{
Understanding the Effects of Physical \& Psychosocial Stress, and Personality Type on Neck Muscle Load among Healthcare Workers
}

\author{
Mohammed J. Al Hassan \\ West Virginia University
}

Follow this and additional works at: https://researchrepository.wvu.edu/etd

\section{Recommended Citation}

Al Hassan, Mohammed J., "Understanding the Effects of Physical \& Psychosocial Stress, and Personality Type on Neck Muscle Load among Healthcare Workers" (2011). Graduate Theses, Dissertations, and Problem Reports. 2198.

https://researchrepository.wvu.edu/etd/2198

This Thesis is protected by copyright and/or related rights. It has been brought to you by the The Research Repository @WVU with permission from the rights-holder(s). You are free to use this Thesis in any way that is permitted by the copyright and related rights legislation that applies to your use. For other uses you must obtain permission from the rights-holder(s) directly, unless additional rights are indicated by a Creative Commons license in the record and/ or on the work itself. This Thesis has been accepted for inclusion in WVU Graduate Theses, Dissertations, and Problem Reports collection by an authorized administrator of The Research Repository @ WVU. For more information, please contact researchrepository@mail.wvu.edu. 


\title{
Understanding the Effects of Physical \& Psychosocial Stress, and Personality Type on Neck Muscle Load among Healthcare Workers
}

\author{
Mohammed J. Al Hassan \\ Thesis submitted to the \\ College of Engineering and Mineral Resources \\ At West Virginia University \\ in partial fulfillment of the requirements \\ for the degree of \\ Master of Science \\ in \\ Industrial Hygiene
}

Ashish D. Nimbarte, Ph.D., Chair

Steve E. Guffey, Ph.D.

Warren R. Myers, Ph.D.

Department of Industrial and Management System Engineering

\section{Morgantown, West Virginia}

2011

Key words: physical and cognitive load; personality; neck and shoulder muscles; electromyography; NASA-TLX

Copyright 2011 Mohammed J. Al Hassan 


\begin{abstract}
Understanding the Effect of Physical \& Psychosocial Stress, and Personality type on Neck Muscle Load among Healthcare Workers
\end{abstract}

\title{
Mohammed J. Al Hassan
}

In spite of strong prevalence of neck and shoulder musculoskeletal disorders among health care workers, the effect of their routine work activities, which demands physical exertion and high cognitive load, on the loading of neck-shoulder musculatures is not clearly understood. Additionally, it is currently unknown as to how the internal loading of the neck-shoulder musculature caused by the external work-related factors is affected by the individual personality. The purpose of this study was to evaluate the musculoskeletal loading of neck-shoulder musculature when human participants performed physically and cognitively demanding exertions. The loading of neck-shoulder musculature was evaluated using objective and subjective assessment methods. Electromyography (EMG) of the neck-shoulder musculature was used as the objective assessment method, whereas NASA-TLX scores were used as the subjective assessment method. Individual personality types were determined using MBIT personality test. Twenty (18 males and 2 females) participants were recruited for data collection. Each participant performed two experimental sessions: Session 1 - physical exertion, participant performed 10 maximum static pulling exertions in semi standing posture simulating a bed-tostretcher patient transfer task. Session 2 - physical and cognitive exertion, during this session, in addition to 10 static pulling exertions (same as session 1), the participant performed mentally demanding tasks such as memorizing and recalling a list of words. The activities of three major neck-shoulder muscles: upper trapezius, sternocleidomastoid, and cervical trapezius, were studied. Muscle activity data showed that the neck-shoulder muscles worked harder while performing a combination of physical and cognitive exertions than purely physical exertions. The effect of the loading of neck-shoulder muscles was found sensitive to the individual personality. In general for all the muscles, among the participants with feeling personalities, a higher increase in the activation level of muscles was observed. The knowledge gained from this study imply that investigations viewing the entire work system (the interaction of physical and psychosocial workplace issues, as well as individual factors) will most likely to derive the root causes of neck- shoulder MSDs among healthcare occupations. 


\section{Acknowledgements}

I would like to express my sincere gratitude and deep appreciation to Dr. Ashish Nimbarte, my major advisor, for his guidance, invaluable recommendation, encouragement, understanding and wisdom. He was never lacking in kindness and support. He believed in me and gave me this opportunity at a crucial time in my life. Without his support this thesis would not have been a reality.

I would also like to extend my appreciation to my committee members, Dr. Steve Guffey and Dr. Warren Myers, for their valuable suggestion on improving the quality of this thesis and for their teaching and advice during my graduate studies at West Virginia University. I wish to thank all my participants for their time, patience and cooperation.

I am indebted to my wife Rabab for her love, encouragement and support which inspired me to reach this goal. Finally, I dedicate this thesis to my lovely kids Rakan and Ghassan. They have always provided me love and are indubitably the source of my strength and confidence. 


\section{$\underline{\text { Table of Contents }}$}

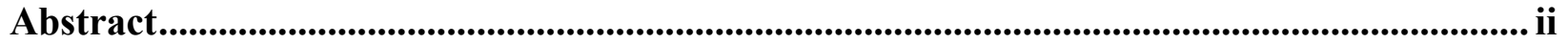

Acknowledgements .............................................................................................................ii

Chapter 1: Introduction ......................................................................................................................... 1

Chapter 2: Literature Review........................................................................................................ 4

2.1 Physical factors _ 4

2.2 Psychosocial factors 6

2.3 Combination of physical and psychosocial factors__ 7

2.4 Individual factors

Chapter 3: Rationale \& Objectives ..................................................................................... 10

3.1 Hypotheses 10

Chapter 4: Methods ..................................................................................................................... 12

4.1. Participants__ 12

4.2. Apparatus _ 12

4.2.1 Electromyography system __ 12

4.2.2 Custom-built isometric pulling strength testing device___ 15

4.3 Experimental Tasks__ 17

4.4. Experimental Design __ 21

4.4.1. Data collection procedure __ 21

4.5. Data Processing and Analysis _ 25

4.5.1. Electromyography__ 25

4.5.2. Discomfort rate (Nasa-TLX)__ 25

4.6. Statistical Analysis__ 26

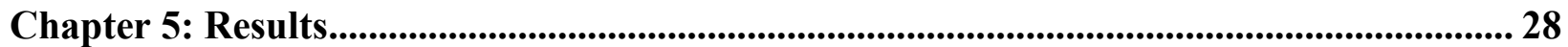

5.1 Anthropometric and Strength Data__ 28

5.2 Electromyography__ 29

5.2.1 Upper trapezius muscle _ 29

5.2.2 Sternocleidomastoid muscle _ 30

5.1.3 Cervical trapezius muscle _ـ 32

5.3 Discomfort Rate (NASA-Task Load Index)___ 34

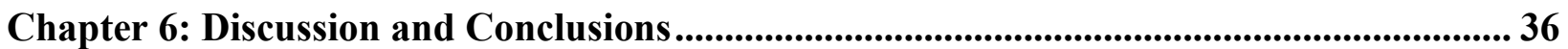


6.1 Discussion__ 36

6.2 Conclusion__ 41

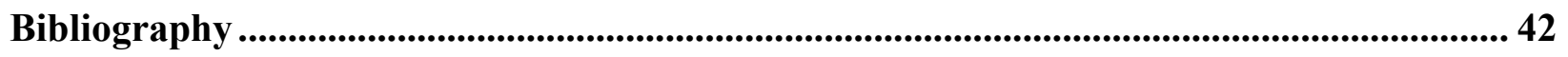

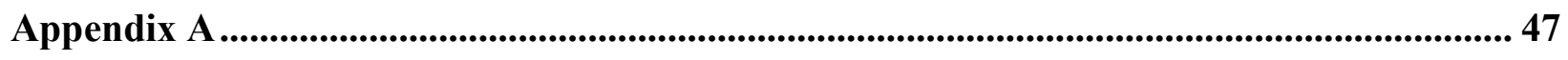

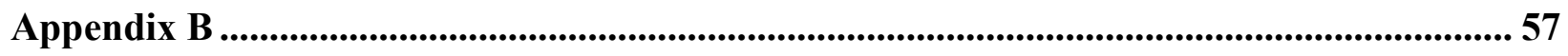

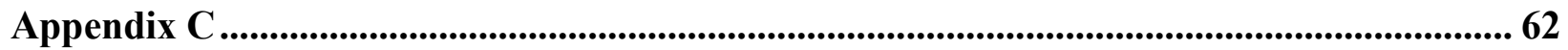

Appendix D ........................................................................................................................ 63

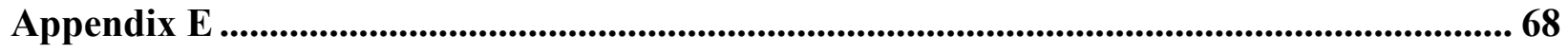

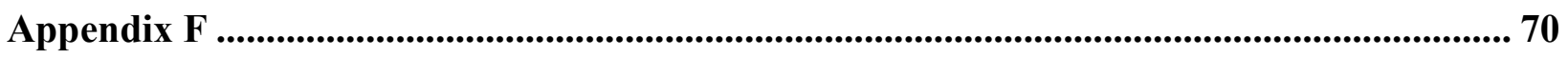

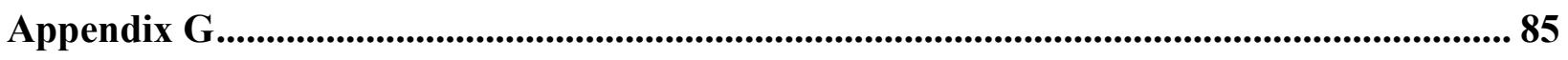




\section{LIST OF TABLES}

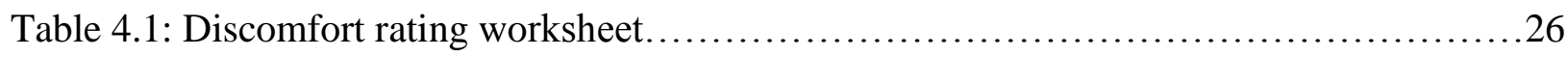

Table 5.1: Participants anthropometry and personality type data........................28

Table 5.2: N-MAV and mean frequency data for upper trapezius muscle....................30

Table 5.3: N-MAV and mean frequency data for sternocleidomastoid muscle................32

Table 5.4: N-MAV and mean frequency data for cervical trapezius muscle....................33 


\section{LIST OF FIGURES}

Figure 4.1: Telemyo 2400 G2 EMG system...........................................13

Figure 4.2: Pre-amplified load wire and electrodes....................................... 14

Figure 4.3: The bipolar Ag/AgCl pre-gelled surface electrodes..............................14

Figure 4.4: A PC-Interface receiver.................................................... 15

Figure 4.5: The custom-built isometric pulling strength device...............................16

Figure 4.6: Advanced digital force gauges................................................

Figure: 4.7: Experimental set up used for studying a bed-to-stretcher patient transfer task.......18

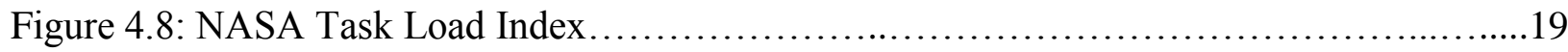

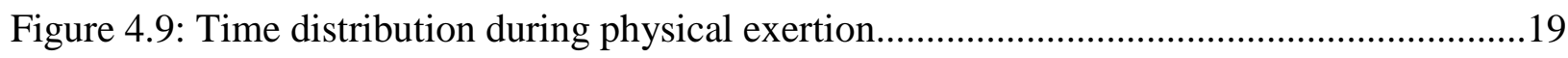

Figure 4.10: Time distribution during physical and cognitive exertion.......................20

Figure 4.11: The location of electrode on sternocleidomastoid muscle ........................22

Figure 4.12: The location of electrodes on trapezius muscle.......................................

Figure 4.13: Time distribution for experimental sessions...................................24

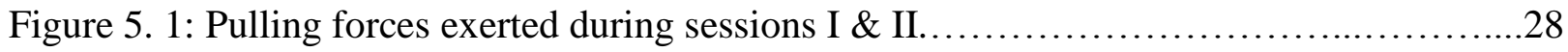

Figure 5.2: Behavior of right (A) and left (B) upper trapezius muscles..............................29 
Figure 5.3: Behavior of right (A) and left (B) sternocleidomastoid muscles..................31

Figure 5.4: Behavior of right (A) and left (B) cervical trapezius muscles....................33

Figure 5.5: NASA-TLX rating score for both sessions ................................. 34 


\section{Chapter 1: Introduction}

Work-related musculoskeletal disorders (MSDs) of the neck, upper extremities, and low back represent major cause of lost workdays in the United States. Because of the musculoskeletal pain in upper extremities and low back, each year one million workers report time away from work for rehabilitation and recovery (Bowman, 1999). The cost associated with the lost workdays due to MSDs range from $\$ 13$ to $\$ 20$ billion per year (NIOSH, 2001). According to the Bureau of Labor Statistics (BLS), in 2008, healthcare was one of the top five occupations in terms of injury statistics with MSDs case counts greater than 10,000 and an incidence rate of 226 cases per 10,000 full-time workers.

Nurses, ambulance attendants, and home care professionals have high prevalence rates of work-related neck MSDs. According to BLS (2002), the incidence rate for neck MSDs was 8.8 per 100 in hospital settings and 13.5 per 100 in nursing home settings. Trinkoff et al., (2002) based on a survey of 1163 randomly-selected currently working nurses from Illinois and New York reported that neck MSDs were prevalent among $46 \%$ of the nurses, followed by the MSDs of shoulder (35\%) and back (47\%). In another survey study by Smith et al., (2006), among 1,162 Japanese nurses, it was found that the MSDs of shoulder (71.9\%) were most commonly reported followed by the lower back (71.3\%), neck (54.7\%), and upper back (33.9\%). Routine work for these professionals include patient transfer and carrying tasks that involve forceful arm exertions and working in awkward postures. Epidemiological studies (Bernard, 1997; Holte and Westgaard, 2002; Malchaire et al., 2001; Walker-Bone and Cooper, 2005) have associated physically demanding tasks that require forceful arm exertions with neck-shoulder MSDs. 
In addition to the physically demanding exertions, healthcare workers are frequently exposed to various work-related psychosocial risk factors due to the very nature of their jobs (Landsbergis 1988). These psychosocial factors include, but are not limited to, cognitive overload, conflicting demands, administrative hassles, and lack of social support (Bates and Moore, 1975). The epidemiological literature shows substantial evidence associating workrelated psychosocial factors and MSDs of neck and shoulder (Camerino et al., 2001b). A study by Holte and Westgaard (2002) shows that in addition to the physical exertions, psychosocial exposures also affect the biomechanical load on various tissues of the body.

The effect of work-related physical and psychosocial factors on the musculoskeletal loading is further complicated by individual factors. A number of epidemiological studies have identified individual factors as important parameters in the development of neck-shoulder MSDs (Hughes et al., 2007; Lagerström et al., 1996; Sommerich et al., 1993). Individual personality traits were found to interact with the physical and psychosocial risk factors in the loading of low back musculature (Marras et al., 2000).

Healthcare workers are exposed to physical as well as psychosocial risk factors during their routine work activities. Although the rates of work-related neck-shoulder MSDs have been decreasing constantly in various industries since 1992, it has increased in healthcare workers (Fragala and Bailey, 2003). In order to develop effective intervention strategies to decrease the neck-shoulder MSDs among the healthcare workers it is critically important to understand how work-related physical and psychosocial factors interact with individual factors to affect the loading of the neck-shoulder musculature. The objective in this study was to understand how physical as well as psychosocial factors affect the loading of neck-shoulder musculature. In 
addition, the role played by the individual factors in the relationship between the physical and psychosocial factors and the loading of neck-shoulder musculature was evaluated. 


\section{Chapter 2: Literature Review}

In this chapter studies focusing on the MSDs among the healthcare workers were reviewed. Most of the existing studies were epidemiological in nature. A few experimental studies have evaluated impact of various work-related factors, common at healthcare workplaces, on the musculoskeletal loading. Primarily the risk factors associated with the MSDs among the healthcare workers were classified into (1) physical factors; (2) psychosocial factors, (3) individual factors.

\subsection{Physical factors}

Josephson et al., (1997) performed a survey study over a period of three years among female nurses to understand the relationship between the job strain and symptoms of musculoskeletal pain. A positive relationship between perceived physical exertion and musculoskeletal symptoms of pain for the neck, shoulders, and back was reported. Linton (1990) conducted a cross-sectional study on approximately 22,200 Swedish healthcare workers using a survey questionnaire. The results of this study showed that repetitive work was positively associated with neck and shoulder pain. Another cross-sectional survey study conducted by Trinkoff et al., (2003) on 2000 US licensed registered nurses reported that individuals performing activities such as moving or lifting heavy loads, lifting or lowering patients/objects to/from the floor, and pushing/pulling heavy objects or people, were at a high risk of neckshoulder MSDs.

Lavender et al., (2000) evaluated a number of patient transfer tasks using three dimensional static strength predictions program and trunk motion model. Following five tasks were studied: (1) transferring a patient from a bed to a stretcher using bed sheets, (2) transferring 
a patient from the ambulance stretcher to a hospital gurney, (3) carrying a victim down a set of stairs and through a landing using a stair chair, (4) carrying a victim down a set of stairs and through a landing using a backboard, and (5) carrying a victim down a straight set of stairs using a stretcher. The results indicated that the risk of low back disorders was associated with several task components, mainly pulling the patient from a bed to a stretcher and lifting the patient on a backboard from the floor.

McGill and Kavcic (2005) evaluated effectiveness of three patient sliding transfer devices on the low back loads. Three subjects performed controlled transfers using these devices. Electromyography was used to measure low back muscle activation levels together with external forces and kinematic. A three-dimensional biomechanical model was used to measure the spine loads. It was found that pushing and pulling transfers required almost twice as much effort than twist transfers. Push transfers caused highest levels of peak EMG across muscles, followed by pull and twist transfers. Authors finally conclude that worker transfer technique is a determinant of back load.

Schibye et al., (2003) evaluated the effect of self-selected and standard recommended patient handling techniques on the changes in the mechanical load on the low back. Nine female healthcare workers participated in this study. Dynamic 3D biomechanical model was used for comparing the two techniques. The tasks studied were as following: 1) turn patient in bed towards the health care worker (HCW) from his back to his left side; 2) reposition patient from lying on the back in the middle of the bed to the nearest bedside; 3) turn patient in bed away from $\mathrm{HCW}$ from his back to his right side; 4) elevate patient from supine position to sitting on edge of the bed; 5) move patient from sitting on the edge of the bed to standing on the floor; 6) move patient from sitting on the bed to supine position; 7) reposition patient posteriorly in the 
seat of the wheelchair; 8) reposition the supine patient towards the head of the bed, HCW at the head of the bed. The results showed a large variation in low back loading with mean values between 4223 to $4446 \mathrm{~N}$, when self-selected technique were used. Use of standard recommended technique decreased the compression value significantly for all tasks with a mean value around $3000 \mathrm{~N}$.

\subsection{Psychosocial factors}

In addition to physical demands, healthcare workers are exposed to high levels of psychosocial factors because of time pressure, lack of job control, high job demands, and low support, which all have been associated with MSDs (e.g. Camerino et al., 2001a; Gunnarsdottir et al., 2003b; Salminen et al., 2003a). Ariens et al., (2001a) performed a three year prospective cohort study to determine whether the work-related psychosocial factors associated with the quantitative job demands such as working under time pressure or working with deadlines, conflicting job demands are risk factors for neck pain. A significant relationship between high quantitative job demands and work-related neck pain was reported by them. Many studies have supported their findings on the relationship between high quantitative job demands and neck pain (Johansson, 2008; Lagerström et al., 1996; Toomingas et al., 1997). Van Yperen and Hagedoorn (2003) reported that among the nurses, the interaction between job demands such as working at fast rate, and/or under time pressure and perceived fatigue was significant when job control was reduced. Based on a cross-sectional study of 267 hospital workers, Wadman and Kjellberg (2007) reported that neck and shoulder illnesses were prevalent in the workers with low skill discretion who were required to perform jobs with high quantitative demands.

Linton (2000) reviewed 913 potentially relevant articles dealing with neck and back MSDs among general public, primary care, and secondary care medical professionals. He found 
that psychological variables, such as stress, distress, anxiety, mood, and depression, played critical roles in the development of neck and back pain. Estryn-Behar et al., (1990) carried out a study in 12 public hospitals in Paris to identify the relationship between working conditions and mental health status of female hospital workers. A total of 1505 female workers, consisting of $43 \%$ nurses, $32 \%$ auxiliaries, $7 \%$ ancillary staff, and $13 \%$ other qualified health care staffs, participated in this study. The results showed diverse levels of stress among all workers, while the mental load was higher for nurses.

Ariens et al., (2001b) demonstrated a strong association between neck pain and psychosocial factors, such as low social support, low job control, and low skill discretion. Bongers et al., (1993) found an association of psychosocial factors, such as time pressure, perceived stress, and high workload with neck and shoulder MSDs. Gunnarsdottir et al., (2003a) conducted an epidemiological study to identify the association between psychosocial work characteristics and musculoskeletal symptoms among female nurses. The results showed a significant association between work-related psychosocial factors (e.g., dissatisfaction with supervisors or the flow of information, insufficient influence at work, dissatisfaction with the hierarchy, extreme time pressure, lack of solidarity, dissatisfaction with the job, harassment, violence or threats at work) and musculoskeletal symptoms among female nursing staff.

\subsection{Combination of physical and psychosocial factors}

Physical exertion and work-related psychosocial stress were found to mediate with each other in the development of musculoskeletal symptoms of neck and shoulder pain. Aasa et al., (2005) conducted a cross-sectional study to examine the association of work-related psychosocial factors (worrying about work condition, psychological demands, and social support) and physical factors with the neck-shoulder and low back disorders among female and 
male ambulance workers. A clear relation between psychosocial factors such as lack of social support, and physical demands such as working in awkward postures and handling heavy tasks, and complaints of neck-shoulder and low back pain among the female workers was found. The male personnel had also shown significant associations between the psychosocial factors and MSDs of neck and shoulder but not with MSDs of the low back. Andersen et al., (2003) found that high levels of distress, high physical work load, and psychosocial workplace factors are associated with pain in the neck and/or shoulder. Devereux et al., (2002b) conducted a study using self administered questionnaire, and found that a combination of physical and psychosocial factors, in the workplace, lead to the risk for neck disorders. Warming et al., (2009) performed a cross-sectional study on 148 registered nurses working at a University hospital to inspect whether physical task and psychosocial factors were associated with musculoskeletal complaint. The physical tasks such as patient handling, and psychosocial factors such as time pressure, feeling of stress, and distraction from work, were found to be clearly associated with low back and neck pain.

\subsection{Individual factors}

Individuals react differently to the same exposure of physical and psychosocial factors. Personality which is defined as "the dynamic organization within the individual of those psychophysical systems that determine his unique adjustments to his environment" by Allport (1937), might influence interaction of an individual with his/her environment. Literature

evaluating interaction of individual personality with work-related exposures is limited. Allread and Marras (2006) hypothesized that workers whose personality preferences (e.g. introversion or feeling types) are not matched with the requirements of their work (e.g. extraverted or thinking environments) will show signs of increased MSDs discomfort compared to those whose 
personality preferences better match their job. Personalities of 133 employees from two distribution centers were evaluated using Myers-Briggs Type Indicator (MBTI) test. A mismatch between one's personality and the nature of their work environment appeared to be related with the increased strain responses. In another study by Marras et al., (2000) influence of personality trait on the function of the lumbar spine system under stress-free and psychosocially stressful conditions was evaluated. Stressful conditions were created by using, non-supportive language and actions, while positive language and action were used to create stress-free condition. Activities of ten trunk muscles using electromyography and trunk kinematic using lumbar motion monitor were studied. Personality was evaluated by Myers Briggs Type Indicator (MBTI) test. The results show that psychosocial stress was linked with the increase in the muscle activities. Also, an increase in muscle co-activation with the increase in stress was observed. It was found that introverts generally reported greater levels of low back discomfort than extroverts. In the situations with low job demands, higher low back loading among the workers whose personalities were less matched with their work environment was observed. Under high job demand conditions, no consistent relationship between low back loading and personality type were found. 


\section{Chapter 3: Rationale \& Objectives}

Neck-shoulder MSDs are prevalent among healthcare workers. Epidemiological studies clearly indicate that routine work activities of healthcare workers are associated with neckshoulder MSDs. However, in spite of strong prevalence of neck MSDs among healthcare workers, the effect of their routine work activities, which demands physical exertion and high cognitive load on the loading of neck-shoulder musculature, is not clearly understood. Additionally, it is not understood how the internal loading of the neck-shoulder musculature caused by the external work-related factors is affected by the individual personality. Therefore, there is a critical need to understand the effect of physical and cognitive exertion on the behavior of neck-shoulder musculature and how this relationship is affected by the individual personality. Thus, the rationale for this research was that the understanding of the relationship between the external work-related exertions, individual personality and the internal musculoskeletal loading would facilitate understanding of the pathomechanism of neck-shoulder MSDs among the healthcare workers.

The objective in this study was to evaluate the musculoskeletal loading of neck-shoulder musculature when human participants performed physically and cognitively demanding exertions. The loading of neck-shoulder musculature was evaluated using objective and subjective assessment methods. Electromyography (EMG) of the neck-shoulder musculature was used as the objective assessment method, whereas NASA-TLX (Task Load Index) scores were used as the subjective assessment method. Individual personality type was determined using MBIT personality test.

\subsection{Hypotheses}

The following hypotheses were tested: 
Hypothesis 1: The type of exertion would not affect the loading of neck-shoulder muscles.

Hypothesis 2: Personality type would not affect the relationship between the external physical and cognitive exertions and the internal loading of neck-shoulder muscles. 


\section{Chapter 4: Methods}

The hypotheses were tested in a laboratory study. Human participants simulated a bed-tostretcher patient transfer task performed under two load conditions: (1) physical, (2) combination of physical with cognitive load.

\subsection{Participants}

A total of twenty (18 males and 2 females) participants were recruited for data collection in this investigation. The participants were students at West Virginia University. The average age, weight, and height of the participants were $25 \pm 2.5 \mathrm{yrs}, 162.4 \pm 22.7 \mathrm{lb}$, and $173 \pm 9.7 \mathrm{~cm}$, respectively. The Physical Activity Readiness Questionnaire (PAR-Q, British Columbia Ministry of Health) was used to screen participants for cardiac and other health problems (e.g., dizziness, chest pain, heart trouble) (Appendix C). Positive answers indicated the perceived presence of health problems. Before the data collection, the experimental procedures and possible risks associated with the study were explained to the participants and their signatures were obtained on the consent form approved by West Virginia University Institutional Review Board (Appendix D).

\subsection{Apparatus}

The apparatus used in this research include the electromyography system, and the custom-built isometric pulling strength testing device.

\subsubsection{Electromyography system}

Electromyography (EMG) is the study of the muscle function through the analysis of the electrical signal generated during muscular contractions (Acierno et al., 1995). Muscle contraction is quantified by recording electrical activity of the muscle using surface or 
intramuscular EMG electrodes. The surface electrodes are employed when collecting data from the superficial muscles. They only require attaching the electrode to the skin. The intramuscular electrodes are mostly used collect an EMG signal from the deep muscles. They require inserting the electrodes through the skin. EMG techniques have been extensively used to study the patterns of activation or tension developed in the muscles during occupational tasks (Sommerich et al., 2000).

In the current study, surface electrodes were used to record EMG of the neck-shoulder musculature. The Telemyo 2400 G2 EMG system was used for data collection (Figure 4.1). This is a 16 channel telemetry EMG system consisting of Telemyo 2400T transmitter, pre-amplified lead wires, and disposable self-adhesive $\mathrm{Ag} / \mathrm{AgCl}$ snap electrodes (Noraxon Inc., AZ, USA). The bipolar $\mathrm{Ag} / \mathrm{AgCl}$ pre-gelled surface electrodes of $1 \mathrm{~cm}$ diameter, inter-electrode distance of $2 \mathrm{~cm}$ connect to Telemyo 2400T transmitter via pre-amplified lead wires (Figures $4.2 \& 4.3$ ). The pre amplifier on the lead wires have a band-pass of 10-1000 Hz (gain 500), CMRR >100 dB, Input Impedance >100 MOhm.

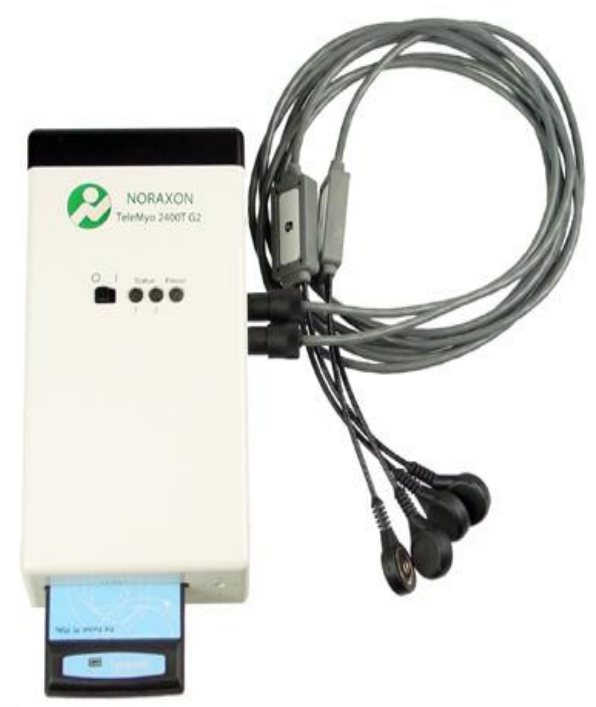

Figure 4.1: Telemyo 2400 G2 EMG system 


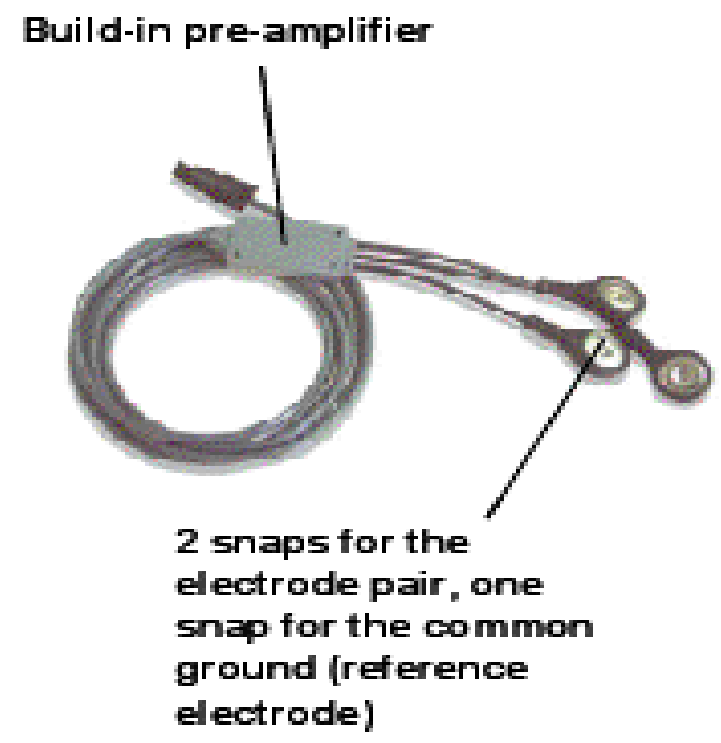

Figure 4.2: Pre-amplified load wire and electrodes

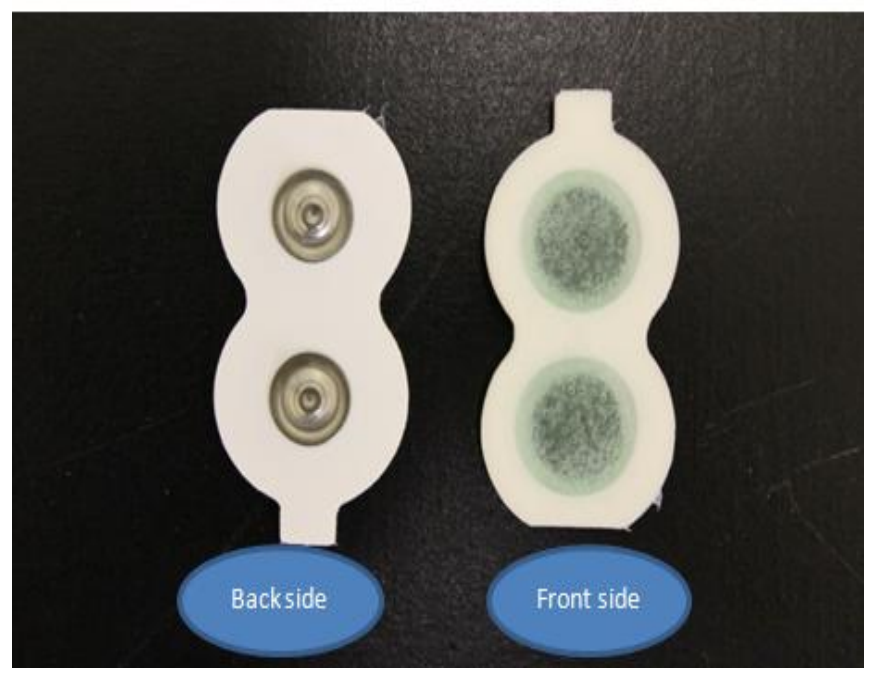

Figure 4.3: The bipolar Ag/AgCl pre-gelled surface electrodes

The Telemyo 2400T transmitter was mounted on the participants using a pouch and belt clip. This transmitter transmits data wirelessly to the PC-interface receiver (Figure 4.4) connected to the host computer. The frequency of EMG data acquisition was set at $1000 \mathrm{~Hz}$. 


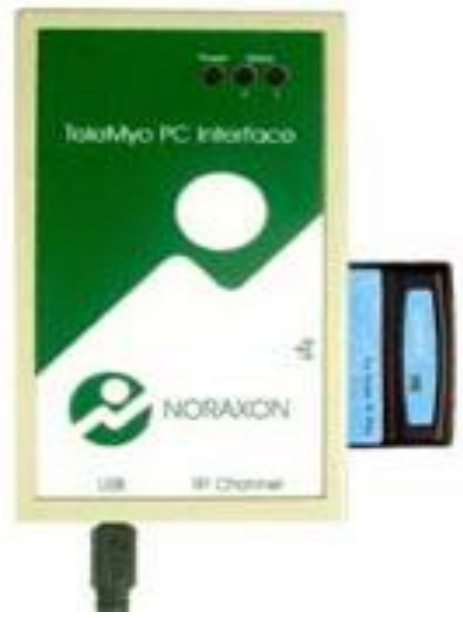

Figure 4.4: A PC-Interface Receiver

\subsubsection{Custom-built isometric pulling strength testing device}

To simulate a bed-to-stretcher patient transfer task, a custom-built isometric pulling strength testing device was used. This device consists of a 6-inch wide slotted steel plate, chain, series 5 advanced digital force gauge, and a pair of sheets (Figure 4.5). Chain attached the force gauge with the steel plate such that the force gauge could be moved up and down along the plate and locked at any position. Force gauge was attached to the pair of cloth sheets using a doublehandle attachment. Cloth sheets were used during the force exertion to make the simulated patient transfer task more realistic.

A series 5 advanced digital force gauge (Mark-10 Corporation, NY, USA) was used to measure force during the maximum static pulling exertions (Figure 4.6). This force gauge is designed to measure tension and compression forces with a sampling rate of 7,000 Hz. It has a range of $0.12 \mathrm{lb}$ to $500 \mathrm{lb}(0.5 \mathrm{~N}$ to $2500 \mathrm{~N})$, with an accuracy of $\pm 0.1 \%$ of full scale and a resolution of $1 / 5000$. It can be used to record mean, peak forces during an exertions. 


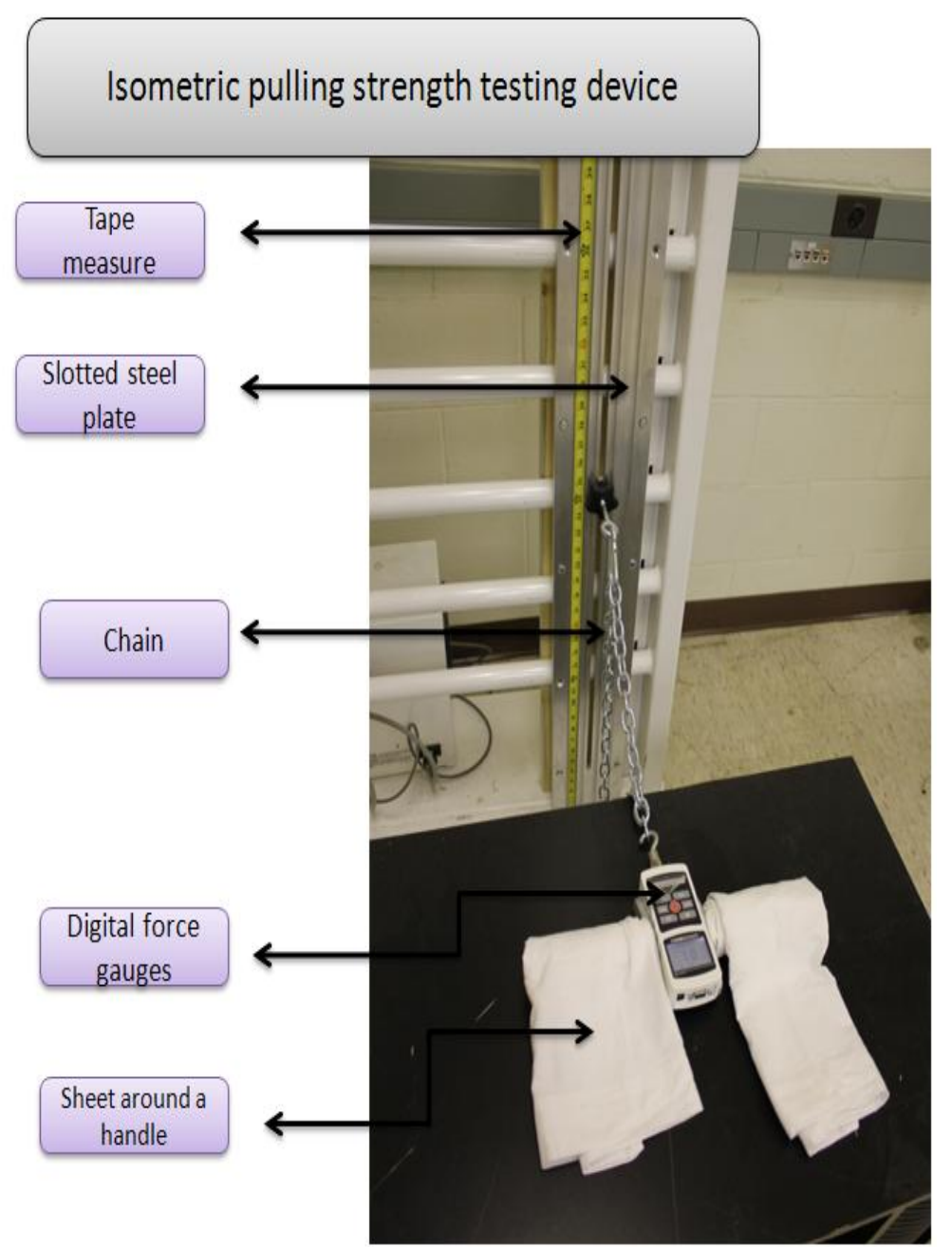

Figure 4.5: Custom-built isometric pulling strength testing device

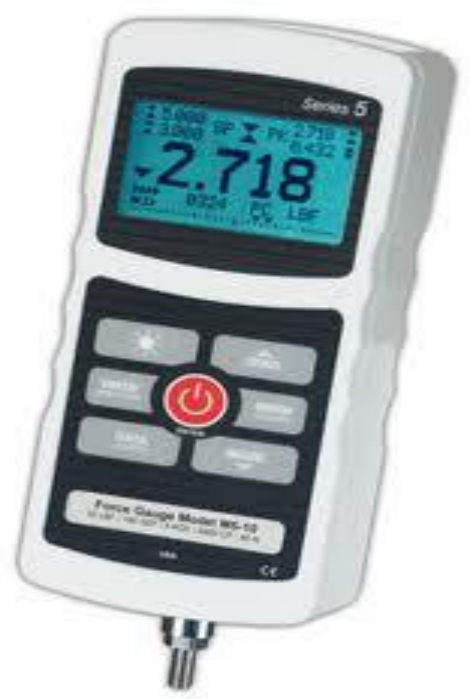

Figure 4.6: Advanced digital force gauges 


\subsection{Experimental Tasks}

Each subject participated in two experimental sessions.

In Session 1 (Physical exertion), participant performed ten maximal isometric pulling exertions simulating a bed-to-stretcher patient transfer task. During pulling task, the height of the force gauge and double handle attachment was adjusted to $66 \mathrm{~cm}$ above the ground level to make it consistent with the average height of beds used in the hospitals (Tzeng and Yin, 2006). During the force exertion, participant stood at a distance of $50 \mathrm{~cm}$ from the column and exerted force using the following joint configurations:

1. Knee joint flexed 5 to 10 degrees.

2. Trunk flexion of 10 to 20 degrees.

3. Right foot placed in front of the left foot with an approximate distance of $45 \mathrm{~cm}$ between the feet

4. Shoulder joint flexed 50-55 degrees and 0 degrees abducted.

5. Elbow joint flexed 5 to 10 degrees and 50-55 degrees supinated.

6. Wrist in the neutral posture.

A sketch of experimental setup and the joint configuration used during the pulling tasks is shown in the figure 4.7 . 

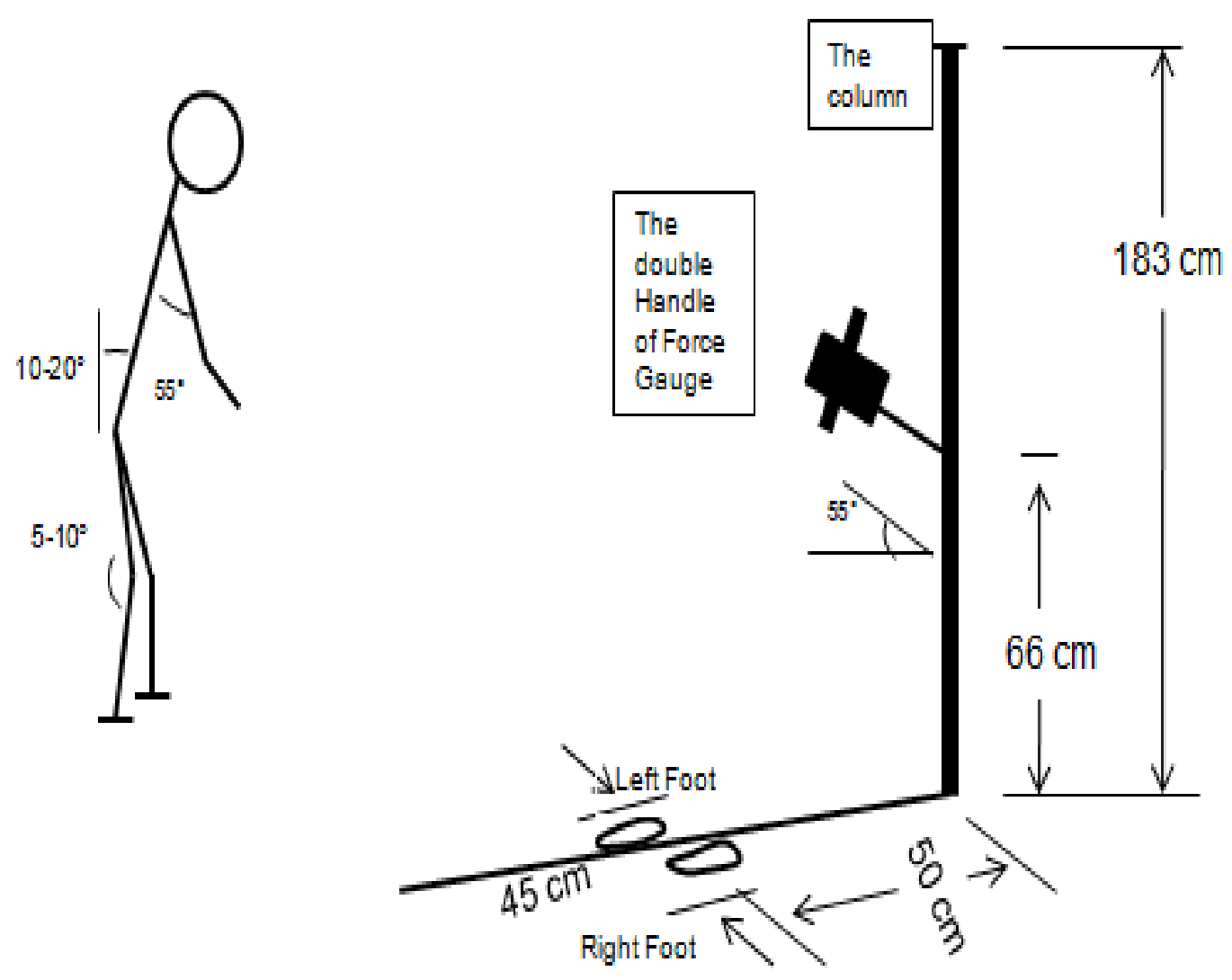

Figure: 4.7: Experimental set up used for studying a bed-to-stretcher patient transfer task.

During the pulling exertions, the participants were instructed to apply the force slowly and steadily without a jerking motions until the maximum exertion was reached (Aghazadeh and Ayoub, 1985). Subjects maintained maximum exertion for approximately 3 seconds. After each exertion, subjects rated their perceived workload using NASA-Task Load Index (TLX). NASATLX comprises of six workload assessment components: mental demand, physical demand, temporal demand, performance, effort and frustration (Figure 4.8). It has been used widely in research studies to evaluate workloads in various industries. 
In Session 2 (Physical and cognitive exertion), in addition to 10 isometric pulling exertions (same as Session 1), the participants were exposed to cognitive loading. Based on Rasmussen's categories of human performance (Rasmussen, 1983), skill-based tasks were used to generate cognitive load. Skill-based tasks relies on rote knowledge and fairly automatic responses with minimal signal processing, such as memorizing and recalling a list of words. Healthcare workers perform various skill-based tasks in daily work activities, such as memorizing a patient's medications, recalling physical therapy schedules, and checking vital signs. During the rest period following the pulling exertions, participants were presented with a list of information to remember before the next physical exertion. Immediately following the pulling exertion, participants were verbally asked questions pertaining to the information presented in the previous rest period and allowed 10 seconds to answer the question verbally. After answering, participants were presented with new information during the remaining rest period (Figure 4.10). A summary of the questions used for generating cognitive load is presented in Appendix B.

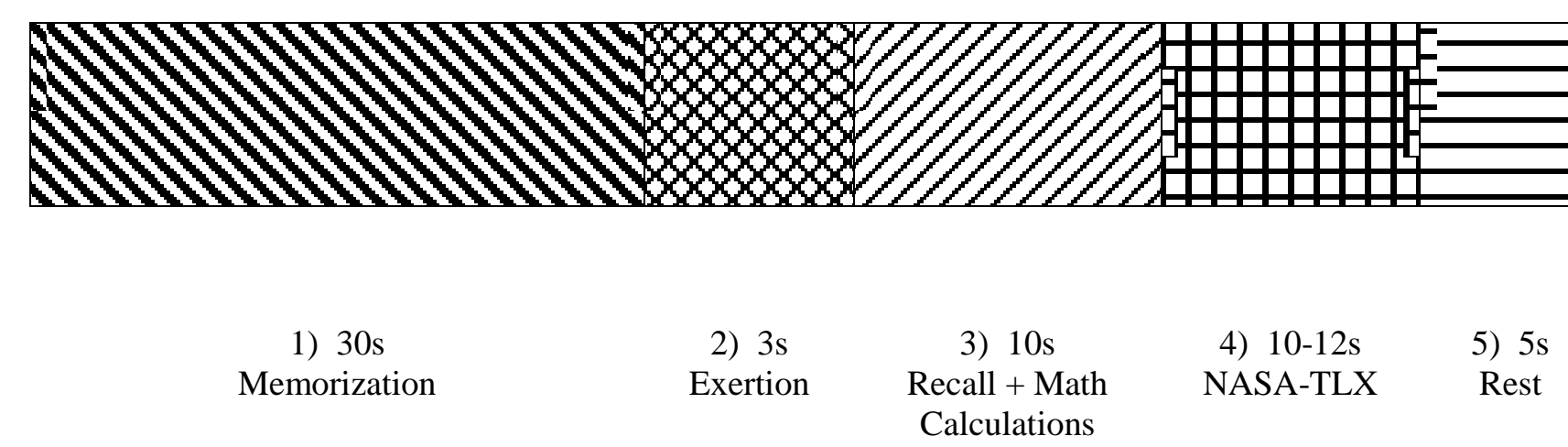

Figure 4.10: Time distribution during physical and cognitive exertion 


\subsection{Experimental Design}

A two-factor mixed experimental design with one within subject variable and one between subject variable was used. Within subject variable, type of exertion, had two fixed levels (physical only and combination of physical and cognitive), and between subject variable, individual personality also had two levels (thinking and feeling).

\subsubsection{Data collection procedure}

The data collection procedures for each participant consisted of the following three steps: (1) subject orientation and measurement, (2) EMG data collection preparation, and (3) actual data collection.

\section{1) Subject orientation and measurement:}

Each participant was introduced to the equipment, data collection procedures, and specifics of the experimental tasks. Subsequently their signatures were obtained on the IRB form. After obtaining their signatures on the IRB form, the demographics (age, height, weight, and sex) as well as following anthropometric measurements, were recorded: the distance between the acromion and $\mathrm{C} 7$, the distance between sternal notch and the mastoid process, and C6-C7 distance.

\section{2) EMG data collection preparation:}

The skin underneath the anatomical landmarks was shaved (if needed), abraded and cleaned with $70 \%$ alcohol, prior to the placement of the EMG electrodes. EMG from the sternocleidomastoid muscle was recorded by placing an electrode along a line drawn from the sternal notch to the mastoid process, at $1 / 3$ the length of the line from the mastoid process as shown in figure 4.11 (Nimbarte et al., 2010) . 


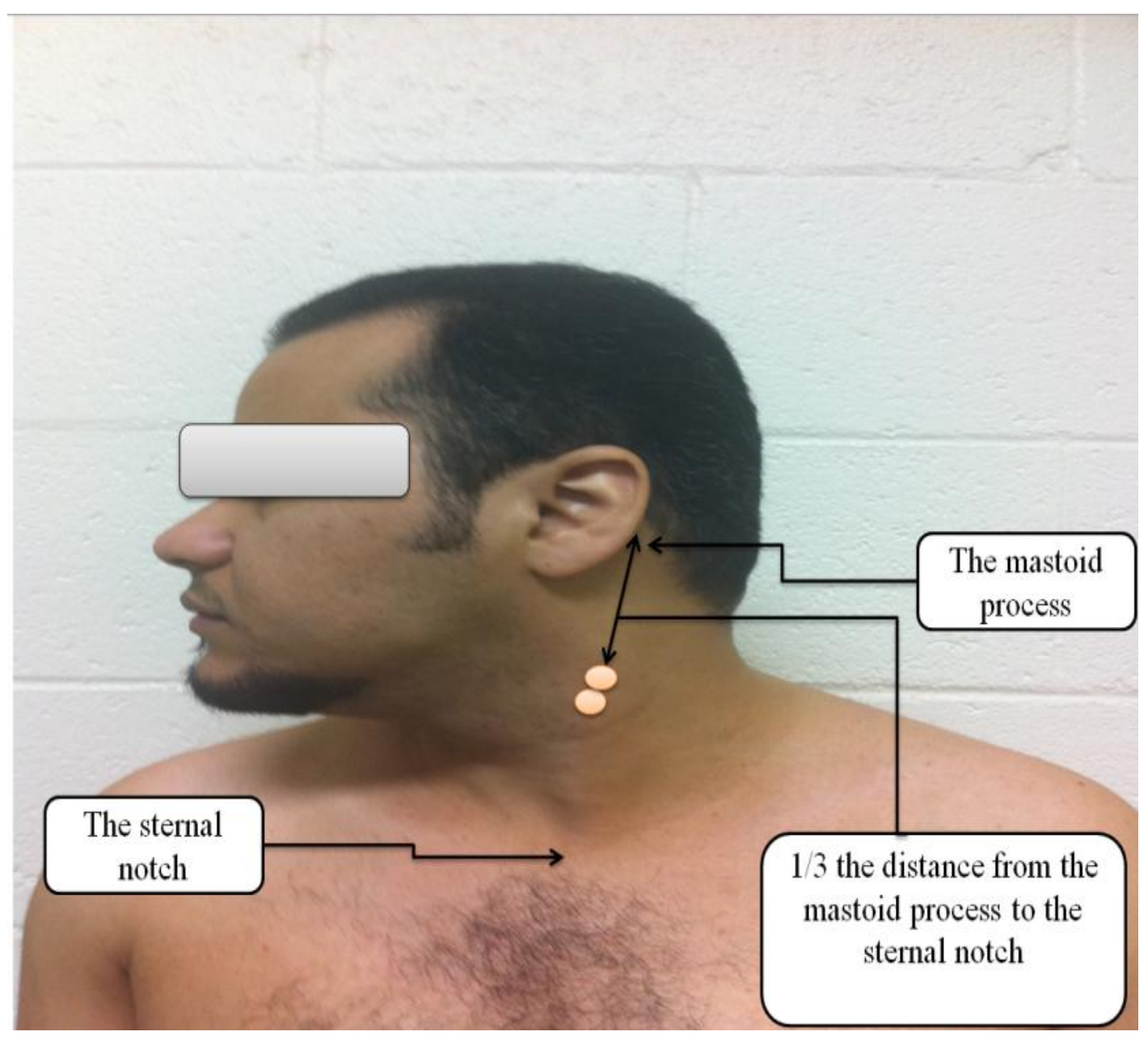

Figure 4.11: The location of electrode on sternocleidomastoid muscle

EMG from the cervical trapezius muscle was measured by placing an electrode between the occipital and C7, at the level of C4 (approximately mid cervical region). The level of C4 was determined by marking a horizontal line at 2.5 times the distance between the C6-C7 vertebrae above the C7. The electrode at this location placed slightly inclined (approximately $35^{\circ}$ ) to the vertical line between the C7 and C4 (Nimbarte et al., 2010) as shown in figure 4.12.

EMG from the upper trapezius muscle in the shoulder region was recorded by placing an electrode along a line joining the acromion and C7, at one-third the distance from the acromion, in accordance with the published recommendations (Farina et al., 2002) as shown in Figure 4.12. 


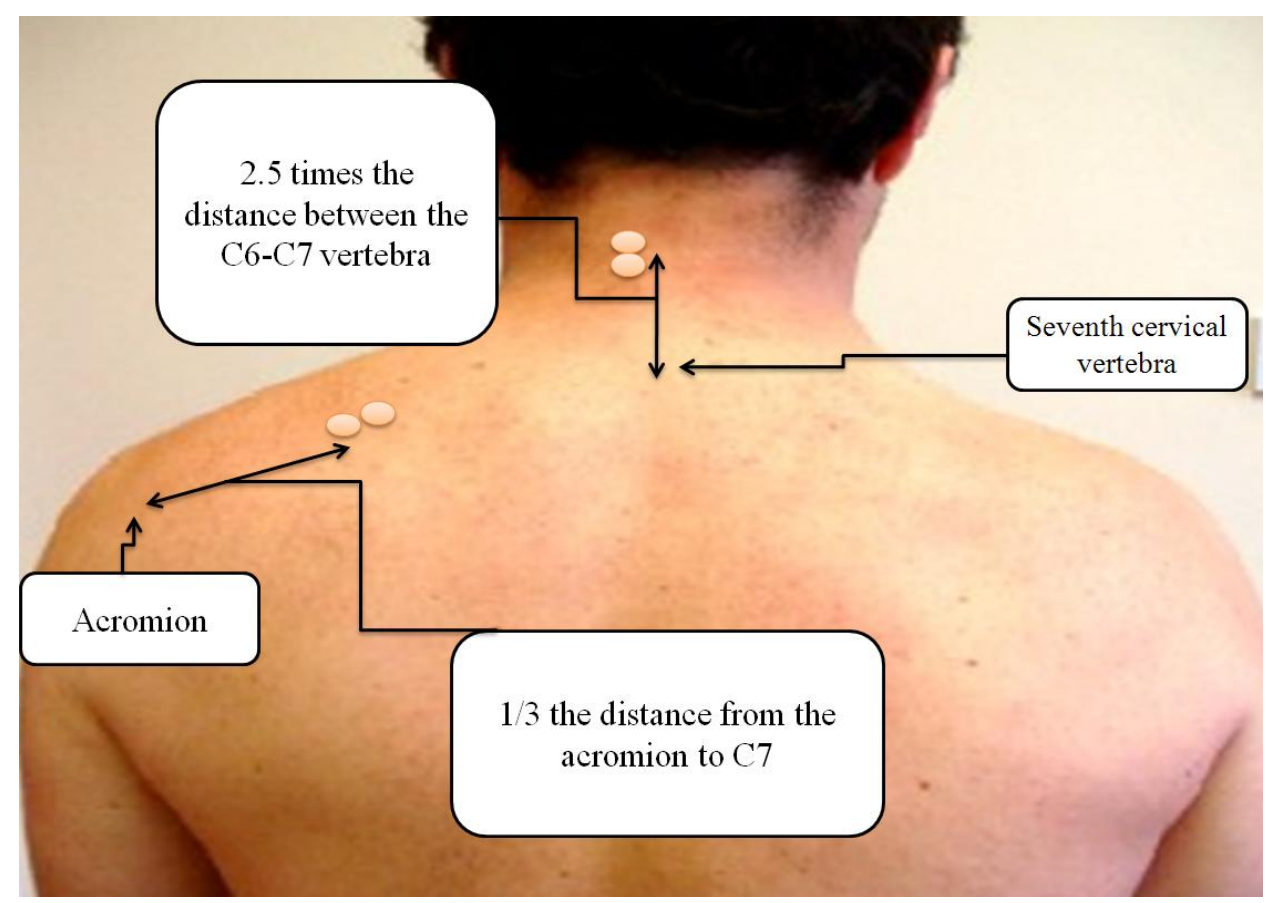

Figure 4.12: The location of electrodes on trapezius muscles

The placement of the surface EMG electrodes was checked for accuracy and cross talk. The sternocleidomastoid muscle electrode location was tested by a measurable EMG signal during head rotation (Vasavada et al., 1998). The cervical upper trapezius muscle electrode location was tested by a measurable EMG signal during flexion-extension of the head (Nimbarte, 2009). For the upper trapezius muscle in shoulder region the action used for testing the electrode location was arm elevation with the arms abducted $90^{\circ}$ in the scapular plane (Bosch and de Looze, 2007). The placement of all electrodes was outlined by black markers to prevent errors in the EMG data collection if electrode/s fell off doing the tasks.

\section{3) Actual data collection:}

Upon arrival, subjects were asked to complete questionnaires of the Myers-Briggs Type Indicator (MBTI) to assess their personality type. The MBTI is based on the original work of Jung who proposed that human behavior is predictable, and personality type remains constant 
throughout life (Myers, 1962). MBTI has been used in more than 700 published studies (Carlson, 1985), and its reliability and validity were evaluated by Bayne (1997) and Harvey (1996). The MBTI questionnaire uses four factors to identify different types of personalities. These factors are "favorite world" (Extraversion vs. Introversion), "information processing preference" (Sensing vs. Intuition), “decision making” (Thinking vs. Feeling), and "structure” (Judging vs. Perceiving). Based on each factor a person can be classified in two different personality types. If all the four factors are combined then 16 different personalities can be evaluated. Since the work of healthcare workers typically involves information processing (Hammer, 1993), only one factor i.e. information processing was used to classify participants into two personality types: thinking and feeling. Participants then performed experimental tasks as described in Section 4.3.

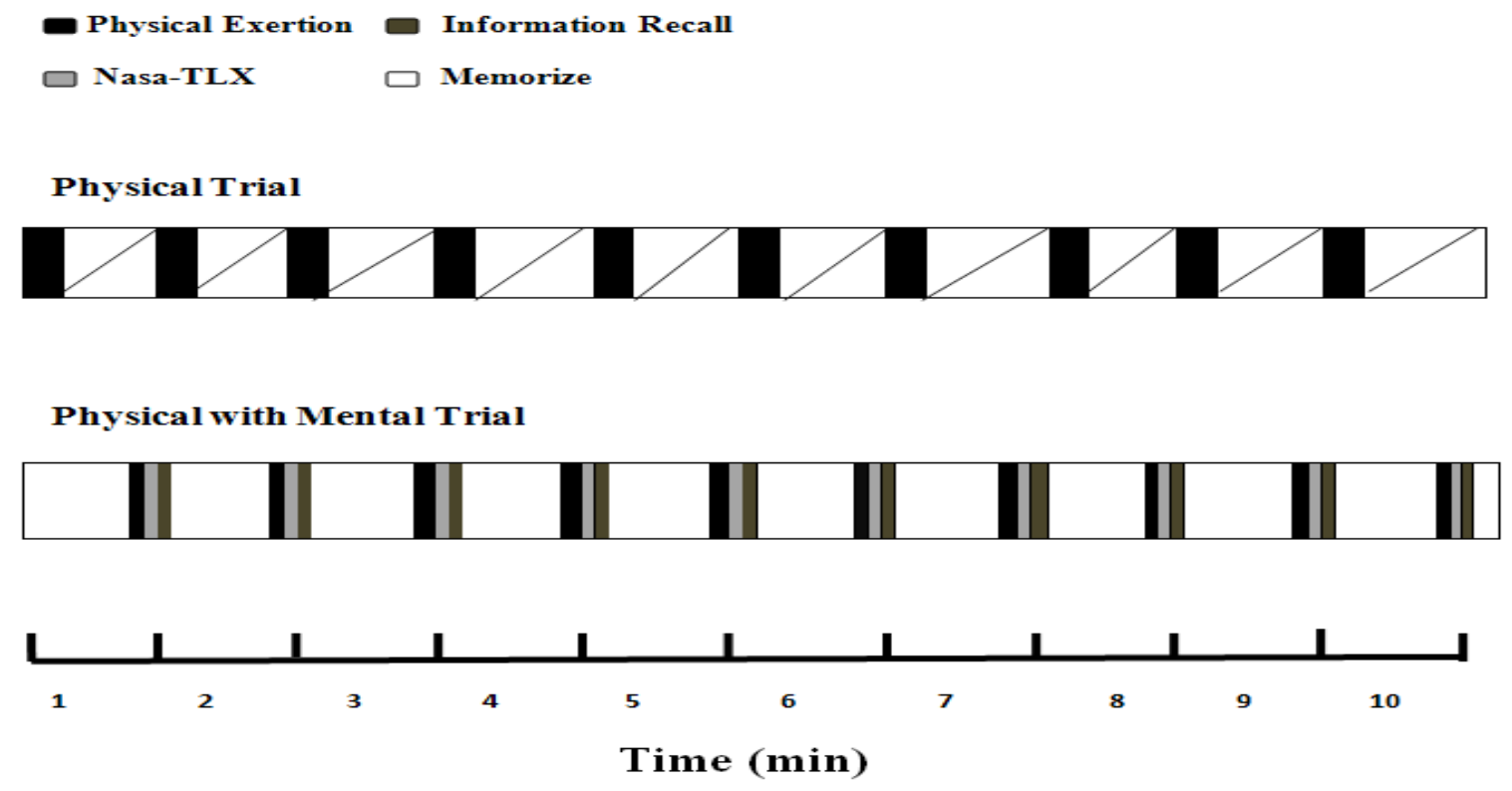

Figure 4.13: Time distribution for experimental sessions.

The overall time distribution for both experimental sessions is shown in figure 4.13. EMG data were collected during the physical exertion only. Subjects were not aware when the data collection began or ended. 


\subsection{Data Processing and Analysis}

\subsubsection{Electromyography}

EMG data were analyzed using time and frequency domain analysis. Time domain analysis was performed to calculate mean absolute values (MAV). The MAV values were quantified by 1) demeaning the EMG signal, 2) performing a full wave rectification, 3) filtering the data to suppress high frequency fluctuation using low-pass Butterworth filter (Fourth order, zero lag filter, cutoff frequency), and 4) determining the average of the EMG data which is the MAV. Comparison of EMG between and within subjects involves normalizing the EMG data. Typically, EMG can be normalized with respect to 1) muscle activation at the maximum voluntary contraction; 2) reference muscle contraction while performing a standardized task (Mathiassen and Winkel, 1990; Turville et al., 1998) and; 3) the peak or mean activation during the tasks (Finsen, 1999; Sommerich et al., 2001). In this study, EMG was normalized using the peak contraction for each muscle during the session 1 to determine the Normalized MAV (NMAV). Frequency domain analysis was performed using fast Fourier transformation to evaluate shift in the mean frequency (Bosch et al., 2007).

\subsubsection{Discomfort rate (Nasa-TLX)}

Adjusted rating were computed for each task condition. A table used for this computation is shown in table 4.1. After completing individual experimental trial, participants were asked to rank the importance of each component over all others from 1 to 6 for each session. The final workload score for each component was determined by averaging the products of component's weight and rating. 
Table 4.1: Discomfort rating worksheet

\begin{tabular}{|l|l|l|l|}
\hline & \multicolumn{2}{|c|}{ WEIGHTED RATING WORKSHEET } \\
\hline \multicolumn{1}{|c|}{ Scale Title } & Weight(W) & Raw Rating (RR) & $\begin{array}{c}\text { Adjusted ratings } \\
\text { W } \times \text { RR }\end{array}$ \\
\hline MENTAL DEMAND & & & \\
\hline PHYSICAL DEMAND & & & \\
\hline TEMPORAL DEMAND & & & \\
\hline PERFORMANCE & & & \\
\hline EFFORT & & & \\
\hline FRUSTRATION & & & \\
\hline
\end{tabular}

\subsection{Statistical Analysis}

Statistical analysis was performed using Minitab 15 software (Minitab Inc. PA, USA). Normality of the data was tested using Kolmogorov-Smirnov test. This test compares the empirical cumulative distribution function of sampled data with the distribution expected if the data were normal. If the difference is sufficiently large, test rejects the null hypothesis of population normality. The $\alpha$-value was set to 0.05 , if the p-value was less than $\alpha$-level; null hypothesis was rejected, concluding that the data was non-normal.

The effect of the type of exertion and the individual personality on the loading of neckshoulder musculature was evaluated using General Linear Model (GLM) with unbalanced design. Type of exertion was treated as a fixed factor with two levels: physical and mental. 
Personality was treated as a fixed factor with two levels: thinking and feeling. Subject was treated as a random factor nested within personality. The model statement used for analysis is as follows:

Subject (Personality) Exertion Personality Exertion* Personality 


\section{Chapter 5: Results}

\subsection{Anthropometric and Strength Data}

The participants' demographic data (age, weight, and height), hand dominance, and their personality type are listed in Table 5.1. The average of maximum forces exerted by the participants during sesssion1 (physical only) and session 2 (combination of physical and cognitive) were $59.9 \mathrm{lb}$ (19.3), $65.9 \mathrm{lb}$ (20.7), respectively (Figure 5.1). The average forces exerted by the participants during session 2 were higher than session 1 . However, the difference was statistically insignificant.

Table 5.1: Participants anthropometry and personality type data

\begin{tabular}{|c|c|c|c|c|c|c|c|c|c|c|}
\hline & Subject & $\begin{array}{r}h o \\
\text { domi }\end{array}$ & $\begin{array}{l}\text { ad } \\
\text { ance }\end{array}$ & & nder & Age & $\begin{array}{c}\text { Weight } \\
\text { (lb) }\end{array}$ & $\begin{array}{c}\text { Height } \\
(\mathrm{cm})\end{array}$ & \multicolumn{2}{|c|}{ Personality Type } \\
\hline & & Right & Left & Male & Female & & & & Thinking & Feeling \\
\hline Number & 20 & 18 & 2 & 18 & 2 & & & & 11 & 9 \\
\hline Mean & & & & & & 25 & 162.4 & 173 & & \\
\hline SD & & & & & & 2.5 & 22.1 & 9.7 & & \\
\hline
\end{tabular}

Force Exertion

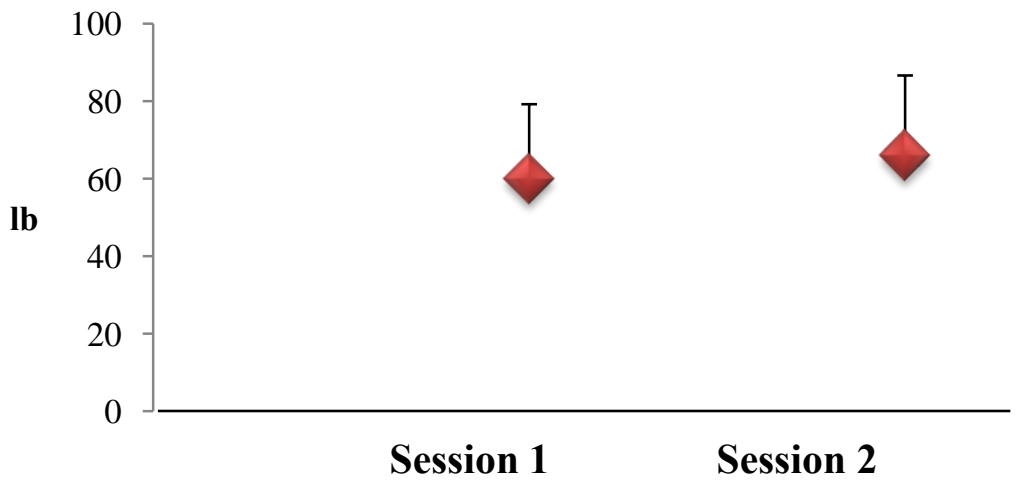

Figure 5. 1: Pulling forces exerted during sessions I \& II 


\subsection{Electromyography}

In the following sections the changes in the behavior of neck-shoulder muscles (upper trapezius, sternocleidomastoid, and cervical trapezius) expressed in terms of N-MAV data and median frequencies with respect to the type of exertion and personality type are explained. The raw data used for performing statistical analysis are presented in Appendix E. Normality assumption for the raw data was found to be true. The results of Kolmogorov-Smirnov test and the statistical analysis (ANOVA tables) are presented in Appendix F.

\subsubsection{Upper trapezius muscle}

(A) Right Upper Trapezius Muscle

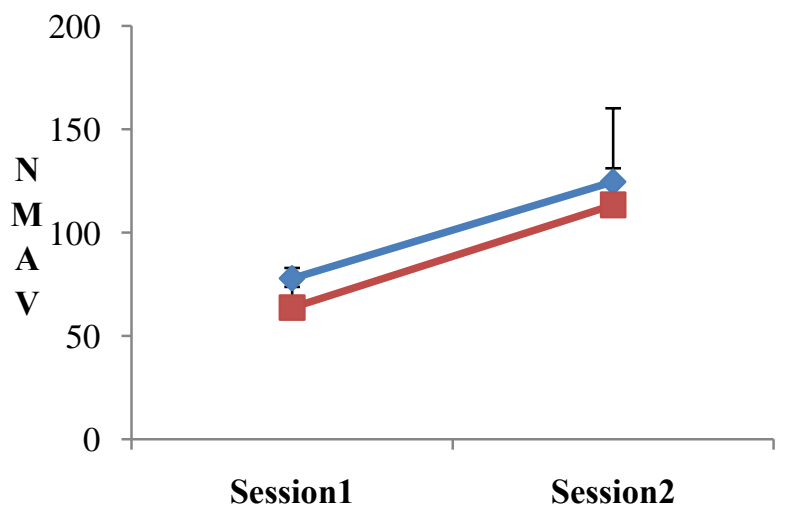

(B) Left Upper Trapezius Muscle

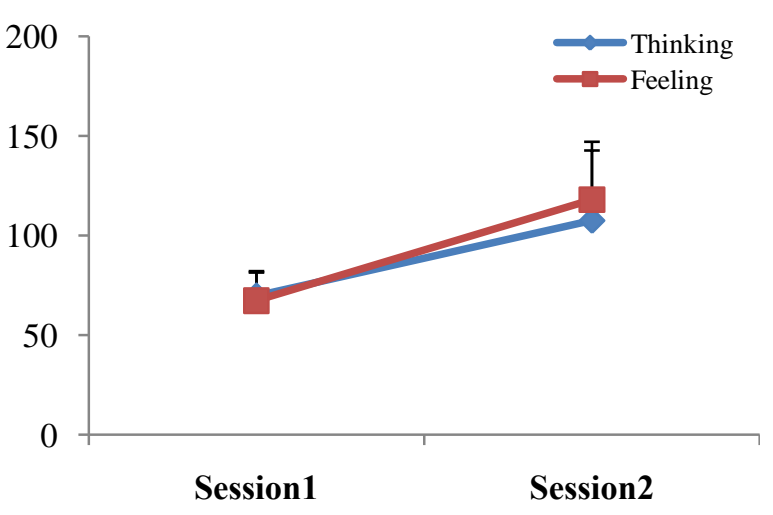

Figure 5.2: Behavior of right (A) and left (B) upper trapezius muscles

The activities of upper trapezius muscles were significantly affected by the type of exertion $(P<0.0001)$. For the participants with thinking personality, with the addition of cognitive load, on an average, the muscle activity increased by $60.0 \%$ and $54.1 \%$ for the right and left side, respectively (Figure 5.2). The corresponding values for the participants with feeling personality were $78.0 \%$ and $75.4 \%$, respectively (Table 5.2). Although, the increase in the muscle activities for the participants with feeling personality was higher than participants with 
thinking personality, the interaction between type of exertion and personality type was statistically insignificant.

Table 5.2: N-MAV and mean frequency data for upper trapezius muscle.

\begin{tabular}{|c|c|c|c|c|c|c|c|c|c|}
\hline & & \multicolumn{4}{|c|}{ Session 1} & \multicolumn{4}{|c|}{ Session 2} \\
\hline & & \multicolumn{2}{|c|}{ Thinking } & \multicolumn{2}{|c|}{ Feeling } & \multicolumn{2}{|c|}{ Thinking } & \multicolumn{2}{|c|}{ Feeling } \\
\hline & & Mean & SD & Mean & SD & Mean & SD & Mean & $\mathrm{SD}$ \\
\hline \multirow{3}{*}{$\begin{array}{c}\text { Right } \\
\text { upper } \\
\text { trapezius } \\
\text { muscle }\end{array}$} & N-MAV & 77.83 & 5.14 & 63.72 & 10.08 & 124.56 & 35.68 & 113.4 & 17.82 \\
\hline & $\begin{array}{l}\text { Mean frequency } \\
\left(1^{\text {st }} \text { exertion }\right)\end{array}$ & 56.36 & 5.26 & 59.48 & 4.84 & 62.91 & 11.35 & 60.04 & 8.56 \\
\hline & $\begin{array}{l}\text { Mean frequency } \\
\left(1^{\text {th }} \text { exertion }\right)\end{array}$ & 58.79 & 10.56 & 63.94 & 9.37 & 60.99 & 12.04 & 64.31 & 11.77 \\
\hline \multirow{3}{*}{$\begin{array}{c}\text { Left } \\
\text { upper } \\
\text { trapezius } \\
\text { muscle }\end{array}$} & N-MAV & 69.7 & 12.42 & 67.23 & 14.16 & 107.42 & 35.26 & 117.96 & 29.11 \\
\hline & $\begin{array}{l}\text { Mean frequency } \\
\left(1^{\text {st }} \text { exertion }\right)\end{array}$ & 57.98 & 12.05 & 61.03 & 12.01 & 51.01 & 7.87 & 53.27 & 9.83 \\
\hline & $\begin{array}{l}\text { Mean frequency } \\
\left(10^{\text {th }} \text { exertion }\right)\end{array}$ & 58.55 & 13.53 & 63.67 & 12.92 & 53.68 & 8.24 & 55.20 & 8.51 \\
\hline
\end{tabular}

No consistent trends were observed in the values of mean frequencies between $1^{\text {st }}$ and $10^{\text {th }}$ exertion (Table 5.2). Effect of type of exertion and personality type on the behavior of mean frequencies was statistically insignificant.

\subsubsection{Sternocleidomastoid muscle}

The activities of sternocleidomastoid muscle were affected by the type of exertion $(P<0.0001)$. The N-MAV data showed that the sternocleidomastoid muscle worked harder during Session 2 than Session 1 (Figure 5.3, Table 5.3). 
(A)Right Sternocleidomastoid muscle

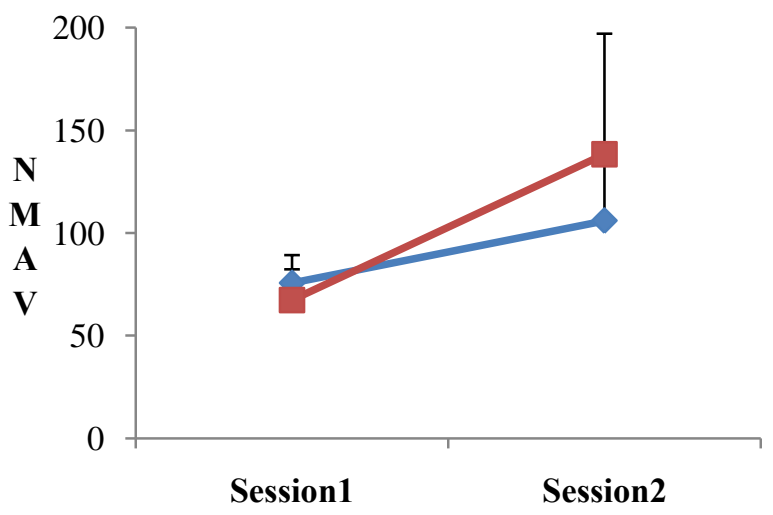

(B)Left Sternocleidomastoid muscle

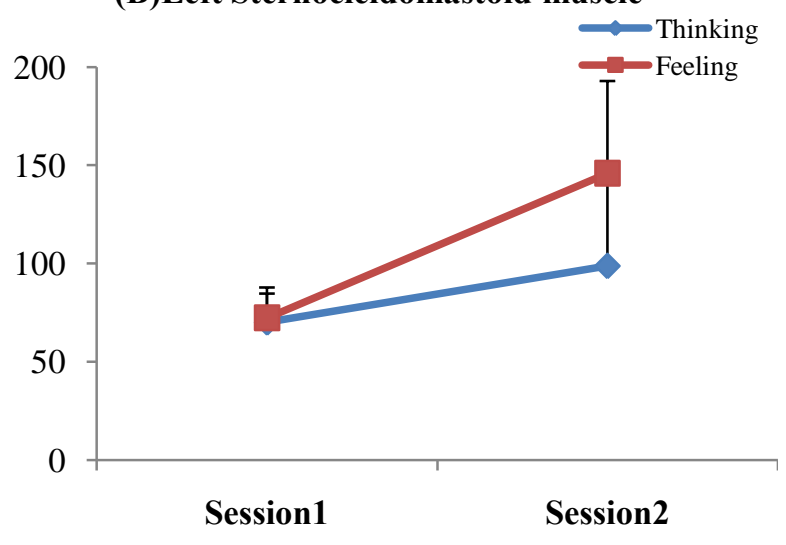

Figure 5.3: Behavior of right (A) and left (B) sternocleidomastoid muscles

A significant interaction was observed between the type of exertion and personality type for the sternocleidomastoid muscle on the left $(P=0.05)$ and right side $(P=0.05)$. The effect of addition of cognitive load had a more pronounced effect on the increase in the muscle activity of the participants with feeling personality than thinking personality (Figure 5.3). On an average, with the addition of cognitive load the muscle activity of the participants with thinking feeling personality increased by $40.1 \%$ and $41.0 \%$ for left and right side, respectively. For the participants with feeling personality, the corresponding values were $105.9 \%$ and $101.7 \%$, respectively. 
Table 5.3: N-MAV and mean frequency data for sternocleidomastoid muscle.

\begin{tabular}{|c|c|c|c|c|c|c|c|c|c|}
\hline & & \multicolumn{4}{|c|}{ Session 1} & \multicolumn{4}{|c|}{ Session 2} \\
\hline & & \multicolumn{2}{|c|}{ Thinking } & \multicolumn{2}{|c|}{ Feeling } & \multicolumn{2}{|c|}{ Thinking } & \multicolumn{2}{|c|}{ Feeling } \\
\hline & & Mean & $\mathrm{SD}$ & Mean & SD & Mean & SD & Mean & $\mathrm{SD}$ \\
\hline \multirow{3}{*}{$\begin{array}{l}\text { Right } \\
\text { sternocleido- } \\
\text { mastoid }\end{array}$} & N-MAV & 75.61 & 13.62 & 67.24 & 15.06 & 105.96 & 31.2 & 138.43 & 58.69 \\
\hline & $\begin{array}{c}\text { Mean frequency } \\
\left(1^{\text {st }} \text { exertion }\right)\end{array}$ & 69.11 & 19.62 & 69.50 & 11.75 & 73.50 & 22.14 & 76.17 & 28.64 \\
\hline & $\begin{array}{l}\text { Mean frequency } \\
\left(10^{\text {th }} \text { exertion }\right)\end{array}$ & 73.44 & 19.23 & 65.81 & 22.05 & 63.45 & 14.87 & 61.36 & 14.81 \\
\hline \multirow{3}{*}{$\begin{array}{c}\text { Left } \\
\text { sternocleido- } \\
\text { mastoid }\end{array}$} & N-MAV & 70.06 & 14.63 & 72.37 & 15.42 & 98.78 & 50.34 & 145.95 & 46.94 \\
\hline & $\begin{array}{l}\text { Mean frequency } \\
\left(1^{\text {st }} \text { exertion }\right)\end{array}$ & 53.09 & 19.15 & 56.91 & 21.53 & 60.34 & 15.15 & 63.28 & 21.04 \\
\hline & $\begin{array}{l}\text { Mean frequency } \\
\left(10^{\text {th }} \text { exertion }\right)\end{array}$ & 55.45 & 18.95 & 56.35 & 15.65 & 55.06 & 11.60 & 52.73 & 17.08 \\
\hline
\end{tabular}

No consistent trends in the behavior of mean frequencies between $1^{\text {st }}$ and $10^{\text {th }}$ exertion were observed for the sternocleidomastoid muscle (Table 5.3). Effect of type of exertion and personality type on the behavior of mean frequencies was statistically insignificant.

\subsubsection{Cervical trapezius muscle}

Figures 5.4 show the behavior of the right and left cervical trapezius muscles during the two sessions for the participants with thinking and feeling personalities. The effect of type of exertion on the activities of cervical trapezius muscle was statistically significant $(P<0.0001)$. The cervical trapezius muscle worked harder while performing Session 2 than Session 1. A higher increase in the muscle activities was observed for the participants with feeling personality than thinking personality with the addition of cognitive load (Figure 5.4). On an average with the addition of cognitive load, for the participants with thinking personalities, the muscle activity 
increased by $34.0 \%$ and $39.5 \%$ for the right and left side, respectively. For the participants with feeling personality the corresponding values were $64.8 \%$ and $71.9 \%$, respectively. The interaction between exertion and personality was statistically insignificant for left and right side cervical trapezius muscles.

(A)Right Crevical Trapezius Muscle

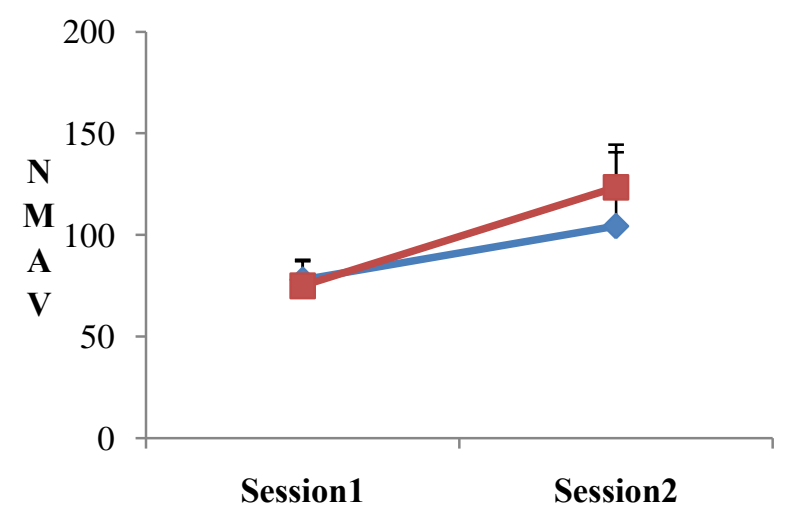

(B)Left Crevical Trapezius Muscle

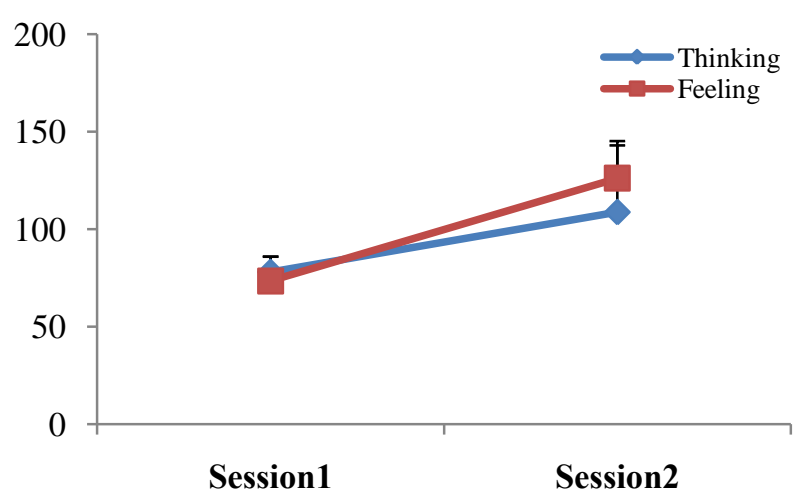

Figure 5.4: Behavior of right (A) and left (B) cervical trapezius muscles

Table 5.4: N-MAV and mean frequency data for cervical trapezius muscle.

\begin{tabular}{|c|c|c|c|c|c|c|c|c|c|}
\hline & & \multicolumn{4}{|c|}{ Session 1} & \multicolumn{4}{|c|}{ Session 2} \\
\hline & & \multicolumn{2}{|c|}{ Thinking } & \multicolumn{2}{|c|}{ Feeling } & \multicolumn{2}{|c|}{ Thinking } & \multicolumn{2}{|c|}{ Feeling } \\
\hline & & Mean & SD & Mean & SD & Mean & SD & Mean & SD \\
\hline \multirow{3}{*}{$\begin{array}{l}\text { Right cervical } \\
\text { trapezius }\end{array}$} & N-MAV & 77.83 & 9.17 & 74.93 & 12.82 & 104.27 & 36.37 & 123.46 & 20.94 \\
\hline & $\begin{array}{l}\text { Mean frequency } \\
\left(1^{\text {st }} \text { exertion }\right)\end{array}$ & 65.17 & 22.82 & 65.03 & 20.46 & 63.09 & 16.51 & 61.58 & 15.24 \\
\hline & $\begin{array}{l}\text { Mean frequency } \\
\left(1^{\text {th }} \text { exertion }\right)\end{array}$ & 64.53 & 25.67 & 63.99 & 18.29 & 63.21 & 15.19 & 59.17 & 10.12 \\
\hline \multirow{3}{*}{$\begin{array}{l}\text { Left cervical } \\
\text { trapezius }\end{array}$} & N-MAV & 77.9 & 7.9 & 78 & 28 & 108.67 & 36.42 & 119.5 & 40.2 \\
\hline & $\begin{array}{l}\text { Mean frequency } \\
\left(1^{\text {st }} \text { exertion) }\right.\end{array}$ & 58.55 & 22.20 & 56.05 & 14.40 & 62.16 & 13.14 & 59.53 & 8.52 \\
\hline & $\begin{array}{l}\text { Mean frequency } \\
\left(10^{\text {th }} \text { exertion }\right)\end{array}$ & 59.84 & 22.12 & 58.30 & 16.01 & 58.29 & 10.54 & 52.40 & 11.86 \\
\hline
\end{tabular}


The mean frequencies between $1^{\text {st }}$ and $10^{\text {th }}$ exertion stayed relatively constant for the sternocleidomastoid muscle (Table 5.4). Effect of type of exertion and personality type on the behavior of mean frequencies was statistically insignificant.

\subsection{Discomfort Rate (NASA-Task Load Index)}

The raw data and the results of the statistical analysis (ANOVA table) are presented in Appendix G.

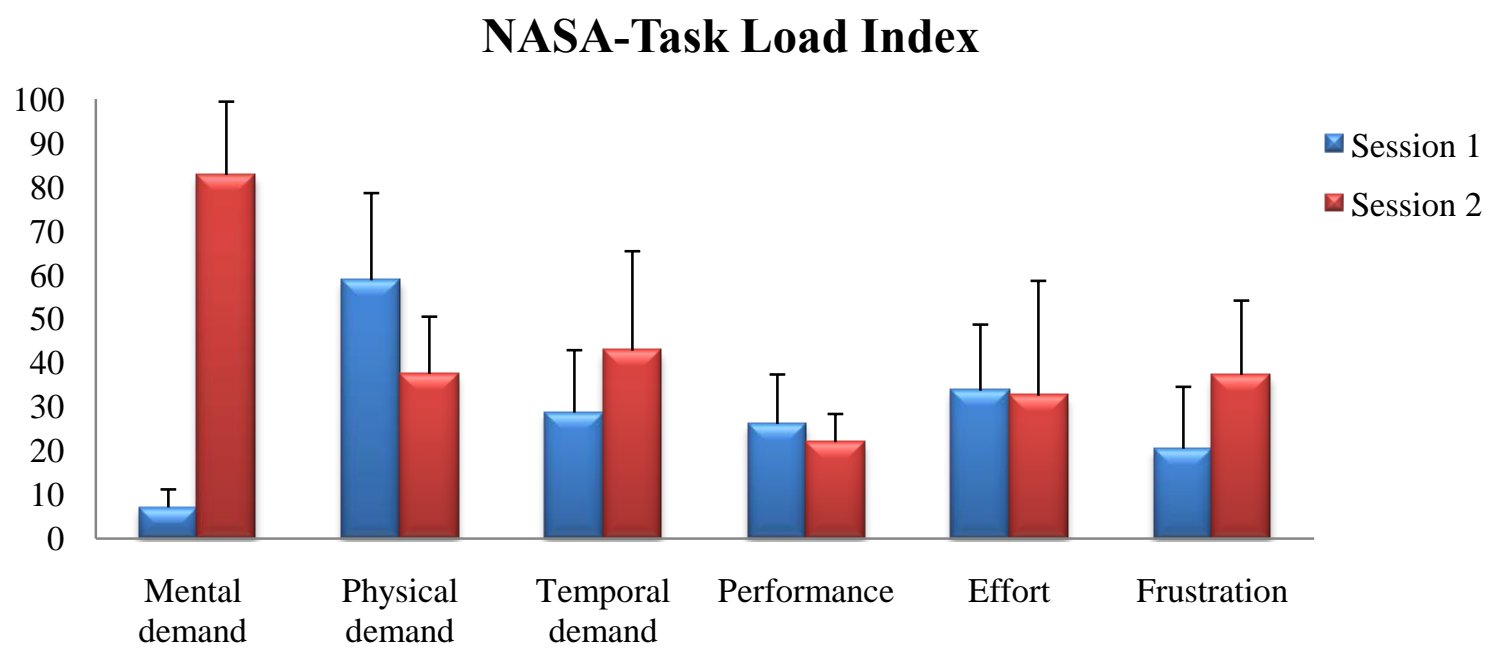

Figure 5.5: NASA-TLX rating score for both sessions

The subjective assessment scores for mental demand, temporal demand, and frustration were higher during Session 2 than Session1 (Figure 5.5). With the addition of cognitive load, scores for the mental demand, temporal demand, and frustration increased by $91.44 \%, 32.9 \%$, and $45.1 \%$, respectively. The increase was statistically significant for mental demand and frustration $(P<0.0001)$. Higher subjective assessment scores for physical demand and performance were observed during Session1 than Session 2. During Session 1, the physical demand and performance were $36.1 \%$ and $15.8 \%$ greater than Session 2, respectively. Statistical 
significant was found only for the physical demand $(P<0.0001)$. No effect of personality and/or exertion $\times$ personality interaction was observed for any subjective workload assessment scores. 


\section{Chapter 6: Discussion and Conclusions}

\subsection{Discussion}

In this study, the loading of neck-shoulder musculature was evaluated when human participants with different personalities performed physically and cognitively demanding exertions. Electromyography (EMG) of the neck-shoulder musculature was used as the objective assessment method. NASA-TLX scores were used to evaluate the subjective assessment method. Individual personality type was determined using MBIT personality test.

Cognitive demand appeared to have a substantial impact on the behavior of the upper trapezius, sternocleidomastoid, and cervical trapezius muscles in the work environment which require physical exertion. The work environment for the healthcare workers is characterized by physical as well as cognitive stress. The findings of this study indicate that during the combined physical and cognitive exertions, neck and shoulder muscles worked significantly harder than during physical exertions only; thus, rejecting the first hypothesis (the type of exertion would not effect on the loading of neck-shoulder musculature). Increased muscle activity with the increase in the mental load was previously reported by Wahlstro“m et al., (2002) and Birch et al., (2000) for the upper trapezius muscle. Upper trapezius muscle is a major shoulder muscle. The findings of this study indicate that in addition to the shoulder muscles, behavior of muscles in the neck region, sternocleidomastoid and cervical trapezius, were also vulnerable to the mental stress. The exact pathophysiology relating the cognitive stress and muscle tension is unknown. A plausible justification for the increased muscle activities with the addition of cognitive load observed in the present study could be the increased sense of time pressure. Lundberg et al., (1999) reported increase in the upper trapezius muscle tension with the increase in the work-related stress and time pressure. In this study, participants performed combined physical and cognitive exertions 
and the physical only exertion in the same duration. This may have induced higher time pressure, during combined physical and cognitive exertions, further augmenting the muscle tension.

Individual factors such as personality types were found to play interacting role in the relationship between the external physical and cognitive exertion and the internal musculoskeletal loading. In general, the loading of neck shoulder muscles among the participants with the feeling personality were found to be more sensitive to the addition of cognitive load. For the upper and cervical trapezius muscles, although interaction between the type of exertion and personality type was statistically insignificant, addition of cognitive load showed a higher increase in the muscle activities for the participants with feeling personality than thinking personality. For the sternocleidomastoid muscle, this interaction was statistically significant; thus, rejecting the second hypothesis (there will be no interaction between the type of exertion and personality type). In the studies performed by Vasseljen et al., (2001) and Allread and Marras (2006), it was found that people of different personality traits respond to cognitive stress differently. Lundberg et al., (1999) found that symptomatic workers developed higher level of muscle tension than asymptomatic workers in response to similar levels of work-related psychosocial stress. Lundberg et al., (1999) further claimed that lower level of muscle tension among the asymptomatic workers could be due to their ability to keep their muscles relaxed. Perhaps, the participants with the thinking personality in this study were able to keep their muscles relatively more relaxed than the feeling personality and therefore showed a comparatively lower increase in the muscle activities with the addition of cognitive load. Thus, based on the findings of this study, it can be argued that personalities may be associated with the individual's ability to keep their muscles tensed or relaxed in response to cognitive stress. 
The findings of subjective workload assessment performed using NASA TLX clearly showed that significantly higher mental and temporal demands were rated by the subjects during combination of physical and cognitive exertion than pure physical exertion. This is a clear indication that the protocol used in this study successfully generated cognitive stress. A higher frustration level was also reported by the participants during combination of physical and cognitive exertion. Although, the participants exerted almost identical levels of force and rested for longer periods during physical exertions than during combination of physical and cognitive exertions, the workload scores for the physical demand reported in this study were higher during pure physical exertions than combination of physical and cognitive exertions. This is because of the relatively higher weights given by the participants to the physical demand during pure physical exertions. When compared pure physical with combination of physical and cognitive exertions, in general, participants perceived similar raw workload ratings for physical demand during pure physical and combination of physical and cognitive exertions, however, higher weights were given to physical demand during pure physical exertions than during the combination of physical and cognitive exertions.

No clear relationship between subjective workload assessments and the objective outcomes (amplitude of the EMG signal) were observed in this study. The lack of relationship might be because NASA TLX assesses the workload on a global (whole body) level. The physical task (simulated bed to stretcher transfer) studied in this investigation demanded active contribution from the upper extremity musculature, rather than whole body. A local perceived discomfort assessment method, designed especially for the neck and shoulder region, could have provided a between understanding of relationship between the subjective and objective assessment outcomes. 
The trends in the behavior of mean frequency data were inconclusive. A decreasing trend in the mean or median power frequencies are the markers of development of neuromuscular fatigue. In this study, the mean frequencies between the $1^{\text {st }}$ and $10^{\text {th }}$ exertions remained unchanged in case of most of the subjects indicating that none of the muscles showed a sign of neuromuscular fatigue. Possibly, the protocol used in this study, i.e. 10 exertions in 10 minutes, might not be strenuous enough to cause neuromuscular fatigue of the neck and shoulder musculatures.

It was the intention of this study to evaluate a link between personality, combination of cognitive and physical load and neck-shoulder musculoskeletal disorders. A number of epidemiological studies have indicated that the risk factors for work-related neck shoulder MSD among the healthcare workers have multidimensional etiologies (Aasa et al., 2005; Andersen et al., 2003; Devereux et al., 2002a; Gunnarsdottir et al., 2003a; Josephson et al., 1999; Lipscomb et al., 2004; Salminen et al., 2003b; Warming et al., 2009). The results of this study show that people with certain types of personalities are more susceptible to increased muscle load than other when exposed to combination of physical and cognitive load. This further substantiate "personality" as one of the key factors in the array of multidimensional etiologies that influence neck-shoulder MSDs among healthcare workers. The results of this study can serve to assist future research efforts related to the assimilation of personality and combination of cognitive and physically intense work among occupations such as healthcare workers. The knowledge gained from this study imply that studies viewing the entire work system (the interaction of physical and psychosocial workplace issues, as well as individual factors) by implementing multi-factorial (physical, psychosocial, individual, etc.) approaches will most likely to derive the root causes of neck- shoulder MSDs among healthcare occupations. 
There are a few limitations of this study that need to be acknowledged. During the combination of physical and cognitive exertions, the cognitive stress was created using tasks that are similar to the ones which are routinely performed by the healthcare workers. These tasks involved remembering and recalling medical terms. All the participants in this study were college students. It is likely that these participants may have felt more stress than healthcare workers because of their unfamiliarity with demands of the cognitive work. Further studies using experienced healthcare workers would further elucidate the relationship between work-related cognitive and physical stress and the risk of neck musculoskeletal disorders among the healthcare workers. The physical task evaluated in this study was isometric in nature. Study design using isometric exertion allows controlling confounding effect of technique of force exertion, however, in the real world situation, the actual patient transfer tasks are dynamic in nature. It is possible that the neck and shoulder muscles may behave differently during such exertions. The participant pool (males vs. females) recruited in this study is different than actual healthcare worker population. In this study only $10 \%$ of the participants were females. Future studies with more number of female participants (up to 60\%), which is a true representative of the healthcare workers population, would provide findings with more pragmatic applications. In this study only two types of personalities based on the information processing preference using basic Myers-Briggs Type Indicator (MBTI) questionnaire were evaluated. Myers-Briggs Type Indicator (MBTI) questionnaire provide sixteen personality classifications. Future studies with more personality classifications, determined using a detailed comprehensive questionnaires, would further facilitate understanding the impact of personality factors in the development of work-related neck and shoulder MSDs. 


\subsection{Conclusion}

Increased cognitive workload can result in increased muscle activity and increased perceived workloads while performing bed-stretcher patient transfer task. Neck-shoulder muscles worked harder while performing a combination of physical and cognitive exertions than while performing pure physical exertions. The effect of the loading of neck-shoulder muscles was found sensitive to the individual personality. In general for all the muscles, among the participants with feeling personalities, a higher increase in the activation level of muscles was observed. In summary, the current investigation supports the premise that adverse psychosocial conditions, characterized by increased cognitive load, with physical demands can increase risk for neck and shoulder MSDs. 


\section{Bibliography}

Aasa U., Barnekow-Bergkvist M., Aengquist K., Brulin C. (2005) Relationships between workrelated factors and disorders in the neck-shoulder and low-back region among female and male ambulance personnel. Journal of Occupational Health 47:481-489.

Acierno S.P., Baratta R.V., Solomonow M. (1995) A practical guide to electromyography for biomechanics, Louisiana State University. Unpublished work.

Aghazadeh F., Ayoub M. (1985) A comparison of dynamic-and static-strength models for prediction of lifting capacity. Ergonomics 28:1409-1417.

Allport G.W. (1937) Personality: A psychological interpretation, New York: Holt, Rinehart and Winston.

Allread W., Marras W. (2006) Does personality affect the risk of developing musculoskeletal discomfort? Theoretical Issues in Ergonomics Science 7:149-167.

Andersen J., Kaergaard A., Mikkelsen S., Jensen U., Frost P., Bonde J., Fallentin N., Thomsen J. (2003) Risk factors in the onset of neck/shoulder pain in a prospective study of workers in industrial and service companies. British Medical Journal 60:649.

Ariëns G., Bongers P., Hoogendoorn W., Houtman I., van der Wal G., van Mechelen W. (2001a) High quantitative job demands and low coworker support as risk factors for neck pain: results of a prospective cohort study. Spine 26:1896.

Ariëns G.A.M., van Mechelen W., Bongers P.M., Bouter L.M., van der Wal G. (2001b) Psychosocial risk factors for neck pain: A systematic review. American Journal of Industrial Medicine 39:180-193.

Bates E., Moore B. (1975) Stress in hospital personnel. The Medical Journal of Australia 2:765.

Bayne R. (1997) The Myers-Briggs type indicator: a critical review and practical guide Nelson Thornes.

Bernard B. (1997) Musculoskeletal disorders and workplace factors: A critical review of epidemiological evidence for work-related musculoskeletal disorders of the neck, upper extremity, and low back (Cincinnati, Ohio (USA): US Department of Health and Human Services, Public Health Service, Centers for Disease Control, National Institute for Occupational Safety and Health), Publication.

Birch L., Juul-Kristensen B., Jensen C., Finsen L., Christensen H. (2000) Acute response to precision, time pressure and mental demand during simulated computer work. Scandinavian Journal of Work, Environment \& Health 26:299-305.

BLS. (2010) Nonfatal Occupational Injuries AND Illness requiring days away from work for state government and local government workers Economics Release, BLS. pp. 7.

Bongers P.M., de Winter C.R., Kompier M.A.J., Hildebrandt V.H. (1993) Psychosocial factors at work and musculoskeletal disease. Scandinavian Journal of Work, Environment, and Health 19:297-312.

Bosch T., de Looze M. (2007) Development of fatigue and discomfort in the upper trapezius muscle during light manual work. Ergonomics 50:161.

Bosch T., De Looze M., Van Dieen J. (2007) Development of fatigue and discomfort in the upper trapezius muscle during light manual work. Ergonomics 50:161-177.

Bowman C. (1999) BLS Projections to 2008: A Summary. Monthly Labor Review 122.

Camerino D., Cesana G., Molteni G., De Vito G., Evaristi C., Latocca R. (2001a) Job strain and musculoskeletal disorders of Italian nurses. Occupational Ergonomics 2:215-223. 
Camerino D., Cesana G.C., Molteni G., De Vito G., Evaristi C., Latocca R. (2001b) Job strain and musculoskeletal disorders of Italian nurses. Occupational Ergonomics 2:215-223.

Carlson J. (1985) Recent assessments of the Myers-Briggs type indicator. Journal of Personality Assessment 49:356-365.

Devereux J., Vlachonikolis I., Buckle P. (2002a) Epidemiological study to investigate potential interaction between physical and psychosocial factors at work that may increase the risk of symptoms of musculoskeletal disorder of the neck and upper limb. British Medical Journal 59:269.

Devereux J.J., Vlachonikolis I.G., Buckle P.W. (2002b) Epidemiological study to investigate potential interaction between physical and psychosocial factors at work that may increase the risk of symptoms of musculoskeletal disorder of the neck and upper limb. Occupational and Environmental Medicine 59:269-277.

Estryn-Behar M., Kaminski M., Peigne E., Bonnet N., Vaichere E., Gozlan C., Azoulay S., Giorgi M. (1990) Stress at work and mental health status among female hospital workers. British Journal of Industrial Medicine 47:20.

Farina D., Madeleine P., Graven-Nielsen T., Merletti R., Arendt-Nielsen L. (2002) Standardising surface electromyogram recordings for assessment of activity and fatigue in the human upper trapezius muscle. European Journal of Applied Physiology 86:469-478.

Finsen L. (1999) Biomechanical aspects of occupational neck postures during dental work. International Journal of Industrial Ergonomics 23:397-406.

Fragala G., Bailey L.P. (2003) Addressing occupational strains and sprains: musculoskeletal injuries in hospitals. American Association of Occupational Health Nurses Journal 51:252-9.

Gunnarsdottir H., Rafnsdottir G., Helgadottir B., Tomasson K. (2003a) Psychosocial risk factors for musculoskeletal symptoms among women working in geriatric care. American Journal of Industrial Medicine 44:679-684.

Gunnarsdottir H.K., Rafnsdottir G.L., Helgadottir B., Tomasson K. (2003b) Psychosocial risk factors for musculoskeletal symptoms among women working in geriatric care. American Journal of Industrial Medicine 44:679-684.

Hammer A. (1993) Introduction to type and careers Consulting Psychologists Press.

Harvey R. (1996) Reliability and validity. MBTI applications: A decade of research on the Myers-Briggs Type Indicator:5-29.

Holte K., Westgaard R. (2002) Daytime trapezius muscle activity and shoulder-neck pain of service workers with work stress and low biomechanical exposure. American Journal of Industrial Medicine 41:393-405.

Hughes L., Babski-Reeves K., Smith-Jackson T. (2007) Effects of psychosocial and individual factors on physiological risk factors for upper extremity musculoskeletal disorders while typing. Ergonomics 50:261-274.

Johansson J. (2008) Psychosocial work factors, physical work load and associated musculoskeletal symptoms among home care workers. Scandinavian Journal of Psychology 36:113-129.

Josephson M., Lagerström M., Hagberg M., Wigaeus Hjelm E. (1997) Musculoskeletal symptoms and job strain among nursing personnel: a study over a three year period. Occupational and Environmental Medicine 54:681. 
Josephson M., Pernold G., Ahlberg-Hultén G., Härenstam A., Theorell T., Vingård E., Waldenström M., Hjelm E.W., Group M.N.S. (1999) Differences in the association between psychosocial work conditions and physical work load in female-and maledominated occupations. American Industrial Hygiene Association Journal 60:673-678.

Lagerström M., Wenemark M., Hagberg M., Wigaeus Hjelm E. (1996) Occupational and individual factors related to musculoskeletal symptoms in five body regions among Swedish nursing personnel. International Archives of Occupational and Environmental Health 68:27-35.

Lavender S., Conrad K., Reichelt P., Johnson P., T Meyer F. (2000) Biomechanical analyses of paramedics simulating frequently performed strenuous work tasks. Applied Ergonomics 31:167-177.

Linton S. (1990) Risk factors for neck and back pain in a working population in Sweden. Work \& Stress 4:41-49.

Linton S. (2000) A review of psychological risk factors in back and neck pain. Spine 25:1148.

Lipscomb J., Trinkoff A., Brady B., Geiger-Brown J. (2004) Health care system changes and reported musculoskeletal disorders among registered nurses. American Journal of Public Health 94:1431.

Lundberg U., Dohns I.E., Melin B., Sandsjö L., Palmerud G., Kadefors R., Ekström M., Parr D. (1999) Psychophysiological stress responses, muscle tension, and neck and shoulder pain among supermarket cashiers. Journal of Occupational Health Psychology 4:245.

Malchaire J., Roquelaure Y., Cock N., Piette A., Vergracht S., Chiron H. (2001) Musculoskeletal complaints, functional capacity, personality and psychosocial factors. International Archives of Occupational and Environmental Health 74:549-557.

Marras W., Davis K., Heaney C., Maronitis A., Allread W. (2000) The influence of psychosocial stress, gender, and personality on mechanical loading of the lumbar spine. Spine 25:3045.

Mathiassen S.E., Winkel J. (1990) Electromyographic activity in the shoulder-neck region according to arm position and glenohumeral torque. European Journal of Applied Physiology and Occupational Physiology 61:370-379.

McGill S., Kavcic N. (2005) Transfer of the horizontal patient: The effect of a friction reducing assistive device on low back mechanics. Ergonomics 48:915-929.

Myers I.B. (1962) The Myers-Briggs type indicator manual. Princeton, NJ: Educational Testing Service.

Nimbarte, A. D. (2009) Modeling the Risk Factors Associated with the Neck Disorders During Manual Material Handling Tasks. A PhD Dissertation.

Nimbarte, A. D., Aghazadh F., Ikuma L., Harvey C. (2010) Neck Disorders among Construction Workers: Understanding the Physical Loads on the Cervical Spine during Static Lifting Tasks. Industrial Health 48:145-153.

NIOSH. (2001) Musculoskeletal Disorders and the Workplace: Low Back and Upper Extremities, Panel on Musculoskeletal Disorders and the Workplace Commission on Behavioral and Social Sciences and Education National Research Council and Institute of Medicine, Washington, D.C.

Rasmussen J. (1983) Skills, rules, and knowledge; signals, signs, and symbols, and other distinctions in human performance models. IEEE transactions on systems, man, and cybernetics 13:257-266.

Salminen S., Kivimäki M., Elovainio M., Vahtera J. (2003a) Stress factors predicting injuries of hospital personnel. American Journal of Industrial Medicine 44:32-36. 
Salminen S., Kivimäki M., Elovainio M., Vahtera J. (2003b) Stress factors predicting injuries of hospital personnel. American Journal of Industrial Medicine 44:32-36.

Schibye B., Hansen A., Hye-Knudsen C., Essendrop M., Böcher M., Skotte J. (2003) Biomechanical analysis of the effect of changing patient-handling technique. Applied Ergonomics 34:115-123.

Smith D., Mihashi M., Adachi Y., Koga H., Ishitake T. (2006) A detailed analysis of musculoskeletal disorder risk factors among Japanese nurses. Journal of Safety Research 37:195-200.

Sommerich C., McGlothlin J., Marras W. (1993) Occupational risk factors associated with soft tissue disorders of the shoulder: a review of recent investigations in the literature. Ergonomics 36:697-717.

Sommerich C., Joines S., Psihogios J. (2001) Effects of computer monitor viewing angle and related factors on strain, performance, and preference outcomes. Human Factors 43:39.

Sommerich C.M., Joines S.M., Hermans V., Moon S.D. (2000) Use of surface electromyography to estimate neck muscle activity. Journal of Electromyography and Kinesiology 10:37798.

Statistics B.o.L. (2002) Survey of occupational inquiries and illnesses, 200, U.S. Department of Labor.

Toomingas A., Theorell T., Michelsen H., Nordemar R. (1997) Associations between self-rated psychosocial work conditions and musculoskeletal symptoms and signs. Scandinavian Journal of Work Environment and Health 23:130-139.

Trinkoff A.M., Lipscomb J.A., Geiger-Brown J., Brady B. (2002) Musculoskeletal problems of the neck, shoulder, and back and functional consequences in nurses. American Journal of Industrial Medicine 41:170-178.

Trinkoff A.M., Lipscomb J.A., Geiger-Brown J., Storr C.L., Brady B.A. (2003) Perceived physical demands and reported musculoskeletal problems in registered nurses. American Journal of Preventive Medicine 24:270-275.

Turville K., Psihogios J., Ulmer T., Mirka G. (1998) The effects of video display terminal height on the operator: a comparison of the 15 and 40 recommendations. Applied Ergonomics 29:239-246.

Tzeng H., Yin C. (2006) The staff-working height and the designing-regulation height for patient beds as possible causes of patient falls. Nursing economics 24:323.

Van Yperen N., Hagedoorn M. (2003) Do high job demands increase intrinsic motivation or fatigue or both? The role of job control and job social support. The Academy of Management Journal 46:339-348.

Vasavada A., Li S., Delp S. (1998) Influence of muscle morphometry and moment arms on the moment-generating capacity of human neck muscles. Spine 23:412.

Vasseljen O., Holte K., Westgaard R. (2001) Shoulder and neck complaints in customer relations: individual risk factors and perceived exposures at work. Ergonomics 44:355372.

Wadman C., Kjellberg A. (2007) The role of the affective stress response as a mediator for the effect of psychosocial risk factors on musculoskeletal complaints--Part 2: Hospital workers. International Journal of Industrial Ergonomics 37:395-403.

Wahlström J., Hagberg M., Johnson P., Svensson J., Rempel D. (2002) Influence of time pressure and verbal provocation on physiological and psychological reactions during work with a computer mouse. European Journal of Applied Physiology 87:257-263. 
Walker-Bone K., Cooper C. (2005) Hard work never hurt anyone: or did it? A review of occupational associations with soft tissue musculoskeletal disorders of the neck and upper limb. British Medical Journal 64:1391.

Warming S., Precht D., Suadicani P., Ebbeh j N. (2009) Musculoskeletal complaints among nurses related to patient handling tasks and psychosocial factors-Based on logbook registrations. Applied Ergonomics 40:569-576. 


\section{Appendix A}

\section{List 1}

\section{Patient's Name}

Sex
Adalbert, George

M
Age

23Y

Date

05/12/2009

Name of Disease

Allergies

\section{Symptoms}

Sneezing, difficulty breathing, cramps, and vomiting.

\section{Drug Calculation Terms}

$1 \mathrm{~kg}=2.2 \mathrm{lbs}, \quad 5 \mathrm{~mL}=1 \mathrm{tsp}, \quad 30 \mathrm{~mL}=1$ ounce,

1 gram $=1000 \mathrm{mg}, \quad 60$ minutes $=1$ hour $, \quad 15 \mathrm{gtt}=1 \mathrm{~mL}, 1$ grain $=60 \mathrm{mg}$

Prescription:

Name of Drug

Formula

Chlorpheniramine

$\mathrm{C}_{16} \mathrm{H}_{19} \mathrm{CIN}_{2}$

Doxylamine

$\mathrm{C}_{17} \mathrm{H}_{22} \mathrm{~N}_{2} \mathrm{O}$

Brompheniramine

$\mathrm{C}_{16} \mathrm{H}_{19} \mathrm{BrN}_{2}$

Diphenhydramine

$\mathrm{C}_{17} \mathrm{H}_{21} \mathrm{NO}$

Diphenylpyraline

$\mathrm{C}_{19} \mathrm{H}_{23} \mathrm{NO}$

Pemirolast

$\mathrm{C}_{10} \mathrm{H}_{8} \mathrm{~N}_{6} \mathrm{O}$

Bromodiphenhydramine

$\mathrm{C}_{17} \mathrm{H}_{20} \mathrm{BrNO}$

Benzylpenicilloyl

Polylysine

$\mathrm{C}_{22} \mathrm{H}_{31} \mathrm{~N}_{3} \mathrm{O}_{6} \mathrm{~S}$

Desloratadine

$\mathrm{C}_{19} \mathrm{H}_{19} \mathrm{CIN}_{2}$

Mequitazine

$\mathrm{C}_{20} \mathrm{H}_{22} \mathrm{~N}_{2} \mathrm{~S}$ 


\section{List 2}

Patient's Name

Sex

Name of Disease
Anthony, Antonius

$\mathbf{M}$

Arthritis
Age

Date
$35 Y$

$\mathbf{0 3 / 1 5 / 2 0 1 0}$

\section{Symptoms}

Loss of movement, Stiffness and swelling in the joints, snapping of the joints, Bony growths at the joints and abnormal angulations.

\section{Drug Calculation Terms}

$1 \mathrm{~kg}=2.2 \mathrm{lbs}, \quad 5 \mathrm{~mL}=1 \mathrm{tsp}, \quad 30 \mathrm{~mL}=1$ ounce,

1 gram $=1000 \mathrm{mg}, \quad 60$ minutes $=1$ hour $, \quad 15 \mathrm{gtt}=1 \mathrm{~mL}, 1$ grain $=60 \mathrm{mg}$

\section{Prescription}

Name of Drug

Formula

Abatacept

Azathioprine

C9H7N7O2S

Auranofin

C20H35AuO9PS

Piroxicam

C15H13N3O4S

Oxaprozin

C18H15NO3

Ketoprofen

C16H14O3

Celecoxib

C17H14F3N3O2S

Penicillamine

C5H11NO2S

L-Histidine

C6H9N3O2

Sulfasalazine

C18H14N4O5S 


\section{List 3}

\begin{tabular}{ccccc} 
Patient's Name & \multicolumn{2}{c}{ Ceslaus, Chester } & Age & 24Y \\
\cline { 2 - 2 } & $M$ & Date & 04/11/2010
\end{tabular}

Name of Disease

Asthma

\section{Symptoms}

Coughing, especially at night, Wheezing Shortness of breath Chest tightness, pain, or pressure

\section{Drug Calculation Terms}

$1 \mathrm{~kg}=2.2 \mathrm{lbs}, \quad 5 \mathrm{~mL}=1 \mathrm{tsp}, \quad 30 \mathrm{~mL}=1$ ounce,

$1 \mathrm{gram}=1000 \mathrm{mg}, \quad 60$ minutes $=1$ hour $, \quad 15 \mathrm{gtt}=1 \mathrm{~mL}, 1$ grain $=60 \mathrm{mg}$

\begin{tabular}{|c|c|}
\hline $\begin{array}{l}\text { Prescription } \\
\text { Name of drug }\end{array}$ & Formula \\
\hline Zafirlukast & C31H33N3O6S \\
\hline Cinalukast & C23H28N2O3S \\
\hline Fluticasone Propionate & C25H31F3O5S \\
\hline Epinephrine & C9H13NO3 \\
\hline Mometasone & $\mathrm{C} 22 \mathrm{H} 28 \mathrm{Cl} 2 \mathrm{O} 4$ \\
\hline Bitolterol & C28H31NO5 \\
\hline Salmeterol & C25H37NO4 \\
\hline Clenbuterol & C12H18Cl2N2O \\
\hline Montelukast & C35H36CINO3S \\
\hline Bambuterol & C18H29N3O5 \\
\hline
\end{tabular}




\section{List 4}

Patient's Name Emiliana, Emily

Sex
F
Age

Date
$52 Y$

08/11/2008

Name of Disease Type 1 Diabetes

\section{Symptom}

Being exceptionally thirsty, dry mouth, the need to urinate often weight loss (even though you may be hungry and eating well), feeling weak and tired, blurry vision

\section{Drug Calculation Terms}

$1 \mathrm{~kg}=2.2 \mathrm{lbs}, \quad 5 \mathrm{~mL}=1 \mathrm{tsp}, \quad 30 \mathrm{~mL}=1$ ounce,

1 gram $=1000 \mathrm{mg}, \quad 60$ minutes $=1$ hour $, \quad 15 \mathrm{gtt}=1 \mathrm{~mL}, 1$ grain $=60 \mathrm{mg}$

\begin{tabular}{|ll|}
\hline $\begin{array}{l}\text { Prescription: } \\
\text { Name of Drug }\end{array}$ & Formula \\
\hline Chlorpropamide & C10H13CIN2O3S \\
Voglibose & C10H21NO7 \\
Miglitol & C8H17NO5 \\
Gliquidone & C27H33N3O6S \\
Pramlintide & C171H267N51O53S2 \\
Sitagliptin & C16H15F6N5O \\
Troglitazone & C24H27NO5S \\
Mitiglinide & C19H25NO3 \\
Acarbose & C25H43NO18 \\
Metformin & C4H11N5 \\
\hline
\end{tabular}




\section{List 5}

\section{Patient's Name}

Sex

Francis, Frank

M

Celiac Disease

\section{Symptoms}

Often have general gastric complaints, such as intermittent diarrhea, abdominal pain and bloating. suffer no gastrointestinal discomfort at all

\section{Drug Calculation Terms}

$1 \mathrm{~kg}=2.2 \mathrm{lbs}, \quad 5 \mathrm{~mL}=1 \mathrm{tsp}, \quad 30 \mathrm{~mL}=1$ ounce,

1 gram $=1000 \mathrm{mg}, \quad 60$ minutes $=1$ hour $, \quad 15 \mathrm{gtt}=1 \mathrm{~mL}, 1$ grain $=60 \mathrm{mg}$

\begin{tabular}{ll}
\hline $\begin{array}{l}\text { Prescription } \\
\text { Name of Drug }\end{array}$ & Formula \\
\hline Prednisolone & C21H28O5 \\
Hydroxocobalamin & C62H90CoN13O15P \\
Olsalazine & C14H10N2O6 \\
Selegiline & C13H17N \\
Cycrimine & C19H29NO \\
Penicillamine & C5H11NO2S \\
OspA lipoprotein & C1198H2012N322O422S2 \\
Pramipexole & C10H17N3S \\
Ropinirole & C16H24N2O \\
Phosphatidylserine & $\mathrm{C13H24NO10P}$ \\
\hline
\end{tabular}




\section{List 6}

\begin{tabular}{cc} 
Patient's Name & Henrietta, Hattie \\
\cline { 2 - 2 } Sex & F \\
\cline { 2 - 2 } Name of Disease & Diarrhea
\end{tabular}

Age

Date

$41 Y$

07/10/2008

\section{Symptoms}

Intestinal flu, cramping abdominal pain, nausea, and vomiting.

\section{Drug Calculation Terms}

$1 \mathrm{~kg}=2.2 \mathrm{lbs}, \quad 5 \mathrm{~mL}=1 \mathrm{tsp}, \quad 30 \mathrm{~mL}=1$ ounce,

1 gram $=1000 \mathrm{mg}, \quad 60$ minutes $=1$ hour $, \quad 15 \mathrm{gtt}=1 \mathrm{~mL}, 1$ grain $=60 \mathrm{mg}$

Prescription:

Name of Drug

Formula

Loperamide

C29H33CIN2O2

Nitazoxanide

C12H9N3O5S

Rifaximin

C43H51N3O11

Bismuth Subsalicylate

C7H6BiO4

Diphenoxylate

C30H32N2O2

Vapreotide

C57H70N12O9S2

Carboprost Tromethamine

C21H36O5

Misoprostol

C22H38O5

Octreotide

C49H66N10O10S2

Aluminium

Al 


\section{List 7}

Patient's Name

Sex

Name of Disease
John Nepomucene

$\mathbf{M}$

Hepatitis
Age

Date

34 Y

$07 / 10 / 2008$

\section{Symptoms}

A short, mild, flu-like illness; nausea, vomiting and diarrhea; loss of appetite; weight loss;

jaundice, itchy skin; and abdominal pain

\section{Drug Calculation Terms}

$1 \mathrm{~kg}=2.2 \mathrm{lbs}, \quad 5 \mathrm{~mL}=1 \mathrm{tsp}, \quad 30 \mathrm{~mL}=1$ ounce,

1 gram $=1000 \mathrm{mg}, \quad 60$ minutes $=1$ hour $, \quad 15 \mathrm{gtt}=1 \mathrm{~mL}, 1$ grain $=60 \mathrm{mg}$

Prescription:

Name of Drug

Entecavir

Telbivudine

Adefovir Dipivoxil

Ribavirin

Atorvastatin

Lactulose

Valganciclovir

Nefazodone

Lamivudine

Simvastatin
Formula

C12H15N5O3

C10H14N2O5

C20H32N5O8P

C8H12N4O5

C33H35FN2O5

C12H22O11

C14H22N6O5

C25H32CIN5O2

C8H11N3O3S

C25H38O5 


\section{List 8}

Patient's Name

Sex

Name of Disease
Justin, Justyn

$\mathbf{M}$

Gonorrhea

\section{Symptoms}

Abnormal discharge from the penis ,Painful or urination. Anal itching, pain, bleeding, or discharge. Sore throat (rare). Pinkeye (conjunctivitis) (rare).

\section{Drug Calculation Terms}

$1 \mathrm{~kg}=2.2 \mathrm{lbs}, \quad 5 \mathrm{~mL}=1 \mathrm{tsp}, \quad 30 \mathrm{~mL}=1$ ounce,

1 gram $=1000 \mathrm{mg}, \quad 60$ minutes $=1$ hour $, \quad 15 \mathrm{gtt}=1 \mathrm{~mL}, 1$ grain $=60 \mathrm{mg}$

\begin{tabular}{|ll}
\hline $\begin{array}{l}\text { Prescription } \\
\text { Name of Drug }\end{array}$ & Formula \\
\hline Cefuroxime & C16H16N4O8S \\
Polymyxin B Sulfate & C56H100N16O17S \\
Spectinomycin & C14H24N2O7 \\
Trovafloxacin & C20H15F3N4O3 \\
Azithromycin & C38H72N2O12 \\
Enoxacin & C15H17FN4O3 \\
Lymecycline & C22H23CIN2O8 \\
Ciprofloxacin & C17H18FN3O3 \\
Amoxicillin & C16H19N3O5S \\
Telithromycin & C43H65N5O10
\end{tabular}




\section{List 9}

Patient's Name

Sex

Name of Disease
Klemens, Klement

$\mathbf{M}$

Meningitis

\section{Symptoms}

Fever, Severe and persistent headache, Stiff and painful neck, especially when trying to touch the chin to the chest. Vomiting., Confusion and decreased level of consciousness, Seizures.

\section{Drug Calculation Terms}

$1 \mathrm{~kg}=2.2 \mathrm{lbs}, \quad 5 \mathrm{~mL}=1 \mathrm{tsp}, \quad 30 \mathrm{~mL}=1$ ounce,

$1 \mathrm{gram}=1000 \mathrm{mg}, \quad 60$ minutes $=1$ hour $, \quad 15 \mathrm{gtt}=1 \mathrm{~mL}, 1$ grain $=60 \mathrm{mg}$

\begin{tabular}{|ll|}
\hline $\begin{array}{l}\text { Prescription: } \\
\text { Name of Drug }\end{array}$ & Formula \\
\hline Sulfacytine & C12H14N4O3S \\
Polymyxin B Sulfate & C56H100N16O17S \\
Sulfadiazine & C10H10N4O2S \\
Sulfisoxazole & C11H13N3O3S \\
Iophendylate & C19H29IO2 \\
Ceftriaxone & C18H18N8O7S3 \\
Fluconazole & C13H12F2N6O \\
Aztreonam & C13H17N5O8S2 \\
Itraconazole & C35H38Cl2N8O4 \\
Sulfamethizole & C9H10N4O2S2 \\
\hline
\end{tabular}




\section{List 10}

Patient's Name

Sex

Romualda, Roma
M

Name of Disease

\section{Symptoms}

Chest pain or discomfort, weakness, sweating, nausea, vomiting, and arrhythmias, sometimes causing loss of consciousness.

\section{Drug Calculation Terms}

$1 \mathrm{~kg}=2.2 \mathrm{lbs}, \quad 5 \mathrm{~mL}=1 \mathrm{tsp}, \quad 30 \mathrm{~mL}=1$ ounce,

1 gram $=1000 \mathrm{mg}, \quad 60$ minutes $=1$ hour $, \quad 15 \mathrm{gtt}=1 \mathrm{~mL}, 1$ grain $=60 \mathrm{mg}$

Prescription:

Name of Drug

Clopidogrel

Ridogrel

Dobutamine

Lercanidipine

Nitrendipine

Amiodarone

Nicardipine

Diltiazem

Nisoldipine

Felodipine
Formula

C16H16CINO2S

C18H17F3N2O3

C18H23NO3

C36H41N3O6

C18H20N2O6

C25H29I2NO3

C26H29N3O6

C22H26N2O4S

C20H24N2O6

C18H19Cl2NO4 


\section{$\underline{\text { Appendix B }}$}

\section{Recalling and calculation: 1}

- List three names of the drugs?

- What are the symptoms of that disease?
- What is the Patient diseases name?

$\mathrm{kg}$

$\mathrm{mL}$

hours

\section{Recalling and calculation: 2}

- List three names of the drugs?

- What are the symptoms of that disease?
- What is the Patient diseases name?
Convert the following:

$2 \mathrm{tsp}=$

180 minutes $=$

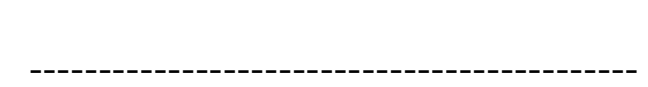

Convert the following:

$20 \mathrm{~kg}=$

3 tsp=

2 gram $=$ lbs

$\mathrm{mL}$

$\mathrm{mg}$ 


\section{Recalling and calculation: 3}

- List three names of the drugs? - What is the Patient diseases name?

- What are the symptoms of that disease?

Convert the following:

3 gram $=$

160 minutes $=$

2 once $=$ $\mathrm{mg}$

hours

$\mathrm{mL}$

\section{Recalling and calculation: 4}

- List three names of the drugs?

- What are the symptoms of that disease?
- What is the Patient diseases name?

Convert the following:

$120 \mathrm{lbs}=$

5 tsp=

4 gram $=$ $\mathrm{kg}$

$\mathrm{mL}$

mg 


\section{Recalling and calculation: 5}

- List three names of the drugs? - What is the Patient diseases name?

- What are the symptoms of that disease?

Convert the following:

5 tsp $=$

4 gram $=$

4 once $=$
$\mathrm{mL}$

$\mathrm{mg}$

$\mathrm{mL}$

\section{Recalling and calculation: 6}

- List three names of the drugs? - What is the Patient diseases name?

- What are the symptoms of that disease?

Convert the following:

$100 \mathrm{lbs}=$

$2 \mathrm{tsp}=$

$2000 \mathrm{mg}=$ $\mathrm{kg}$

$\mathrm{mL}$

g 


\section{Recalling and calculation: 7}

- List three names of the drugs? - What is the Patient diseases name?

- What are the symptoms of that disease?

Convert the following:

$800 \mathrm{lbs}=$

2 gram $=$

$\mathrm{kg}$

240 minutes $=$

$\mathrm{mg}$

hours

\section{Recalling and calculation: 8}

- List three names of the drugs? - What is the Patient diseases name?

- What are the symptoms of that disease?

Convert the following:

3 gram $=$

160 minutes $=$

2 once $=$ $\mathrm{mg}$

hours

$\mathrm{mL}$ 


\section{Recalling and calculation: 9}

- List three names of the drugs? - What is the Patient diseases name?

- What are the symptoms of that disease?

Convert the following:

$120 \mathrm{lbs}=$

5 tsp=

4 gram $=$ $\mathrm{kg}$

$\mathrm{mL}$

$\mathrm{mg}$

\section{Recalling and calculation: 10}

- $\quad$ List three names of the drugs?

- What is the Patient diseases name?

- What are the symptoms of that disease?

Convert the following:

5 tsp $=$

$\mathrm{mL}$

4 gram $=$

4 once $=$

$\mathrm{mg}$

$\mathrm{mL}$ 


\section{Appendix C}

Following questions which are part of the Physical Activity Readiness Questionnaire (PAR-Q, British Columbia Ministry of Health) used to screen participants for cardiac and other health problems (e.g. dizziness, chest pain, heart trouble):

1) Has your doctor ever said that you have a heart condition and that you should only do physical activity recommended by a doctor?

2) Do you feel pain in your chest when you do physical activity?

3) In the past month, have you had chest pain when you were not doing physical activity?

4) Do you lose your balance because of dizziness or do you ever lose consciousness?

5) Do you have a bone or joint problem that could be made worse by a change in your physical activity?

6) Is your doctor currently prescribing drugs (for example, water pills) for your blood pressure or heart condition?

7) Do you know of any other reason why you should not do physical activity? 


\section{$\underline{\text { Appendix D }}$}

\section{WestVirginiaUniversity.}

Office of Research Compliance

\section{CONSENT AND INFORMATION FORM}

OMR ICF

Principal Investigator: Nimbarte, Ashish

Department: ENGINEERING - Ind./Mgt. Sys. Engineering

Tracking Number: $\mathrm{H}-22894$

Study Title:

Understanding the effect of physical and psychosocial stress, and personality type on the loading of neck shoulder musculature.

\section{Co-Investigator(s):}

Mohammed Al Hassan

Sponsor

Contact Persons In the event you experience any side effects or injury related to this research, you should contact Dr.Nimbarte at 304/293-9473. (After hours contact Dr.Nimbarte at 225/226-8813.) If you have any questions, concerns, or complaints about this research, you can contact Dr. Nimbarte at 304/293-9473 or Mohammed at 304/2820397 .For information regarding your rights as a research subject, you may contact the Office of Research Compliance at 304/293-7073.

Introduction You, , have been asked to participate in this research study, which has been explained to you by Dr. Ashish Nimbarte, Ph.D., and Mohammed Al Hassan, B.S.in the department of Industrial and Management Systems Engineering at WVU. This research is being conducted to fulfill the requirements for a master thesis of Mr. Mohammed

$\begin{array}{ll}\text { Tracking \#: } & \mathrm{H}-22894 \\ \text { Approved On: } & 01 / 31 / 2011 \\ \text { Valid } & 01 / 30 / 2012 \\ \text { Through: } & \\ \text { Last } & \\ \text { Amended: } & \text { N/A }\end{array}$

Page $\begin{array}{cc}1 & 5 \\ \text { of } & \end{array}$

Initials Date 
Al Hassan in the area of neck shoulder musculoskeletal disorders in the Department of Industrial and Management System Engineering (IMSE)at West Virginia University, under the supervision of Dr. Nimbarte

\section{Purposes of the Study}

The purpose of this study is to understand how physically and mentally demanding exertions and your personality affect the loading of the neck-shoulder musculature. Surface Electromyography (EMG) and NASA-TLX scores will be used to quantify the loading of the neck-shoulder musculature. Surface electromyography is a technique, in which sensors are placed on the muscles of interest and electrical activity is recorded using a computer. There is no pain. NASA-TLX scores are obtained based on your subjective responses of physical and mental stress caused by the physically and mentally demanding exertions. Individual personality type will be determined using Myers-Briggs Type Indicator (MBIT) personality test. The total duration of experiment is approximately 1 hour. We expect to enroll approximately 40 participants.

\section{Description of Procedures}

At the beginning of the experiment, to identify your personality we will use Myers-Briggs Type Indicator (MBTI) questionnaire. You will have the opportunity to see the questionnaire before signing this consent form. This study involves two experimental sessions. During first session you will perform ten pulling exertions. You will perform these exertions using your maximum strength. Duration of each exertion will be 3 seconds followed by a rest period of 45 seconds. During the exertions, activities of neck muscles will be recorded using surface electromyography. Surface electromyography is a technique, in which sensors are placed on the muscles of interest and electrical activity is recorded using a computer. There is no pain. After each exertion you will be asked to report your perceived workload using NASAsk Load Index (TLX). During second session, in addition to ten pulling exertions you will perform mental tasks during the rest period of 45 seconds. Mental tasks consist of reading and recalling lists of medication and patient symptoms, and perform math calculation. Same type of data, electromyography and perceived workload using NASALX, will be collected during second session. Duration of each session will be 10 minutes. The entire experiment will take approximatelyone hour to complete.

$\begin{array}{lllll}\text { Tracking \#: } & \mathrm{H}-22894 & \text { Page } \begin{array}{c}2 \\ \text { of }\end{array} & 5 & \\ \text { Approved On: } & 01 / 31 / 2011 & & \text { Initials } & \text { Date } \\ \text { Valid } & 01 / 30 / 2012 & & & \\ \text { Through: } & & & \\ \text { Last } & \text { N/A } & & \end{array}$




\section{Risks and Discomforts}

There is a minimum risk of muscle or ligament strain associated with this experiment. To further minimize these risks, during the force exertion apply forces that you can safety and dependably exert. Apply forces slowly and steadily without jerking motion, until maximum exertion is reached. You will be maintaining the maximum exertion for a minimal duration of 3 seconds. You will be given sufficient rest period between the exertions to prevent fatigue and overexertion. Furthermore, at any time during the study, if you feel uncomfortable with any method or performing the requirements, you will be allowed to withdraw from the study without any penalty. In case of muscle or ligament strain or a musculoskeletal injury (chances of which are very slim) the local emergency service (911) will be contacted. In case of any physical injury to participants during this research project, treatment is not available at West Virginia University, nor is there any insurance carried by the University or its personnel applicable to cover any such injury. Treatment and financial compensation for such injury must be provided through the participant's own insurance program..

\section{Alternatives}

You do not have to participate in this study.

\section{Benefits}

You may not receive any direct benefit from this study, but the knowledge gained from the successful completion of this study will allow us to more precisely identify, the physical and psychosocial risk factors associated with work-related neck-shoulder musculoskeletal disorders.

\section{Financial Considerations}

No monetary compensation will be given for participating in this study and participants do not incur any costs as a result of participation in the study. It is very important for you to understand that neither the investigator nor WVU or it associated affiliates has the funds set aside to pay for the cost of lost work wages or any care or treatment that might be necessary because you get hurt or sick taking part in this study. Any injuries that may result from this study would not be eligible for Workers 'Compensation as this is not joblated injury. Understand that any treatments necessary will be billed to the participant or to your personal health insurance, and you may wish to consult your insurance provider before participating in this study

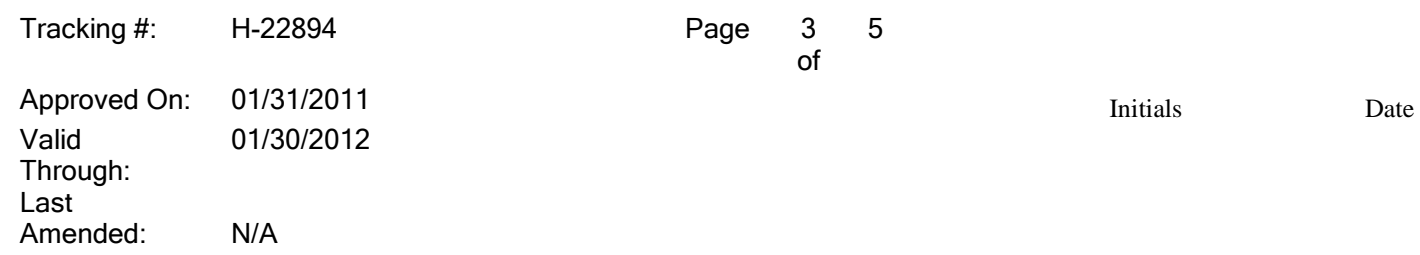




\section{Confidentiality}

Any information about you that is obtained as a result of your participation in this research will be kept as confidential as legally possible. Your research records and test results, just like hospital records, may be subpoenaed by court order or may be inspected by federal regulatory authorities without your additional consent. In any publications that result from this research, neither your name nor any information from which you might be identified will be published without your consent

\section{Voluntary Participation}

Participation in this study is voluntary. You are free to withdraw your consent to participate in this study at any time. Refusal to participate or withdrawal will not affect your employee status at West Virginia University or your class standing or grades and will involve no penalty to you. In the event new information becomes available that may affect your willingness to participate in this study, this information will be given to you so that you can make an informed decision about whether or not to continue your participation. You have been given the opportunity to ask questions about the research, and you have received answers concerning areas you did not understand.

$\begin{array}{llllll}\text { Tracking \#: } & \mathrm{H}-22894 & \text { Page } \begin{array}{c}4 \\ \text { of }\end{array} & 5 & \text { Initials } & \text { Date } \\ \text { Approved On: } & 01 / 31 / 2011 & & & \\ \text { Valid } & 01 / 30 / 2012 & & & \\ \text { Through: } & & & & \\ \text { Last } & \text { N/A } & & \end{array}$


Upon signing this form, you will receive a copy.

I willingly consent to participate in this research.

Signature of Subject or

Printed Name

Date

Time

Subjects Legal Representative

The participant has had the opportunity to have questions addressed. The participant willingly agrees to be in the study.

$\begin{array}{ll}\text { Tracking \#: } & \mathrm{H}-22894 \\ \text { Approved On: } & 01 / 31 / 2011 \\ \text { Valid } & 01 / 30 / 2012 \\ \text { Through: } & \end{array}$

Tracking \#: $\quad \mathrm{H}-22894$

Through:

\section{Page $\begin{array}{cc}5 & 5 \\ \text { of }\end{array}$}

Initials Date 


\section{Appendix E}

\section{The raw N-MAV data}

\begin{tabular}{|c|c|c|c|c|c|c|c|c|}
\hline Sub & Session & Personality & $\begin{array}{l}\text { Right } \\
\text { Upper } \\
\text { Trapezius }\end{array}$ & $\begin{array}{l}\text { Left } \\
\text { Upper } \\
\text { Trapezius }\end{array}$ & $\begin{array}{l}\text { Right } \\
\text { Sternocleidomastoid }\end{array}$ & $\begin{array}{l}\text { Left } \\
\text { Sternocleidomastoid }\end{array}$ & $\begin{array}{l}\text { Right } \\
\text { Cervical } \\
\text { Trapezius }\end{array}$ & $\begin{array}{l}\text { Left } \\
\text { Cervical } \\
\text { Trapezius }\end{array}$ \\
\hline 1 & Physical & Thinking & 79.13353 & 57.48447 & 88.57826 & 68.14388 & 85.46043 & 89.54608 \\
\hline 2 & Physical & Thinking & 67.87346 & 46.81342 & 78.03069 & 82.36311 & 84.31498 & 75.56433 \\
\hline 3 & Physical & Thinking & 82.19565 & 74.30968 & 90.56433 & 75.32042 & 78.82979 & 78.18987 \\
\hline 4 & Physical & Thinking & 77.35714 & 78.223 & 87.72152 & 78.20375 & 79.90132 & 65.84192 \\
\hline 5 & Physical & Thinking & 83.10791 & 85.98394 & 82.97177 & 86.5534 & 89.62963 & 86.25157 \\
\hline 6 & Physical & Thinking & 81.43552 & 73.93204 & 76.63559 & 76.35046 & 86.07477 & 89.81818 \\
\hline 7 & Physical & Thinking & 82.4 & 76.59664 & 67.85577 & 56.79845 & 64.69208 & 71.5016 \\
\hline 8 & Physical & Thinking & 73.56989 & 68.583 & 64.22222 & 58.81201 & 70.63393 & 79.01136 \\
\hline 9 & Physical & Thinking & 71.53552 & 54.77603 & 76.27685 & 71.57542 & 61.08046 & 69.39024 \\
\hline 10 & Physical & Thinking & 82.13992 & 65.86985 & 75.81186 & 80.61033 & 81.12069 & 76.95192 \\
\hline 11 & Physical & Thinking & 75.42857 & 84.09016 & 42.99138 & 35.94268 & 74.3913 & 74.79275 \\
\hline 1 & Physical & Feeling & 72.23127 & 73.552 & 88.06748 & 87.44565 & 72.85068 & 75.11053 \\
\hline 2 & Physical & Feeling & 66.13703 & 58.56557 & 81.13208 & 56.55512 & 68.69792 & 67.19606 \\
\hline 3 & Physical & Feeling & 61.9676 & 47.80159 & 72.98837 & 79.20313 & 72.52222 & 67.63187 \\
\hline 4 & Physical & Feeling & 76.2377 & 88.74074 & 73.60382 & 87.19677 & 85.76471 & 87.26891 \\
\hline 5 & Physical & Feeling & 63.94862 & 71.92793 & 53.73333 & 63.51852 & 87.89516 & 75.65625 \\
\hline 6 & Physical & Feeling & 67.10484 & 66.25413 & 49.728 & 60.9434 & 72.32075 & 74.34463 \\
\hline 7 & Physical & Feeling & 68.84154 & 74.68317 & 78.42342 & 85.54987 & 85.25 & 84.69565 \\
\hline 8 & Physical & Feeling & 54.52096 & 77.75106 & 61.99786 & 83.90196 & 82.53205 & 82.53205 \\
\hline 9 & Physical & Feeling & 42.45601 & 45.81571 & 45.47759 & 47.01198 & 46.49682 & 45.78422 \\
\hline 1 & Physical and cognitive & Thinking & 103.7764 & 70.67115 & 101.8961 & 74.12487 & 91.47051 & 92.43746 \\
\hline 2 & Physical and cognitive & Thinking & 148.9455 & 101.2579 & 109.3606 & 149.5965 & 117.0935 & 106.7494 \\
\hline 3 & Physical and cognitive & Thinking & 103.9855 & 89.87097 & 100.7675 & 87.34724 & 87.11348 & 74.17089 \\
\hline 4 & Physical and cognitive & Thinking & 151.1071 & 149.4774 & 139.2827 & 94.9866 & 114.989 & 115.4983 \\
\hline 5 & Physical and cognitive & Thinking & 112.3597 & 101.9277 & 118.5736 & 147.945 & 89.51282 & 113.0314 \\
\hline 6 & Physical and cognitive & Thinking & 172.9197 & 123.8511 & 97.42373 & 94.50593 & 116.5421 & 154.5909 \\
\hline 7 & Physical and cognitive & Thinking & 72.56 & 64.90756 & 72.86538 & 55.06977 & 51.43695 & 59.42492 \\
\hline 8 & Physical and cognitive & Thinking & 123.1398 & 100.7287 & 73.53086 & 63.61619 & 100.8304 & 130.0682 \\
\hline 9 & Physical and cognitive & Thinking & 74.7541 & 66.87697 & 104.1289 & 73.34078 & 67.05747 & 70.06098 \\
\hline 10 & Physical and cognitive & Thinking & 178.2922 & 171.0359 & 176.4948 & 208.482 & 192.1724 & 180.5288 \\
\hline 11 & Physical and cognitive & Thinking & 128.3571 & 140.9836 & 71.18103 & 37.61783 & 118.7391 & 98.75648 \\
\hline 1 & Physical and cognitive & Feeling & 125.9387 & 142.6602 & 148.1744 & 124.4444 & 156.6725 & 146.7892 \\
\hline
\end{tabular}




\begin{tabular}{|c|c|c|c|c|c|c|c|c|}
\hline 2 & Physical and cognitive & Feeling & 115.0977 & 134.624 & 164.7239 & 158.4239 & 114.819 & 121.7035 \\
\hline 3 & Physical and cognitive & Feeling & 116.4286 & 139.7268 & 253.9937 & 170.6496 & 130.5208 & 134.3045 \\
\hline 4 & Physical and cognitive & Feeling & 122.9602 & 68.26984 & 95.10465 & 111.9844 & 99.96667 & 116.2857 \\
\hline 5 & Physical and cognitive & Feeling & 116.1639 & 147.037 & 163.9141 & 216.8194 & 156.5546 & 155.1261 \\
\hline 6 & Physical and cognitive & Feeling & 142.9249 & 139.9459 & 90.32381 & 95.49383 & 124.2742 & 124.6094 \\
\hline 7 & Physical and cognitive & Feeling & 96.55645 & 90.26403 & 70.336 & 93.33962 & 114.6541 & 123.3898 \\
\hline 8 & Physical and cognitive & Feeling & 81.73103 & 90.27723 & 86.17117 & 128.5678 & 106.0089 & 105.0435 \\
\hline 9 & Physical and cognitive & Feeling & 102.7844 & 108.7977 & 173.141 & 213.8039 & 107.6282 & 107.6282 \\
\hline
\end{tabular}




\section{Appendix F}

Participants with thinking personality during session1

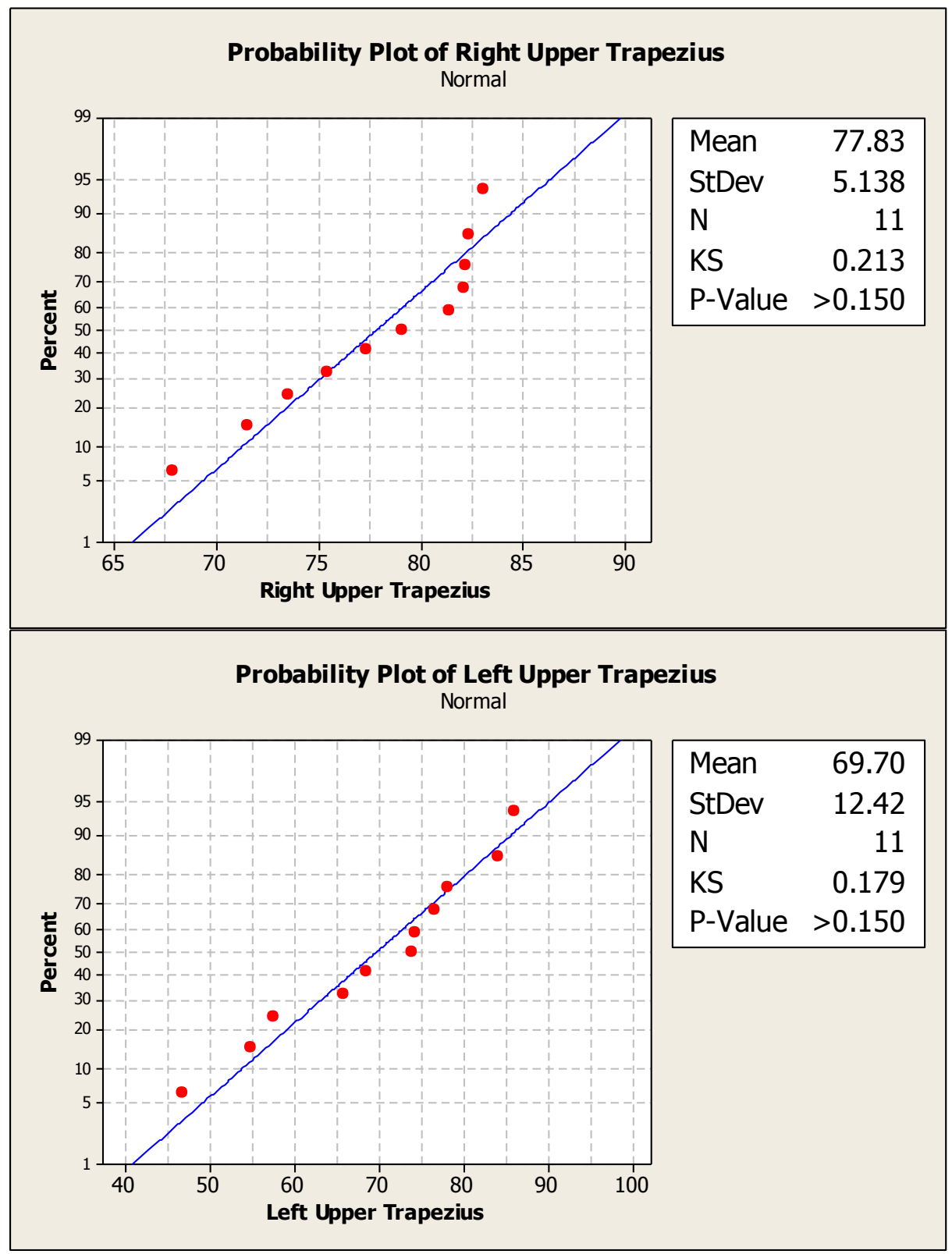




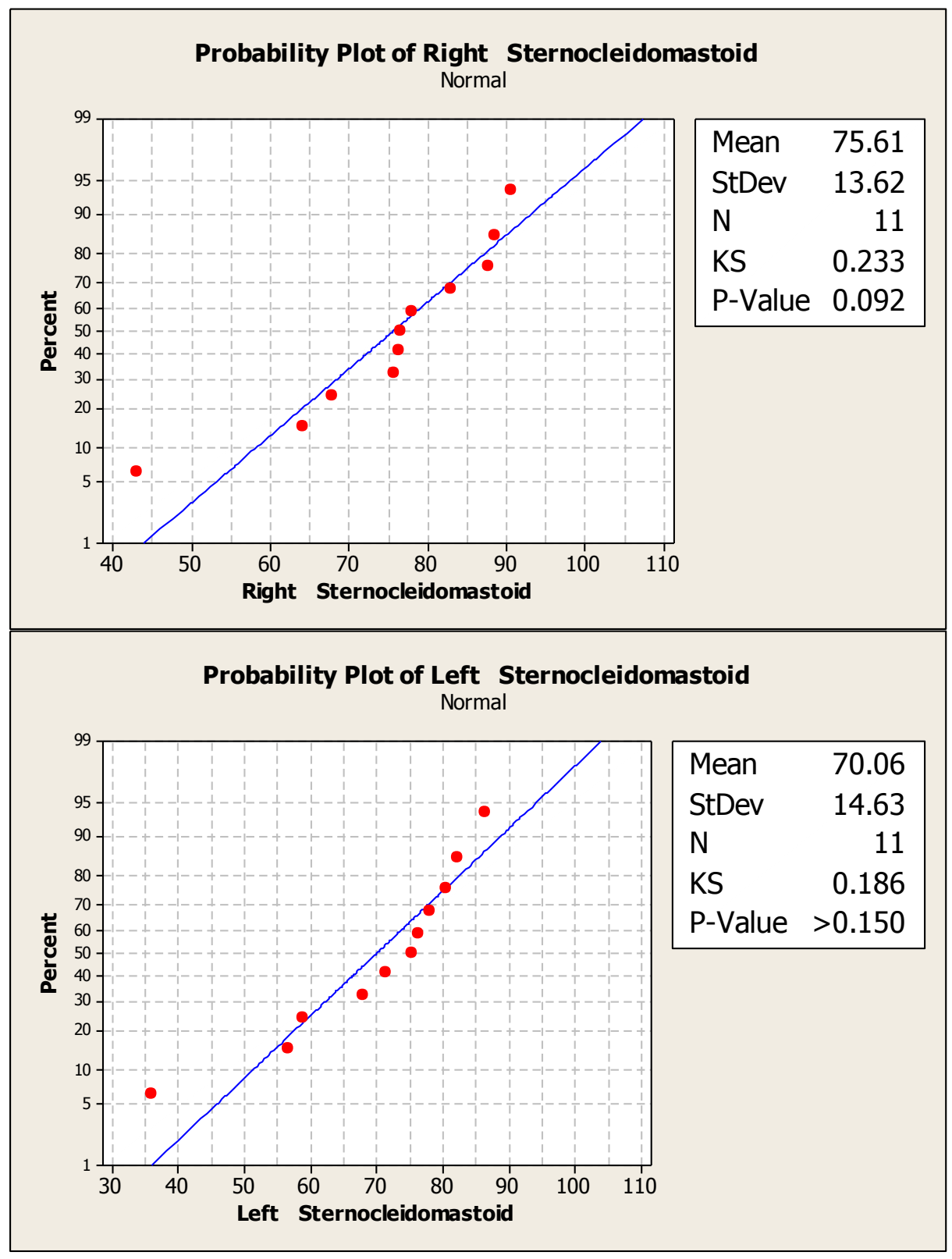




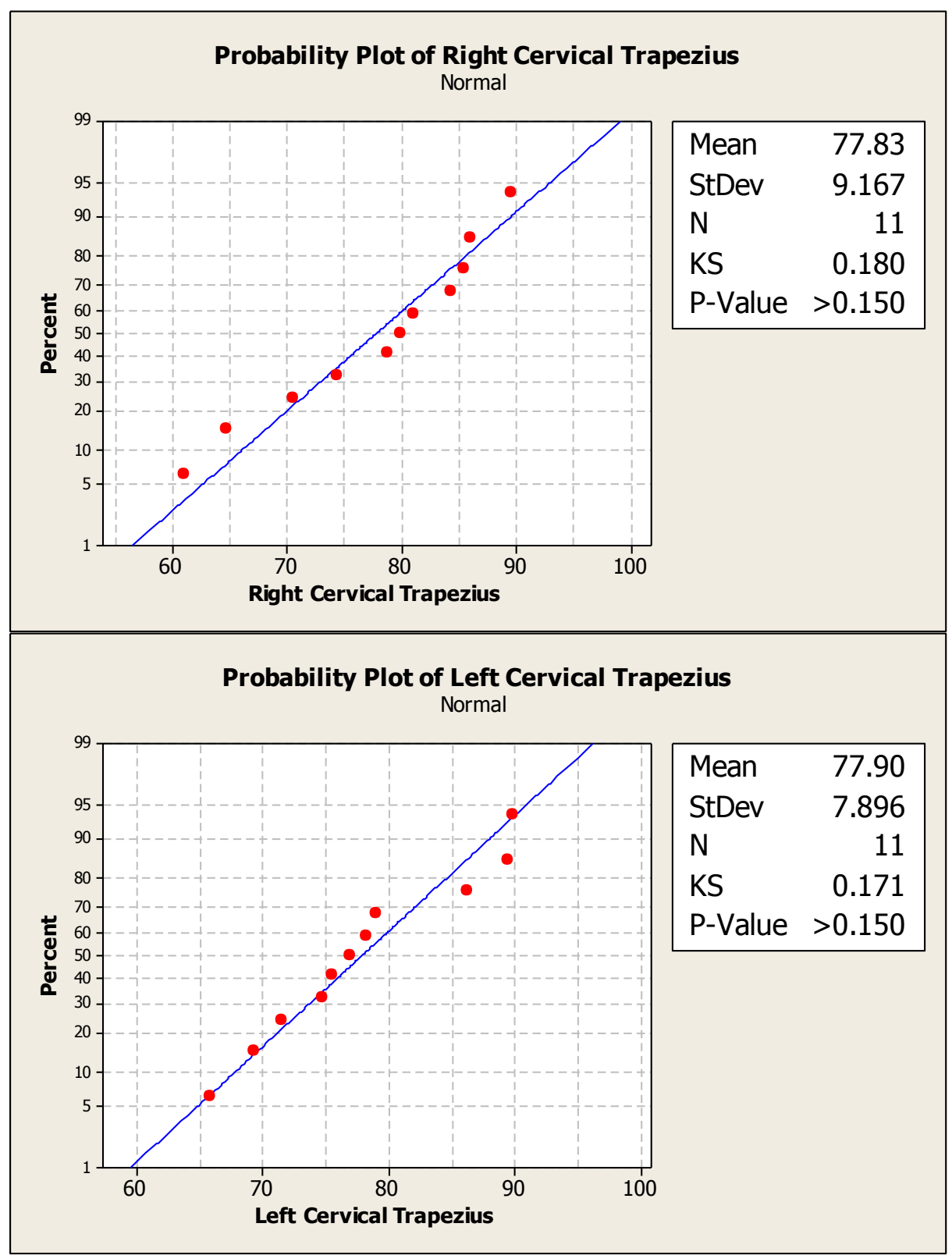


Participants with thinking personality during session2

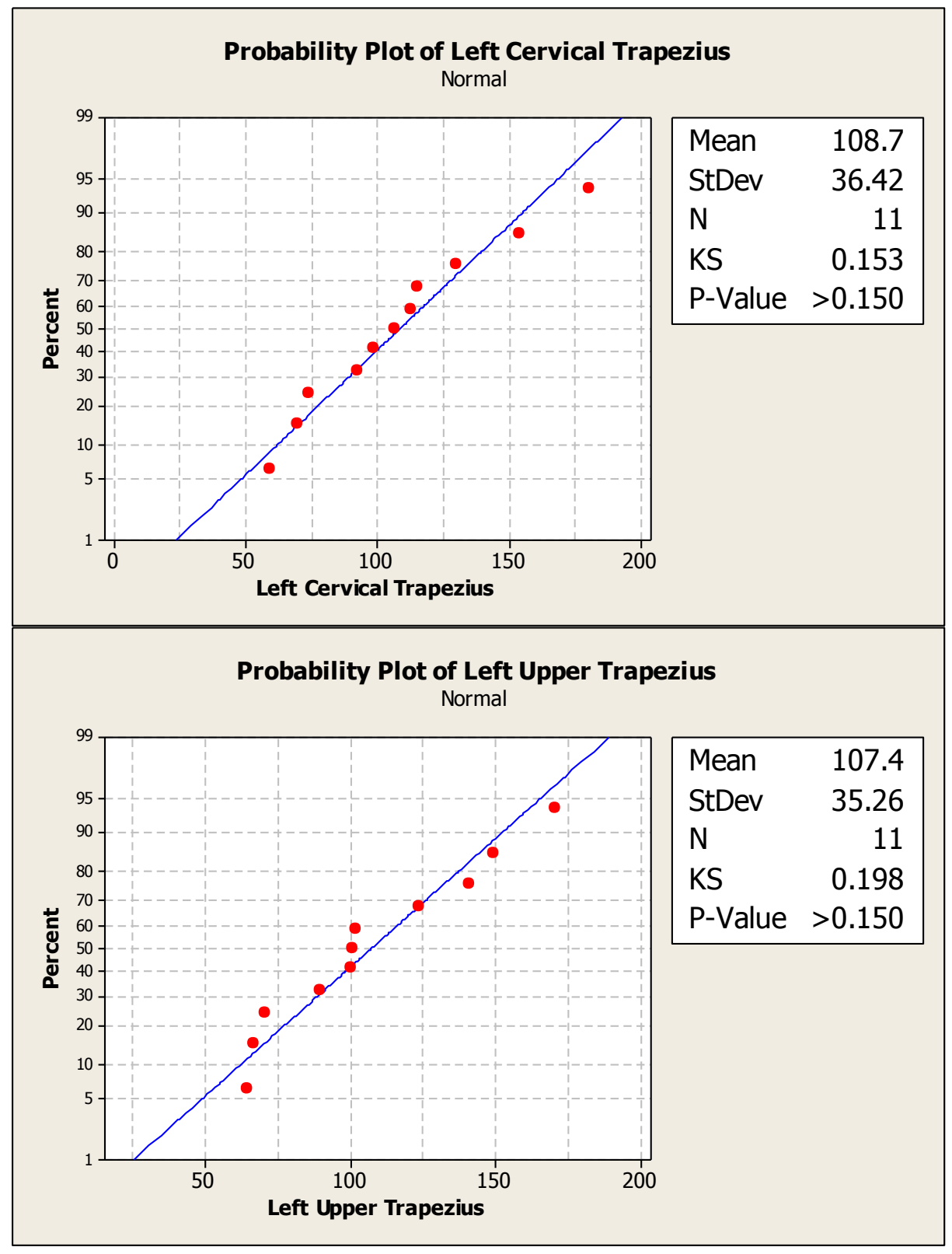




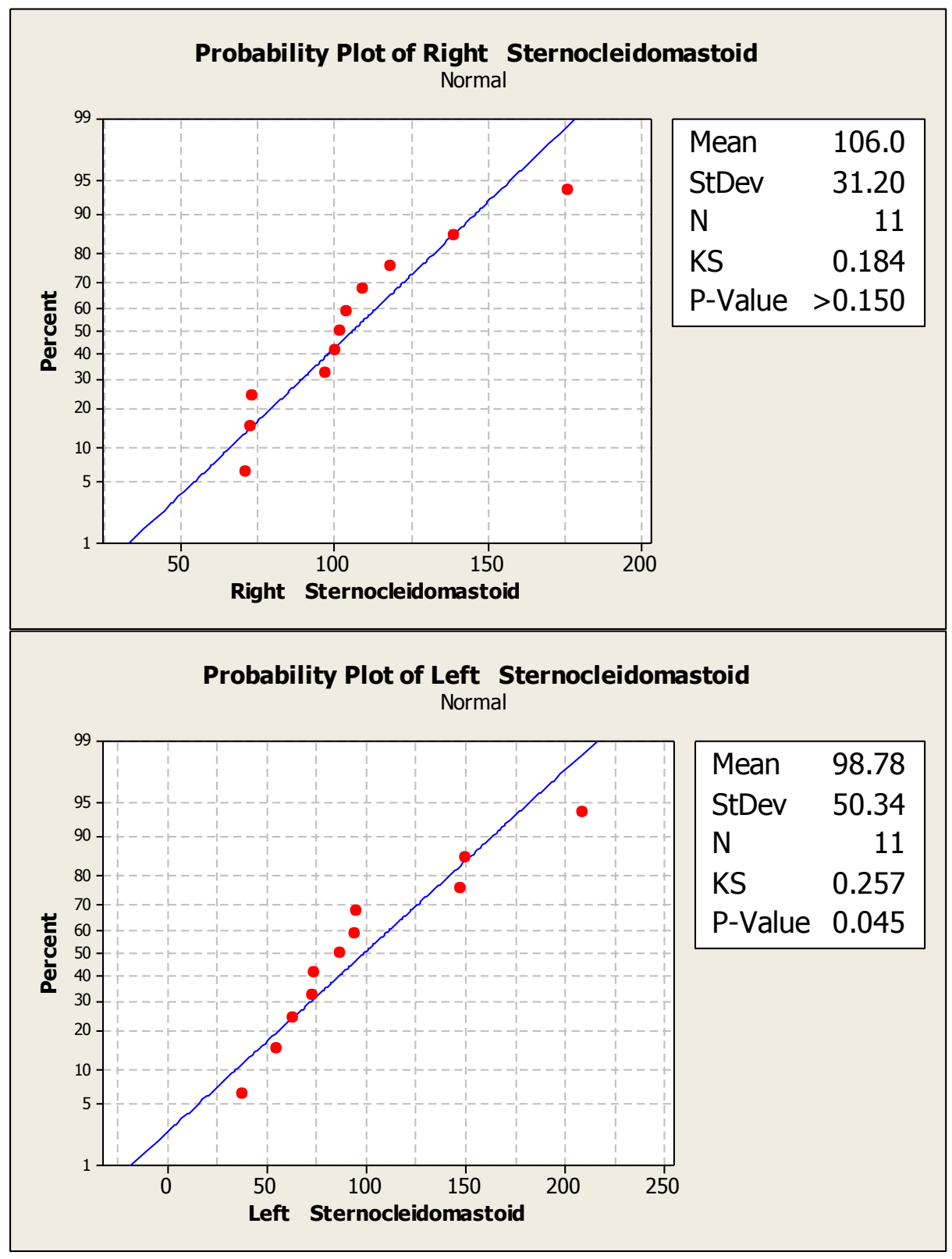




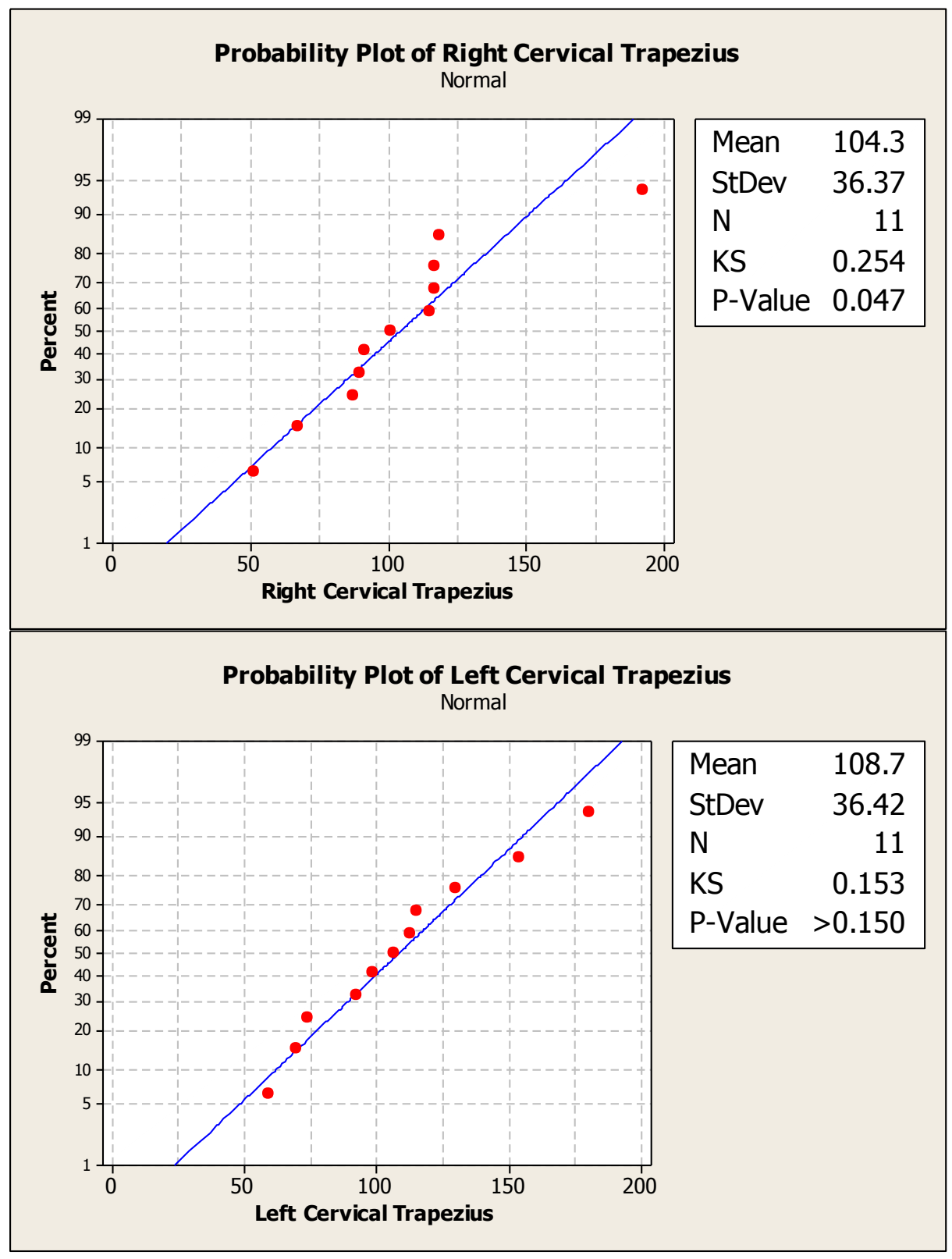


Participants with feeling personality during session1

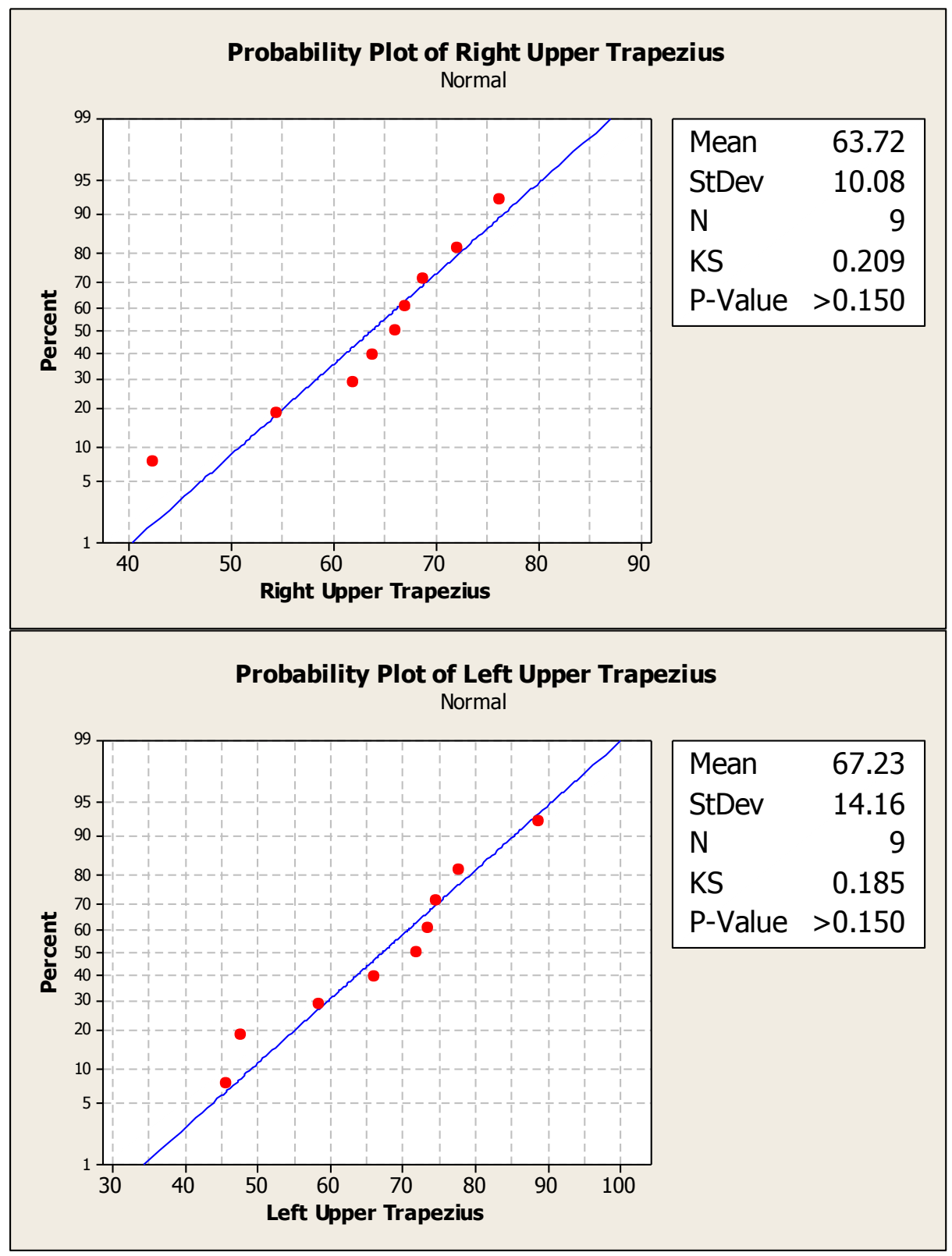




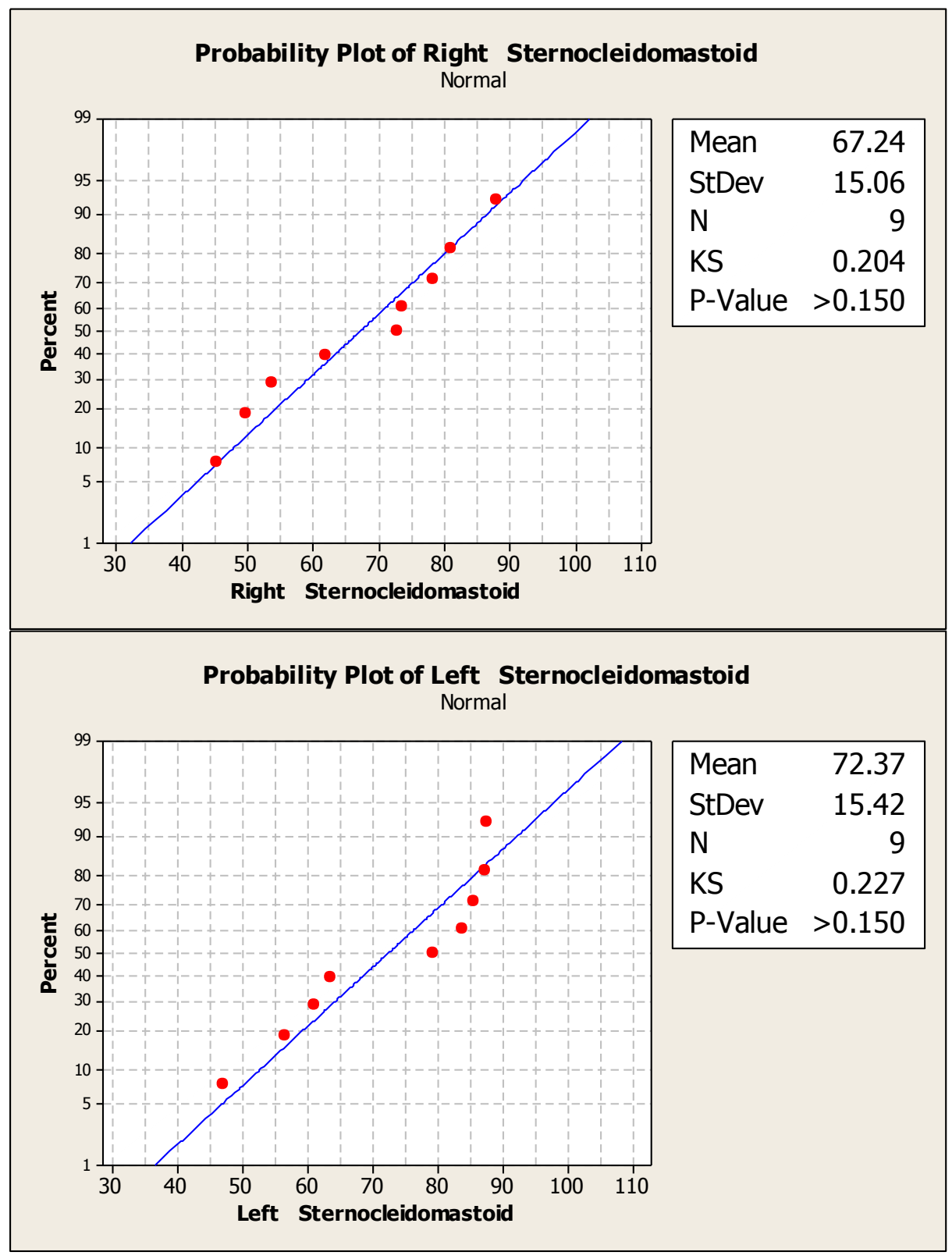




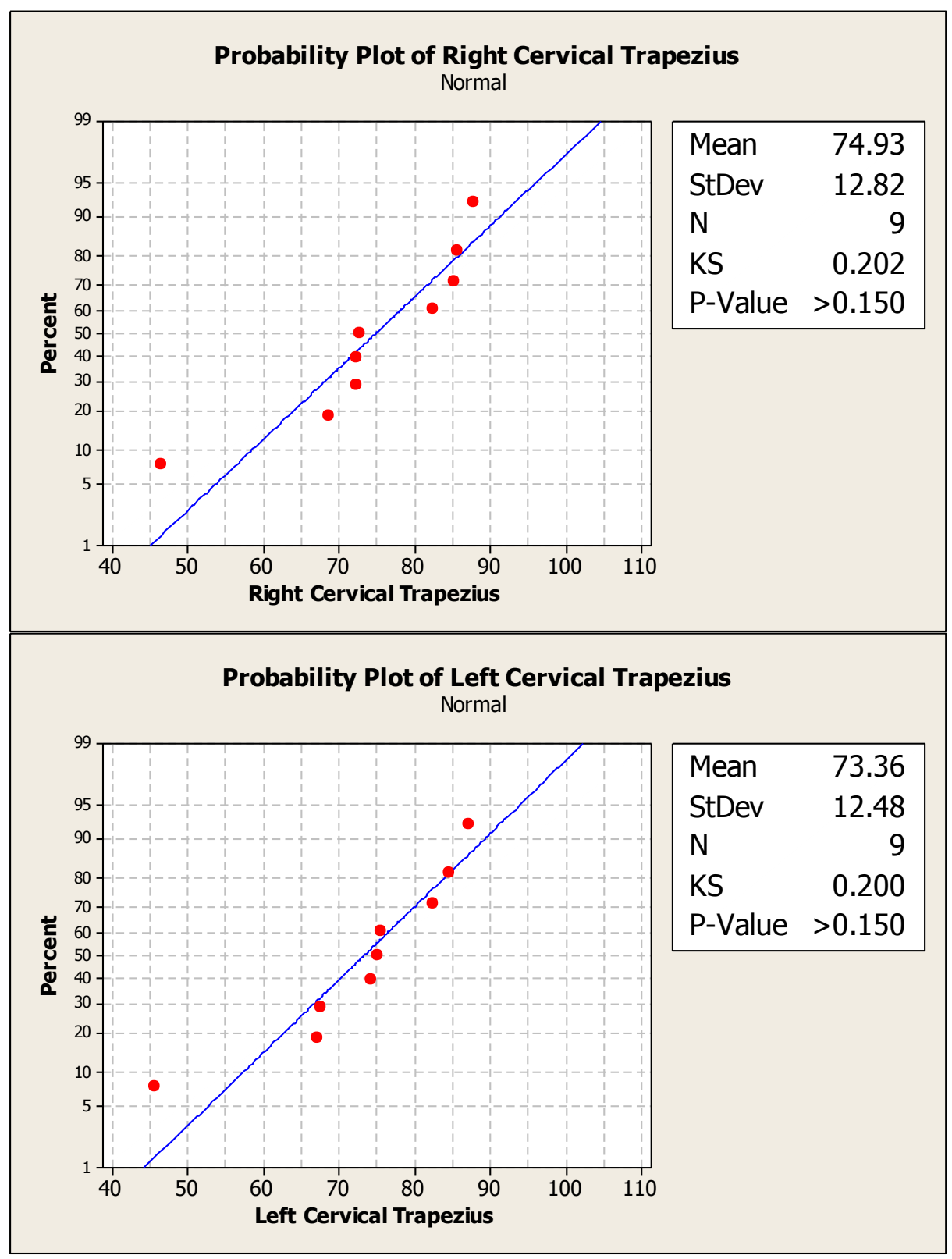


Participants with feeling personality during session2

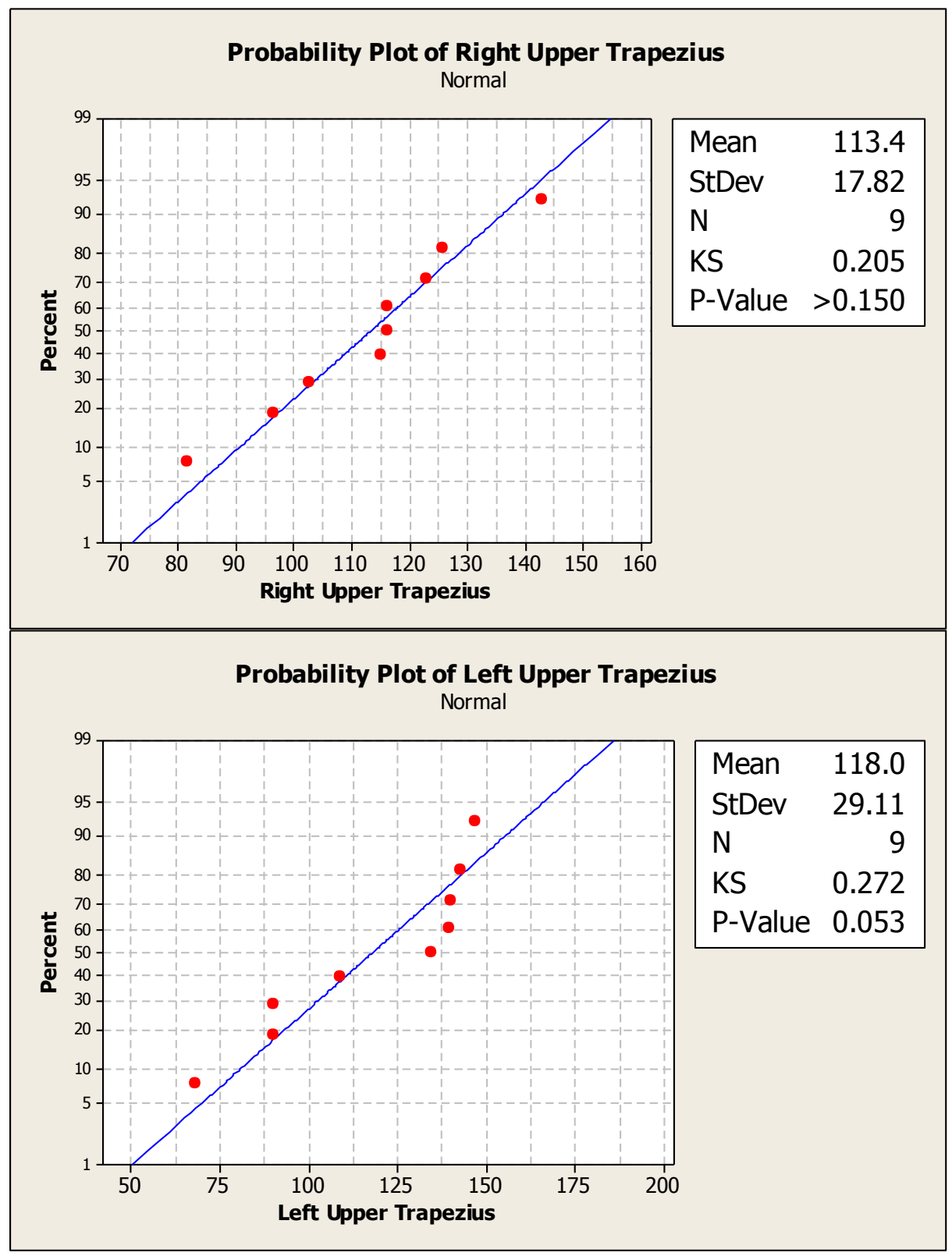




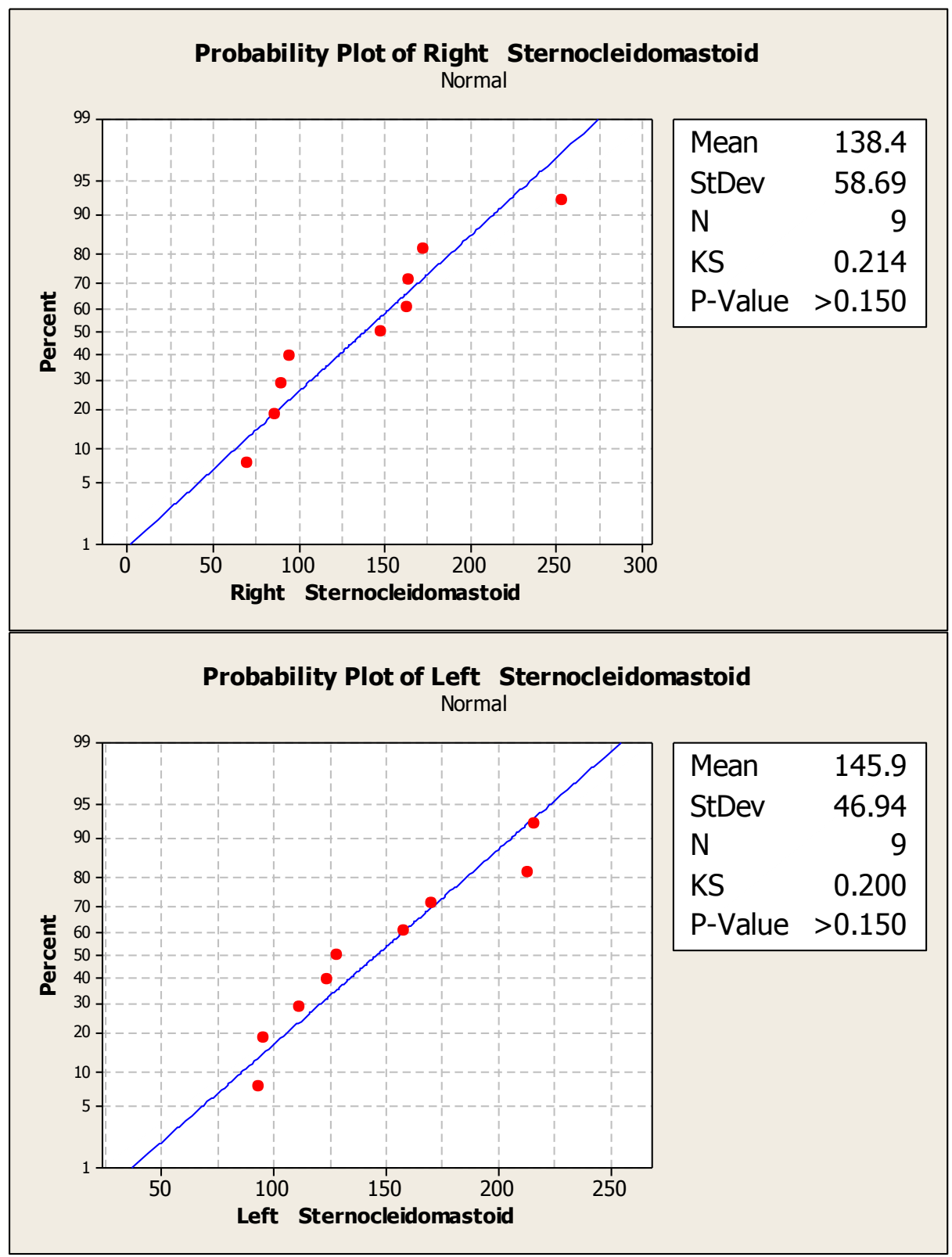




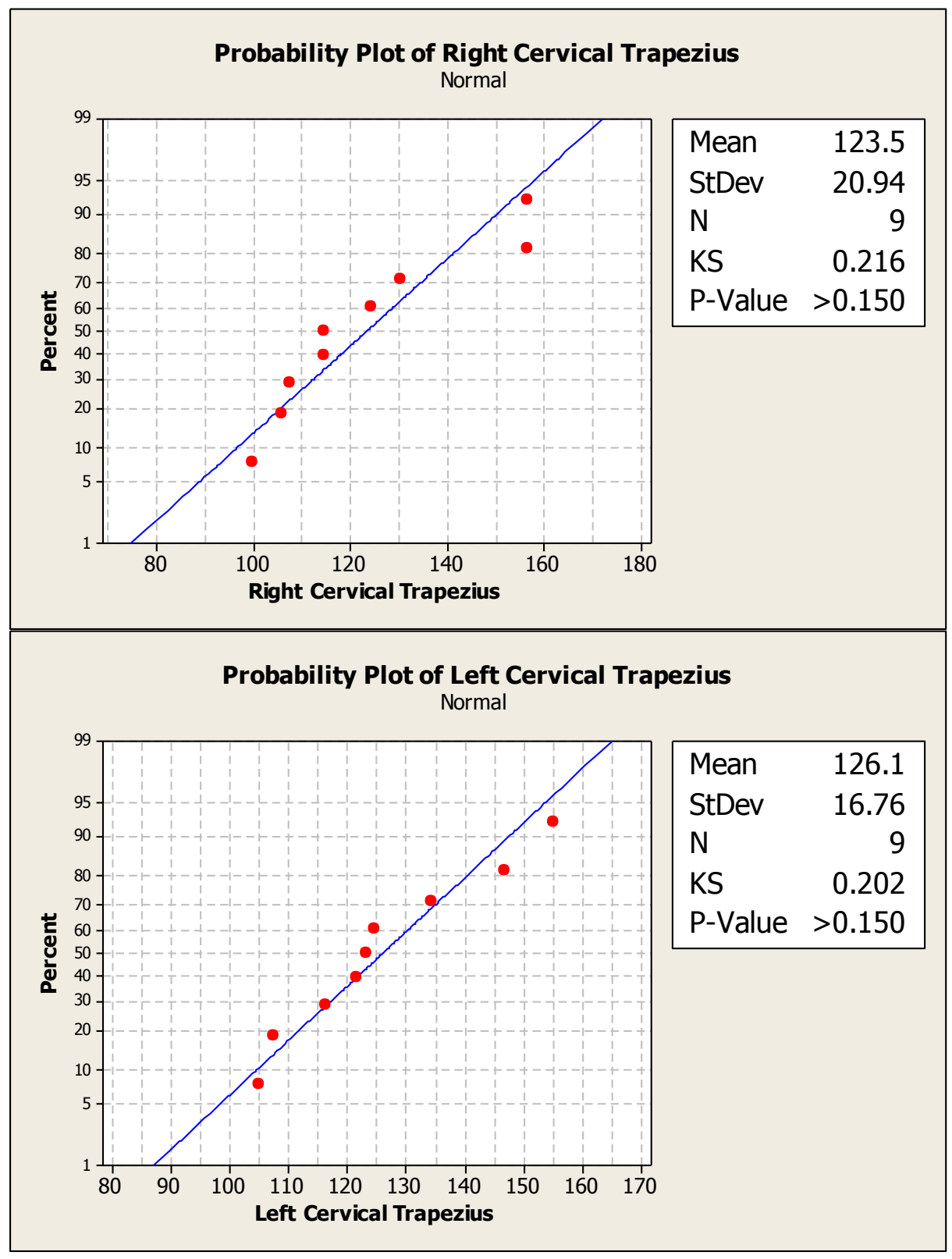




\section{General Linear Model: Right Upper Trap versus Session, Personality, Sub}

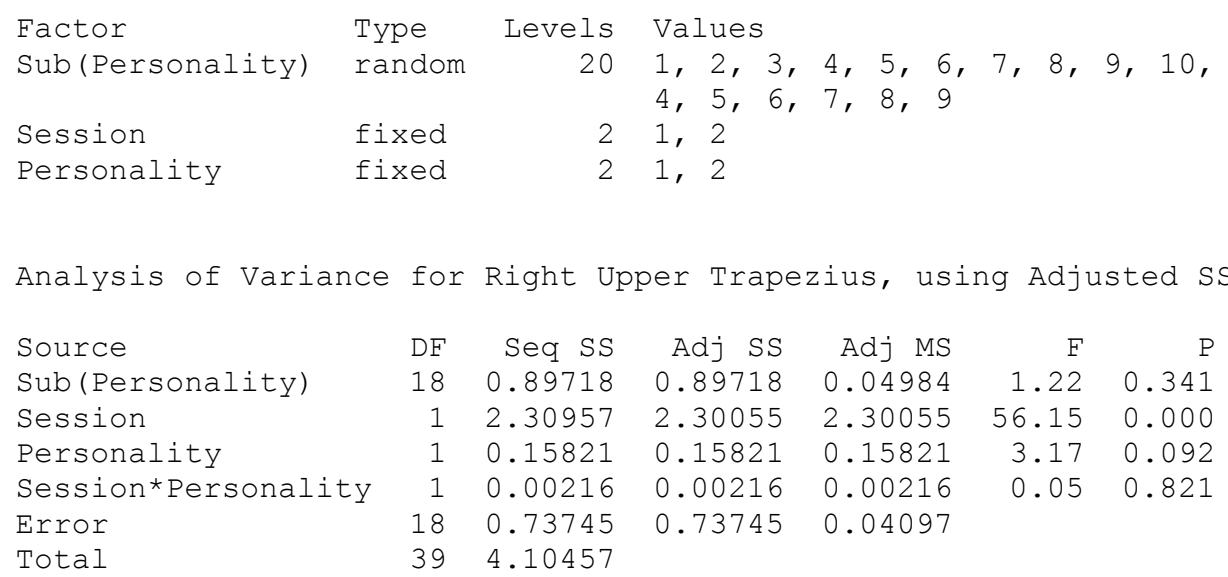

\section{General Linear Model: Left Upper Trape versus Session, Personality, Sub}

$\begin{array}{llrl}\text { Factor } & \text { Type } & \text { Levels } & \text { Values } \\ \text { Sub(Personality) } & \text { random } & 20 & 1,2,3,4,5,6,7,8,9,10,11,1,2,3, \\ & & 4,5,6,7,8,9 \\ \text { Session } & \text { fixed } & 2 & 1,2 \\ \text { Personality } & \text { fixed } & 2 & 1,2\end{array}$

Analysis of Variance for Left Upper Trapezius, using Adjusted SS for Tests

$\begin{array}{lrrrrrr}\text { Source } & \text { DF } & \text { Seq SS } & \text { Adj SS } & \text { Adj MS } & \text { F } & \text { P } \\ \text { Sub(Personality) } & 18 & 1.09189 & 1.09189 & 0.06066 & 0.95 & 0.539 \\ \text { Session } & 1 & 1.89851 & 1.93603 & 1.93603 & 30.46 & 0.000 \\ \text { Personality } & 1 & 0.01614 & 0.01614 & 0.01614 & 0.27 & 0.612 \\ \text { Session*Personality } & 1 & 0.04185 & 0.04185 & 0.04185 & 0.66 & 0.428 \\ \text { Error } & 18 & 1.14390 & 1.14390 & 0.06355 & & \\ \text { Total } & 39 & 4.19228 & & & & \end{array}$

\section{General Linear Model: Right Sternocl versus Session, Personality, Sub}

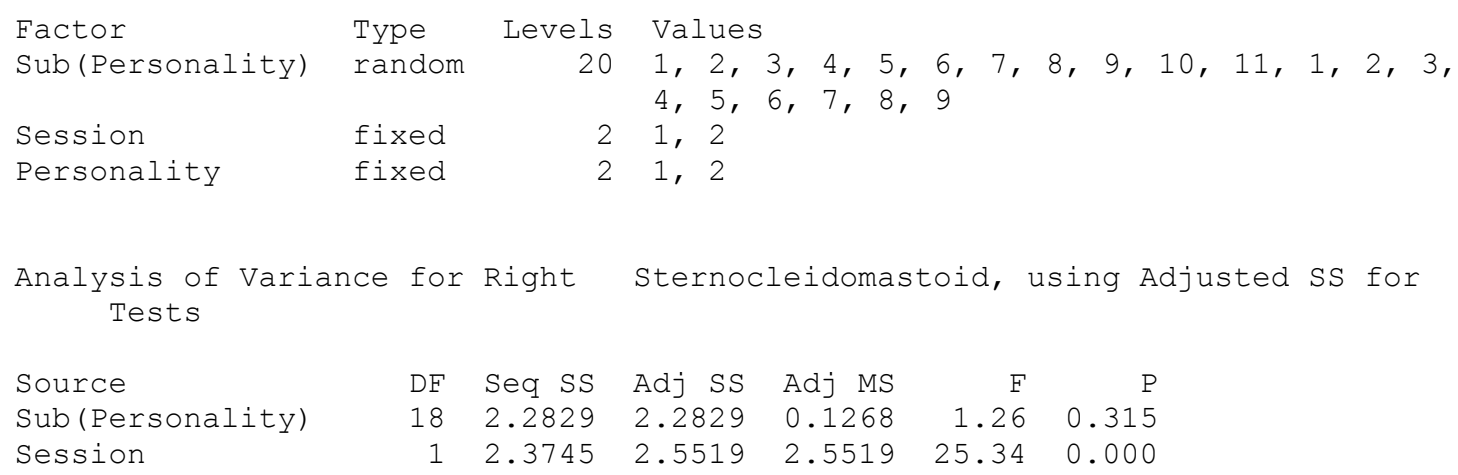




$\begin{array}{lrrrrrr}\text { Personality } & 1 & 0.1439 & 0.1439 & 0.1439 & 1.13 & 0.301 \\ \text { Session*Personality } & 1 & 0.4129 & 0.4129 & 0.4129 & 4.10 & 0.058 \\ \text { Error } & 18 & 1.8127 & 1.8127 & 0.1007 & & \\ \text { Total } & 39 & 7.0269 & & & & \end{array}$

\section{General Linear Model: Left Sternocle versus Session, Personality, Sub}

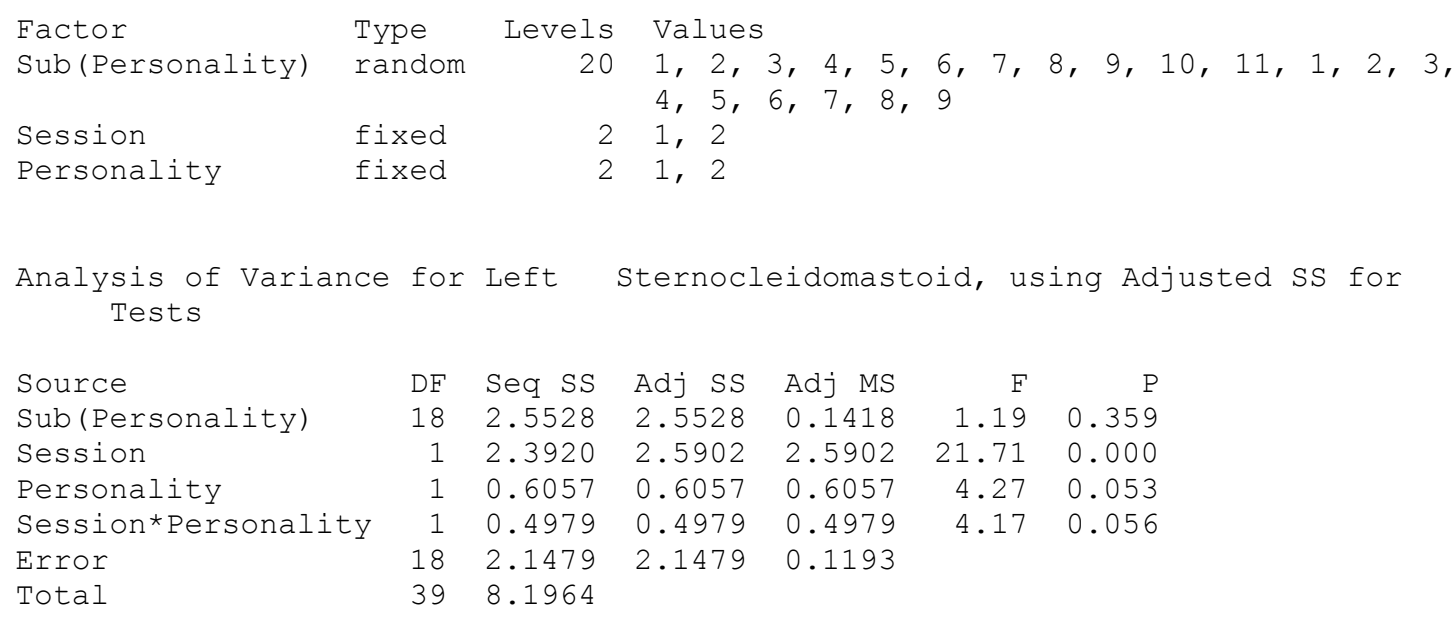

\section{General Linear Model: Right Cervical T versus Session, Personality, Sub}

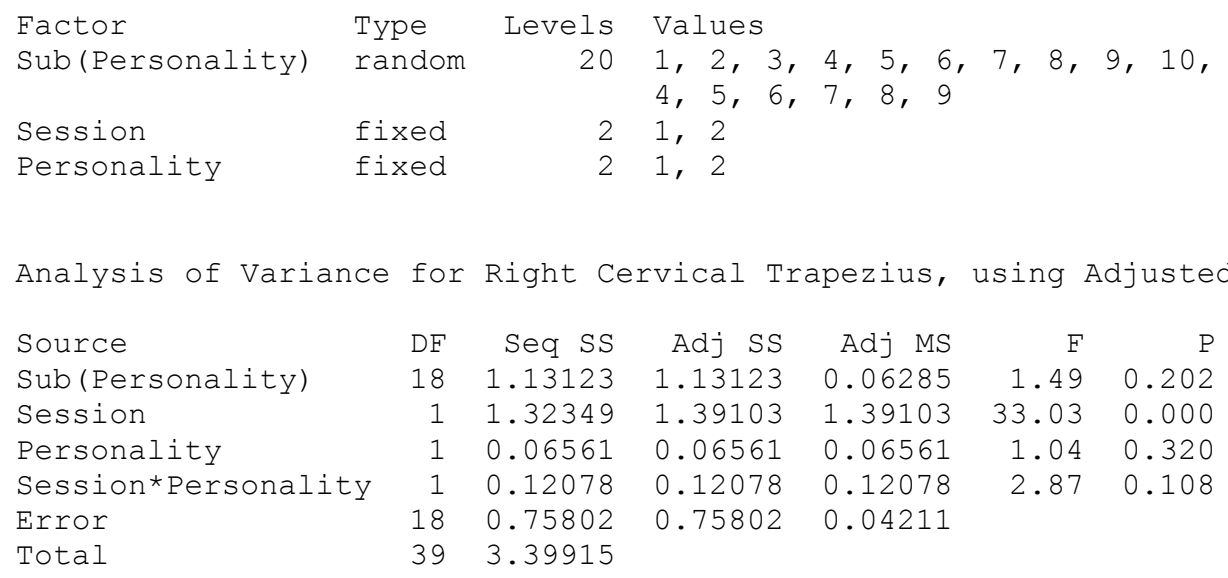

\section{General Linear Model: Left Cervical Tr versus Session, Personality, Sub}

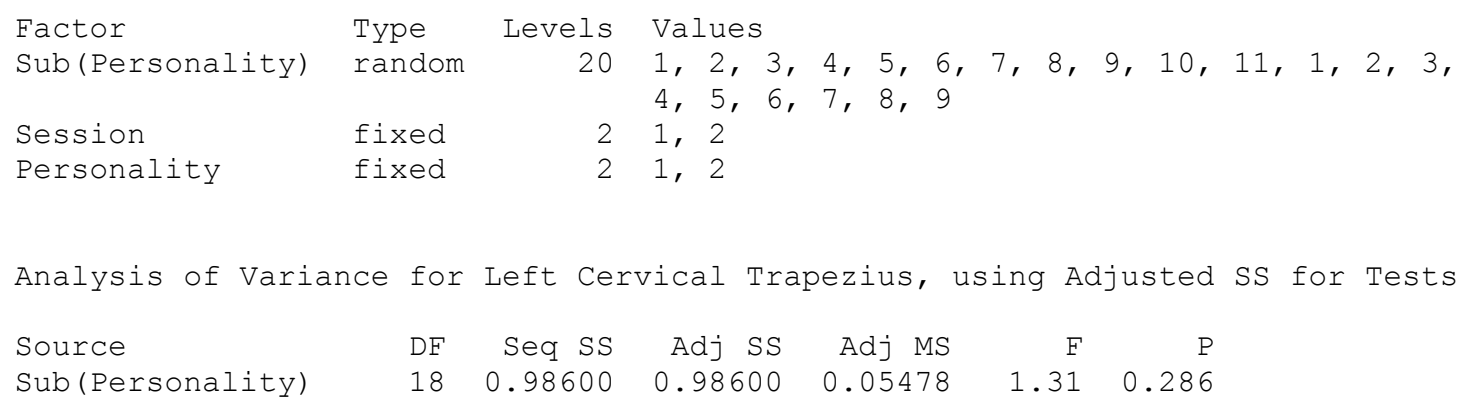




$\begin{array}{lrrrrrr}\text { Session } & 1 & 1.65290 & 1.72600 & 1.72600 & 41.29 & 0.000 \\ \text { Personality } & 1 & 0.04115 & 0.04115 & 0.04115 & 0.75 & 0.398 \\ \text { Session*Personality } & 1 & 0.11947 & 0.11947 & 0.11947 & 2.86 & 0.108 \\ \text { Error } & 18 & 0.75251 & 0.75251 & 0.04181 & & \\ \text { Total } & 39 & 3.55204 & & & & \end{array}$




\section{$\underline{\text { Appendix G }}$}

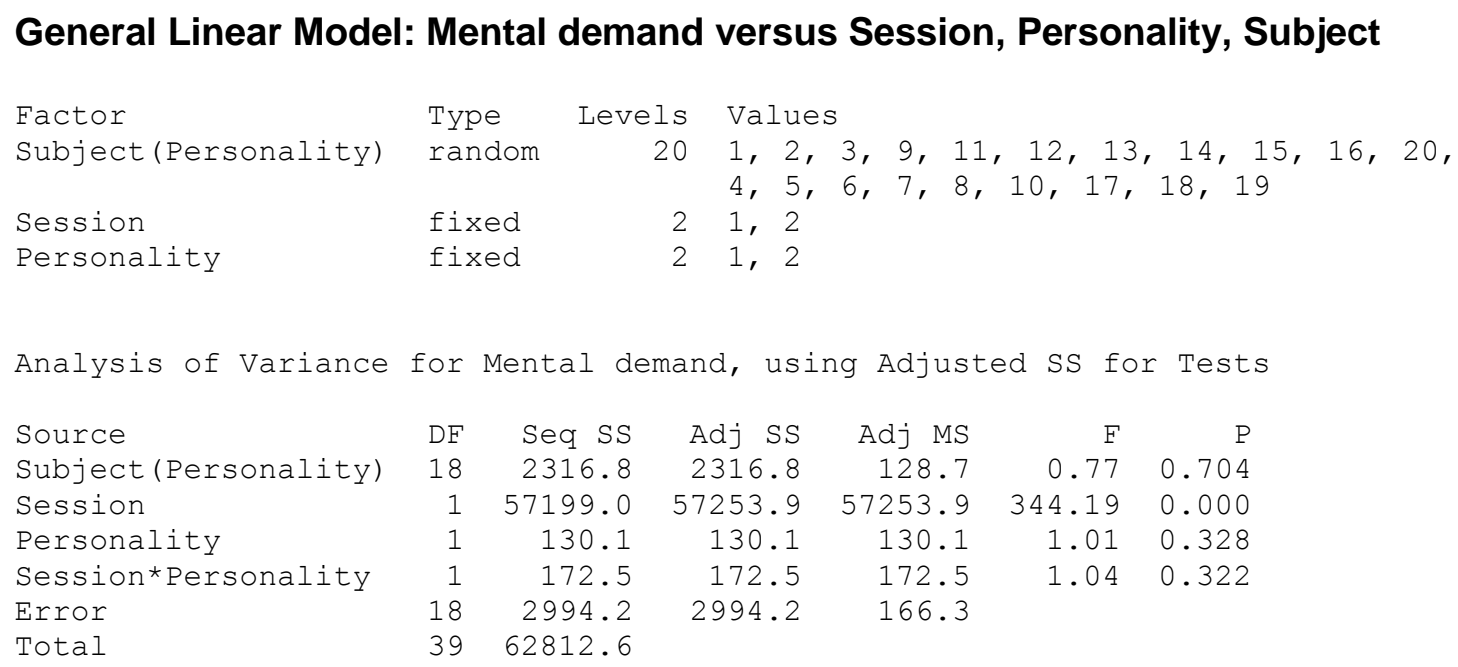

\section{General Linear Model: Physical demand versus Session, Personality, Subject}

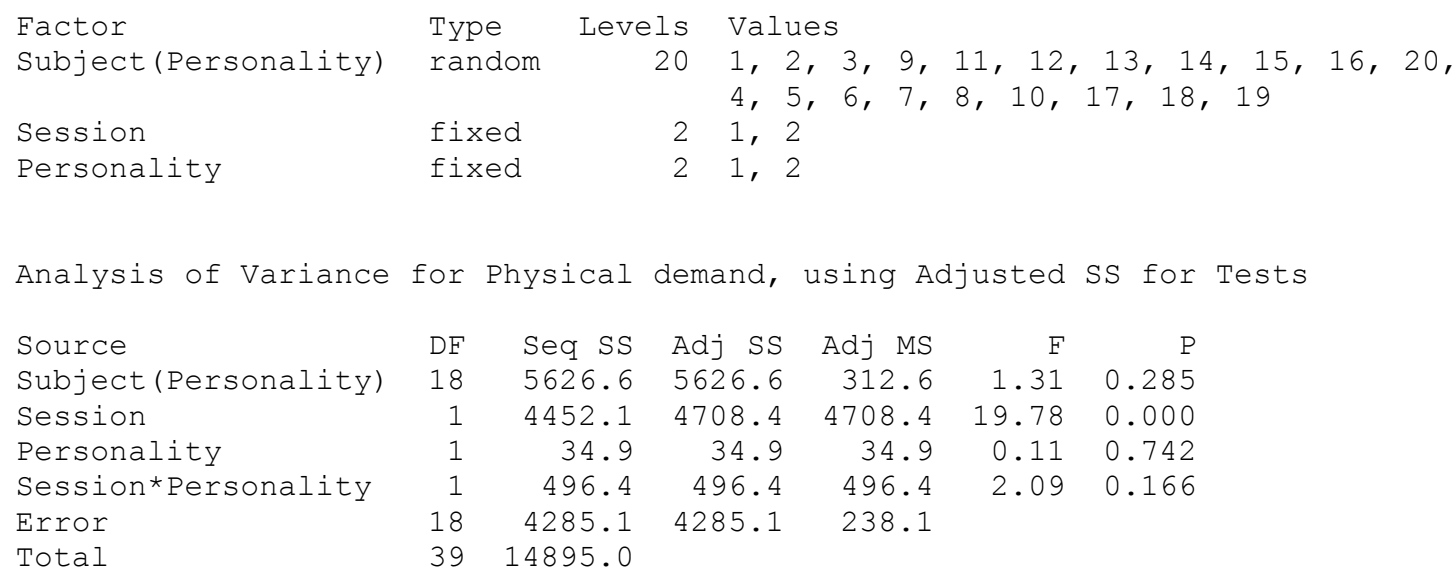

\section{General Linear Model: Temporal dem versus Session, Personality, Subject}

\begin{tabular}{|c|c|c|c|c|c|c|c|}
\hline Factor & \multicolumn{2}{|c|}{ Type $\quad$ Levels } & $\mathrm{Val}$ & ues & & & \\
\hline Subject (Personality) & rar & dom & $\begin{array}{l}1 \\
4\end{array}$ & $\begin{array}{l}2,3,9, \\
5,6,7,\end{array}$ & $\begin{array}{l}11,12, \\
8,10,\end{array}$ & $\begin{array}{l}13,14,15, \\
17,18,19\end{array}$ & 16,20 \\
\hline Session & fix & ed & 1, & 2 & & & \\
\hline Personality & fix & ed & 21, & 2 & & & \\
\hline Source & $\mathrm{DF}$ & Seq SS & Adj SS & Adj MS & F & $\mathrm{P}$ & \\
\hline Subject (Personality) & 18 & 5801.9 & $5801 \cdot 9$ & 322.3 & 0.99 & 0.512 & \\
\hline Session & 1 & 1759.6 & 1672.7 & 1672.7 & 5.12 & 0.036 & \\
\hline Personality & 1 & 930.8 & 930.8 & 930.8 & 2.89 & 0.106 & \\
\hline
\end{tabular}


General Linear Model: Performance versus Session, Personality, Subject

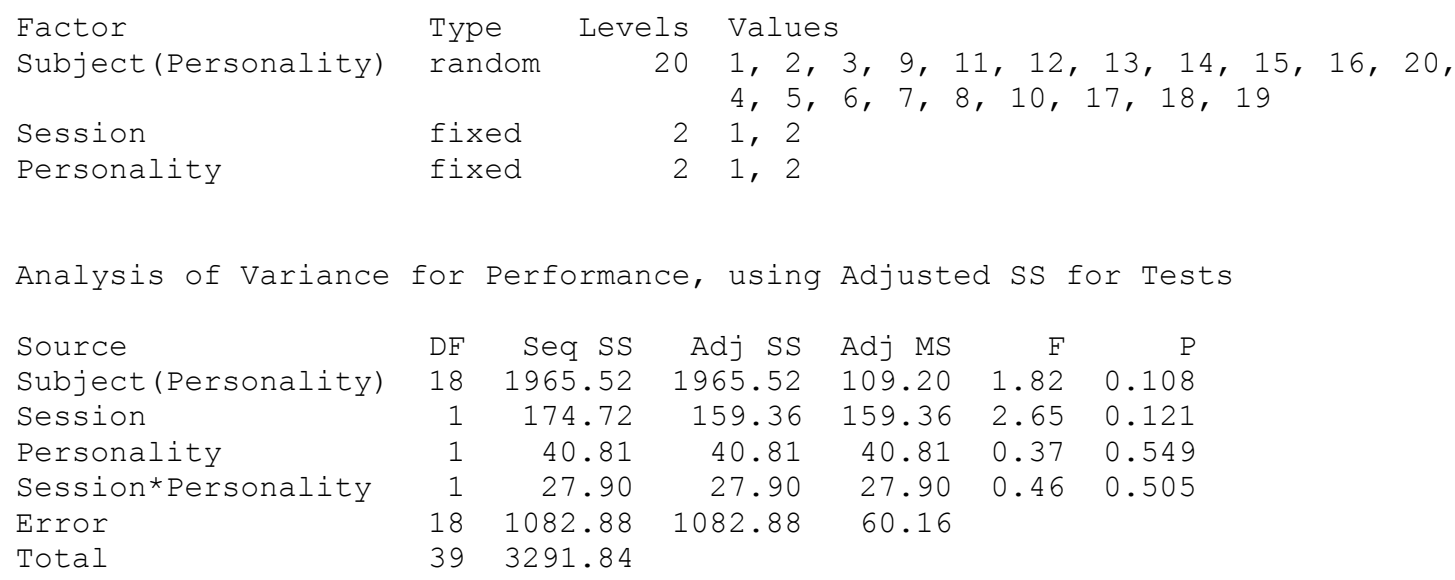

\section{General Linear Model: Effort versus Session, Personality, Subject}

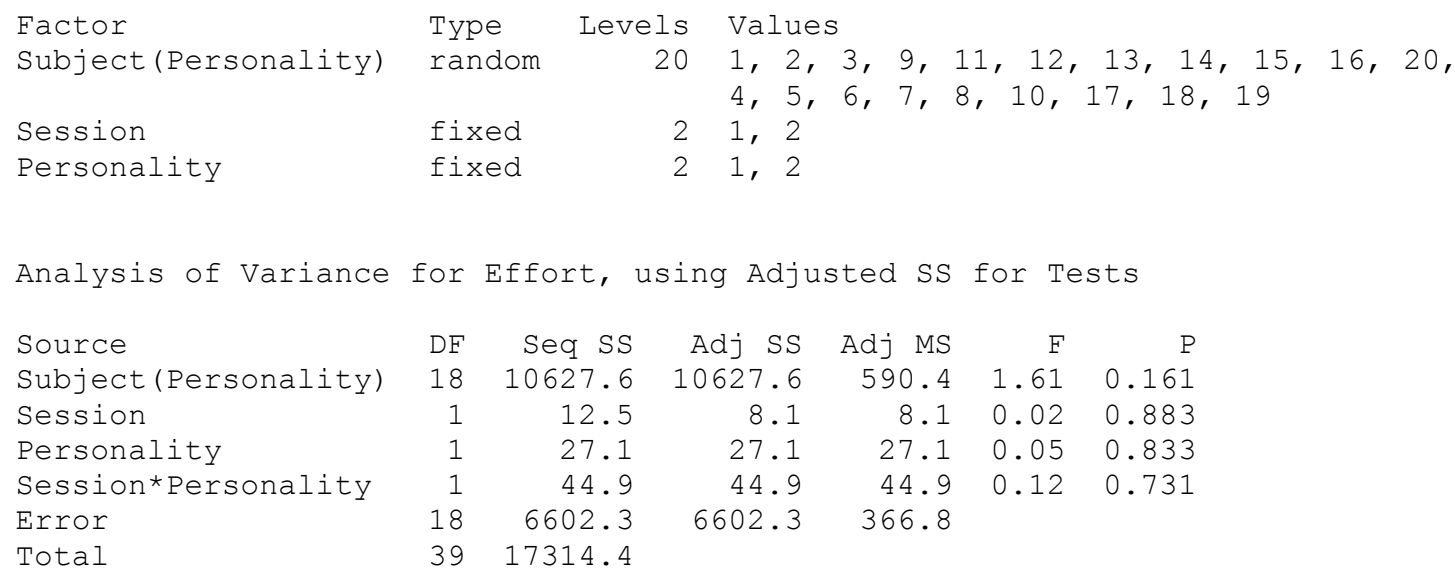

\section{General Linear Model: Frustration versus Session, Personality, Subject}

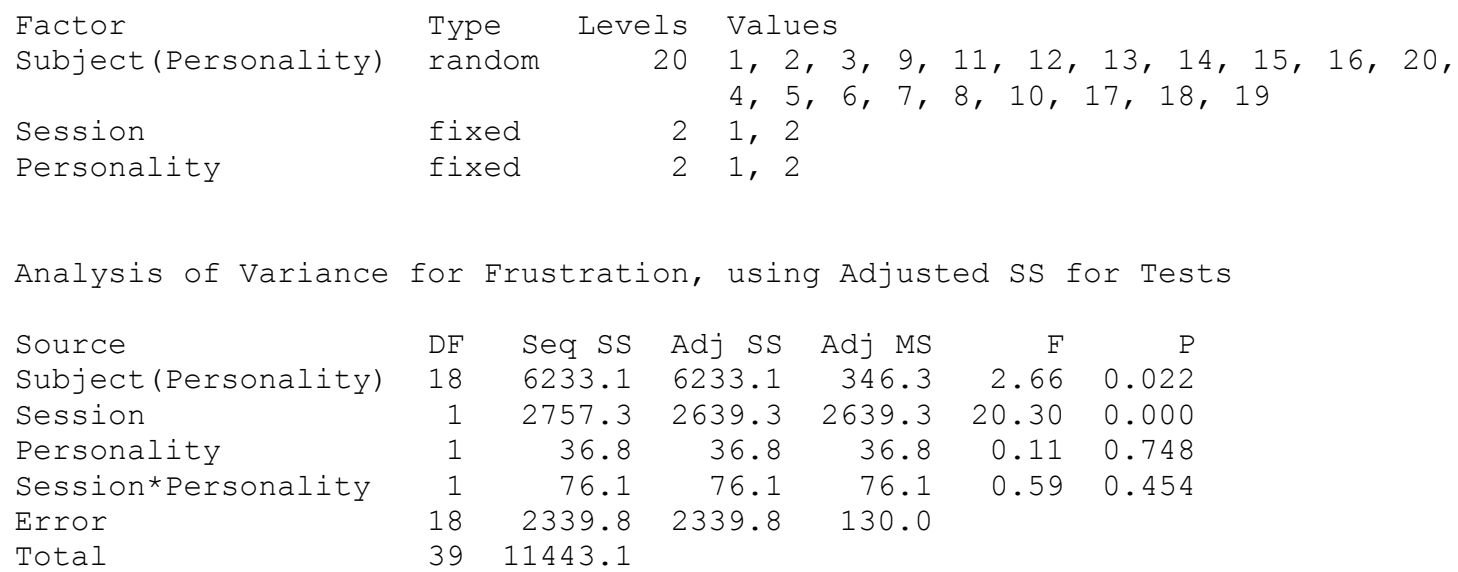


The Raw Data for all Participants for NASA TLX in both Sessions

\begin{tabular}{|c|c|c|c|c|c|c|c|c|c|c|c|c|c|c|c|c|c|c|c|c|}
\hline Subject number & 1 & 2 & 3 & 4 & 5 & 6 & 7 & 8 & 9 & 10 & 11 & 12 & 13 & 14 & 15 & 16 & 17 & 18 & 19 & 20 \\
\hline \multicolumn{21}{|l|}{ Session 1} \\
\hline Mental demand & 3.3 & 14.7 & 7.6 & 7 & 6 & 4 & 7 & 2 & 4 & 16 & 3 & 10 & 8 & 6 & 5 & 8 & 2 & 4 & 13 & 11 \\
\hline Physical demand & 49.2 & 60.6 & 66 & 78 & 48 & 54 & 78 & 60 & 48 & 66 & 78 & 48 & 30 & 55 & 85 & 57 & 108 & 36 & 45 & 25 \\
\hline Temporal demand & 7 & 17.4 & 59.5 & 33 & 15 & 12 & 33 & 24 & 30 & 30 & 50 & 12 & 32 & 48 & 36 & 43 & 15 & 30 & 31 & 15 \\
\hline Performance & 24 & 50 & 25.8 & 32 & 25 & 24 & 32 & 14 & 20 & 12 & 40 & 9 & 35 & 30 & 39 & 23 & 40 & 22 & 15 & 9 \\
\hline Effort & 37.5 & 44 & 41.4 & 45 & 7 & 28 & 45 & 50 & 8 & 55 & 36 & 32 & 54 & 25 & 42 & 40 & 33 & 8 & 29 & 12 \\
\hline Frustration & 13.5 & 3.8 & 55.2 & 18 & 16 & 50 & 18 & 20 & 12 & 16 & 16 & 18 & 15 & 50 & 10 & 10 & 20 & 12 & 18 & 17 \\
\hline \multicolumn{21}{|l|}{ Session 2} \\
\hline mental demand & 68.4 & 44.4 & 89.4 & 72 & 84 & 108 & 84 & 102 & 62 & 78 & 54 & 96 & 78 & 88 & 102 & 100 & 96 & 84 & 75 & 89 \\
\hline Physical demand & 30.6 & 25.6 & 45.6 & 40 & 26 & 8 & 26 & 26 & 38 & 44 & 45 & 35 & 45 & 50 & 26 & 54 & 60 & 49 & 34 & 45 \\
\hline temporal demand & 50 & 116.4 & 60.8 & 60 & 18 & 19 & 18 & 36 & 45 & 48 & 54 & 35 & 32 & 25 & 33 & 40 & 39 & 40 & 38 & 31 \\
\hline performance & 19.4 & 38.7 & 11.7 & 27 & 20 & 18 & 20 & 24 & 19 & 20 & 16 & 20 & 18 & 17 & 28 & 33 & 24 & 20 & 22 & 21 \\
\hline effort & 10.7 & 87.5 & 30.6 & 14 & 68 & 28 & 68 & 80 & 10 & 13 & 8 & 11 & 56 & 40 & 19 & 48 & 10 & 11 & 19 & 17 \\
\hline frustration & 39.2 & 7.2 & 74 & 34 & 45 & 40 & 45 & 10 & 39 & 60 & 24 & 27 & 48 & 44 & 55 & 33 & 24 & 21 & 31 & 40 \\
\hline
\end{tabular}

